\title{
Beyond the What and How: Why Parents Want to Know about Their Adolescents' Lives.
}

\author{
Elizabeth Yale Babskie
}

Follow this and additional works at: https://researchrepository.wvu.edu/etd

\section{Recommended Citation}

Yale Babskie, Elizabeth, "Beyond the What and How: Why Parents Want to Know about Their Adolescents' Lives." (2016). Graduate Theses, Dissertations, and Problem Reports. 8172.

https://researchrepository.wvu.edu/etd/8172

This Dissertation is protected by copyright and/or related rights. It has been brought to you by the The Research Repository @ WVU with permission from the rights-holder(s). You are free to use this Dissertation in any way that is permitted by the copyright and related rights legislation that applies to your use. For other uses you must obtain permission from the rights-holder(s) directly, unless additional rights are indicated by a Creative Commons license in the record and/ or on the work itself. This Dissertation has been accepted for inclusion in WVU Graduate Theses, Dissertations, and Problem Reports collection by an authorized administrator of The Research Repository @ WVU.

For more information, please contact researchrepository@mail.wvu.edu. 
Beyond the What and How: Why Parents Want to Know about Their Adolescents' Lives

Elizabeth Yale Babskie, M.A., M.S.

Dissertation submitted to The Eberly College of Arts and Sciences

at West Virginia University

in partial fulfillment of the requirements for the degree of

Doctorate of Philosophy in

Psychology

Aaron Metzger, Ph.D., Chair

Amy Gentzler, Ph.D.

Cheryl McNeil, Ph.D.

Christine Rittenour, Ph.D.

Lesley Cottrell, Ph.D.

Department of Psychology

Morgantown, West Virginia

2016

Keywords: adolescence, parenting, parental monitoring, adolescent disclosure, parental knowledge, parent-adolescent communication, social cognitive domain theory 


\section{ABSTRACT \\ Beyond the What and How: Why Parents Want to Know about Their Adolescents' Lives}

\section{Elizabeth Yale Babskie}

As adolescents spend more time away from home and increasingly engage in unsupervised activities, parents are challenged with allowing their children more responsibility while still promoting positive youth development (Smetana, Campione-Barr, \& Metzger, 2006). Extant research shows that parents continue to play an important roll in facilitating positive adolescent development through their knowledge of what their adolescent children are doing and whom they are with when away from home or school (Racz \& McMahon, 2011). Recent research has focused on understanding the sources of parents' knowledge and has identified both parentdriven (rules, solicitation, indirect, covert) and adolescent-driven (disclosure, secrecy, concealment) strategies. Much of the findings suggest adolescent disclosure is a primary source of parental knowledge, while research regarding the effectiveness of parent-driven strategies is inconsistent (Anderson \& Branstetter, 2012; Kerr, Stattin, \& Burk, 2010). These inconsistencies may exist because parents' involvement in the process that facilitates parental knowledge is more complex than previously studied, as previous research has investigated parental information gathering from the vantage that parents are motivated to obtain information in order to protect their adolescent children from harm. However, beyond parents' desire to keep their children safe, parents likely have other motivations for learning about their adolescent children's lives, including but not limited to promoting emotional well-being, desiring to keep their adolescent out of trouble, promoting future success, and maintaining a good relationship with their adolescent. From a social domain perspective, parents' knowledge-seeking motivations may vary based on the type of adolescent behavior parents desire knowledge about, including conventional activities, dating behaviors, peer behaviors, school-related behaviors, and substance use. However, parents' motivations for knowledge about these behaviors may also vary as a function of individual characteristics, such as adolescent age, gender, parental knowledge, and parental harmfulness beliefs. Furthermore, the information gathering strategies parents employ to gain knowledge likely depend on the motivation driving their information seeking. In addition, adolescents are expected to recognize their parents have different knowledge-seeking motivations and youths' perceptions of the motivations driving their parents' information seeking may influence adolescents' own information management. Therefore, the present study had multiple goals: (1) investigate the extent to which parents' motivations for desiring knowledge differ based on the type of adolescent behavior, (2) examine individual differences in parents' knowledge-seeking motivations, (3) investigate behavior-specific associations between parents knowledge-seeking motivations and information gathering strategies, (4) examine adolescent reports of their parents' knowledge-seeking motivations, (5) investigate behaviorspecific associations between adolescent-reported parental knowledge-seeking motivations and adolescents' information management. Participants included 196 adolescents $(M=16.04, S D=$ 1.25 , range $13-19,62 \%$ female $)$ and their parents $(N=193, M=45.36, S D=6.31$, range 30-64, $84 \%$ female) who completed questionnaires. Parents and adolescents reported parental motivations for gaining knowledge about seven behavior categories, including conventional, dating expression, dating identity, dating supervision, peers, school, and substance use. Parents also reported how much knowledge they have about each behavior, how harmful they believe the 
behaviors are, and the strategies they utilize to gather information about the behaviors, including rules, solicitation, indirect and covert monitoring strategies. Additionally, adolescents reported their engagement in delinquent and substance use behaviors, as well as the ways in which they share information with their parents about each behavior, including adolescent disclosure, secrecy and concealment. Results indicated that parents' motivations did, indeed, vary based on the type of behavior. Across behaviors, parents were most motivated to protect their adolescents' physical safety, however, more variability emerged in parent-reported motivation for desiring knowledge about multifaceted behaviors such as dating and peer-related behaviors. Adolescent age, gender and parental harmfulness beliefs qualified parents' knowledge-seeking motivations regarding multifaceted behaviors. Contrary to parents' reports, adolescents reported their parents were most motivated to keep them out of trouble across behaviors. Adolescent gender qualified adolescent-reported parental knowledge-seeking motivations across all behavior categories except school-related behaviors. Finally, parental knowledge-seeking motivations were associated with different parental information gathering strategies and adolescent information management in both the parent and adolescent-report models. In sum, these results suggest that parental information gathering is more complex than previously researched as both parent and adolescent-reported parental knowledge-seeking motivations varied by type of behavior and were influenced by important contextual and psychological factors. Additionally, parentalknowledge seeking motivations were linked to different parental information gathering and adolescent information management strategies. 


\section{ACKNOWLEDGMENTS}

I would like to thank the Eberly College of Arts and Sciences and the Department of Psychology for their financial support for this project. I would like to thank Dr. Aaron Metzger, my dissertation chair and advisor, for his guidance throughout this project and my graduate tenure. I am also grateful for the support, recommendations, and time from my committee members Drs. Amy Gentzler, Cheryl McNeil, Christine Rittenour, and Lesley Cottrell. I would also like to thank my fellow lab members, Drs. Katelyn Ferris and Benjamin Ooserthoff for their continued support.

I dedicate this dissertation to those who have and will continue to truly inspire me:

To my parents, Donna and David Yale, for their unconditional love and support. They taught me the value of education and have always encouraged me to reach for the stars.

To my husband, Dr. Daniel Babskie, for his loyalty, love, and encouragement. He has always had faith in my ability to achieve and inspires me to be a better version of myself.

To my siblings, Jediah, Timothy, and Barbie Yale, for always having my back. Through every "adventure" I have begun they have encouraged me to keep swimming.

To my nephews and niece, Bryghton, Ephram, Hudson, and Natalie Yale, for the sweetest love and fresh perspectives. I hope the love of learning develops early and continues to grow throughout their lives. 
Table of Contents

I. Introduction (pp. 1 - 16)

a. Parental Knowledge (pp. 2 - 5)

b. Parental Motivation for Knowledge (pp. 5 - 7)

c. Domain Differences in Parental Knowledge-Seeking Motivations (pp. 7 - 8)

d. Individual Differences in Parents' Knowledge-Seeking Motivations (pp. 9 - 11)

e. Links between Parents' Knowledge-Seeking Motivations and Parents' Information Gathering Strategies (p. 11)

f. Adolescents' Perceptions of Parental Knowledge-Seeking Motivations (pp. 12 14)

g. Current Study (pp. 14 - 16)

II. Research Questions and Hypotheses (pp. 16 - 19)
a. Research Question 1 (p. 16)
b. Research Question 2 (p. 17)
c. Research Question 3 (pp. 17 - 18)
d. Research Question 4 (p. 18)
e. Research Question 5 (p. 19)

III. Method (pp. 19 - 28)
a. Participants (pp. $19-21$ )
b. Procedure (p. 21)
c. Measures (pp. 21 - 26)

i. Behavior Categories (p. 22)

ii. Parental Motivation for Knowledge (pp. 22 - 23) 
iii. Parent-Report Measures (pp. 23 - 25)

iv. Adolescent-Report Measures (pp. 25 - 26)

d. Data Analysis Strategy (pp. 26 - 28)

IV. Results (pp. 28 - 49)

a. Data Cleaning and Preliminary Analyses (pp. 28 - 29)

b. Differences in Parents' Motivations for Knowledge (pp. 30 - 33)

c. Associations between Parents' Motivations and Information Gathering Strategies (pp. 33 - 38)

d. Differences in Adolescent-Reported Parental Motivations for Knowledge (pp. 38 41)

e. Associations between Adolescent-Reported Parental Motivations and Information Management Strategies (pp. 41 - 48)

f. Additional Analyses (pp. 48 - 49)

V. Discussion (pp. 49 - 67)

a. Parental Motivations for Knowledge (pp. 51 - 57)

b. Adolescents' Perceptions of Parental Motivation for Knowledge (pp. 57 - 62)

c. Limitations and Future Directions (pp. 63 - 67)

VI. References (pp. 68 - 79)

VII. Tables (pp. 80 - 109)

VIII. Figures (pp. 110 - 113)

IX. Appendices (pp. 114 - 137) 
During adolescence, individuals undergo substantial physiological, cognitive, and social change (Collins \& Steinberg, 2006). Adolescents begin to spend more time engaging in unsupervised activities with peers and less time in shared activities with their parents (Smetana, Campione-Barr, \& Metzger, 2006). At the same time, adolescents begin to increasingly view areas of their lives as personal and outside of parents' jurisdiction (Hawk, Hale, Raaijmakers, \& Meeus, 2008; Petronio, 2010; Smetana, 1988). These changes lead to adjustments in the parentchild relationship, through which parents begin to renegotiate previous boundaries of the relationship and gradually relinquish control over some behaviors (Koepke \& Denissen, 2012; Smetana, Campione-Barr et al., 2006). Consequently, parents must begin to trust their adolescents to make good decisions when they are away from home (Smetana, Campione-Barr et al., 2006). Despite these transformations in the parent-adolescent relationship, parents continue to play an essential role in facilitating positive development throughout adolescence (Collins \& Steinberg, 2006).

One well-researched way that parents continue to exert a positive influence on their adolescents' development involves the amount of knowledge parents have about their children when adolescents are outside of the home or school (Barber, Stolz, \& Olsen, 2005; Crouter \& Head, 2002; Dishion \& McMahon, 1998). Increased parental knowledge is associated with a host of positive youth development outcomes, including fewer problematic behaviors such as delinquency and substance use (Crouter \& Head, 2002, Racz \& McMahon, 2011). Recent studies have examined the effectiveness of various sources of parental knowledge including parentinitiated information gathering strategies (e.g., parental control and solicitation) and adolescent information management strategies (e.g., adolescent disclosure and secrecy). Consistently, parents' knowledge is found to be best facilitated through adolescents' freely sharing information 
with their parents, whereas parent-initiated attempts to gain information about their adolescents yield inconsistent results (Anderson \& Branstetter, 2012; Crouter \& Head, 2002; Kerr, Stattin, \& Burk, 2010; Laird, Marrero, \& Sentse, 2010; Waizenhofer, Buchanan, \& Jackson-Newsom, 2004). One potential reason for mixed findings regarding the effectiveness of parents' efforts to gain knowledge about their adolescents is that a majority of previous research has investigated parents' knowledge and their desire to obtain knowledge solely as a mechanism for protecting their children from harm or reducing their children's engagement in health risk behavior (Dishion \& McMahon, 1998; Racz \& McMahon, 2011). However, it is likely that parents have multiple reasons for wanting to know about their adolescents' lives such as wanting to keep their children out of trouble, promoting their children's emotional well-being, and maintaining a good relationship with their child. If parents have different motivations for desiring knowledge, they may engage in distinct monitoring behaviors based on those motivations, which may help explain some of the inconsistencies in the link between parents' monitoring attempts and adolescent outcomes.

The first goal of the present study was to investigate variations in parental motivations for gaining knowledge about distinct types of adolescent behaviors. The second aim was to examine individual differences in parents' motivations and whether motivations vary as a function of parents' conceptualizations of different behaviors, adolescent characteristics (e.g., gender, age), or adolescents' level of engagement in different behaviors. The third goal of the present study was to examine links between parental motivations for knowledge and the strategies parents utilize to gather information. Finally, this study investigated youths' perceptions of their parents' motivations and adolescents' own information management strategies.

\section{Parental Knowledge}


Research on parental knowledge and monitoring has a long history within developmental science. Early studies consistently documented that parental monitoring, conceptualized as paying close attention to and tracking children's whereabouts and activities, was predictive of adolescent engagement in fewer problem behaviors and more positive developmental outcomes, including less delinquency, less substance use, fewer risky sexual behaviors, and better school performance (Crouter \& Head, 2002; Dishion \& McMahon, 1998). However, within the last 15 years, researchers have identified inconsistencies between conceptualizations of parental monitoring and measurement of the construct (Kerr \& Stattin, 2000). Previous measures of parental monitoring asked adolescents and parents how much parents knew about their children's activities and whereabouts (Kerr \& Stattin, 2000). Example items from such measures include the following: "Do your parents know where you are? Do your parents know whom you are with? How much do your parents really know?" (Crouter, Manke, \& McHale, 1995; Fletcher, Darling, \& Steinberg, 1995; Weintraub \& Gold, 1991).

The seminal work of Kerr \& Stattin (2000) helped researchers recognize the importance of distinguishing parents' knowledge from parents' monitoring behaviors and suggested three key sources of parental knowledge. Parental control involves parents using limit setting and rules about where their children can go as well as rules about the types of information adolescents are required to tell their parents (Stattin \& Kerr, 2000). The second parent-driven strategy, parental solicitation, involves parents directly asking their adolescents for information or soliciting information (Stattin \& Kerr, 2000). The third source of parental knowledge was adolescents sharing information with their parents, called adolescent disclosure. Adolescent disclosure, or freely offering information to their parents, was found to be a stronger predictor of parental knowledge than parents' own monitoring behaviors (Kerr \& Stattin, 2000; Kerr et al., 2010). A 
great deal of subsequent research has found that adolescent disclosure is more consistently predictive of parental knowledge and positive developmental outcomes compared to parental information gathering strategies (Keijsers, Branje, VanderValk, \& Meeus, 2010; Kerr et al., 2010; Marshall, Tilton-Weaver, \& Bosdet, 2005; Masche, 2010; Tilton-Weaver et al., 2010; Metzger et al., 2013). Studies have provided inconsistent evidence concerning the effectiveness of parents' own information gathering strategies (Anderson \& Branstetter, 2012; Crouter \& Head, 2002). Parental solicitation and control have been associated with less substance use and lower levels of externalizing problem behaviors in some research (Borawski, Ievers-Landis, Lovegreen, \& Trapl, 2003; Fletcher, Steinberg, \& Williams-Wheeler, 2004; Waizenhofer et al., 2004; Wang et al., 2013), while other studies have found no significant associations between parents' strategies and adolescents' problem behaviors, over and above adolescent disclosure (Keijsers, Branje, VanderValk et al., 2010; Kerr et al., 2010). In fact, direct parent information seeking strategies may be counterproductive to the acquisition of knowledge in some cases, as adolescents have reported feeling overly controlled and an invasion of privacy due to some types of parent-initiated strategies (Hawk et al., 2008; Hawk et al., 2012). Feelings of privacy invasion have been associated with increases in adolescent secret keeping over time, and subsequent decreases in parental knowledge (Hawk et al., 2012). High levels of parental control, or rules, regarding adolescents' behaviors have been associated with decreased adolescent disclosure about those behaviors (Metzger et al., 2013). In addition to the strategies outlined by Stattin \& Kerr, research has assessed other strategies parents may use such as talking to other influential persons in adolescents' lives, including the adolescent's teachers, friends and friends' parents (Crouter, Bumpus, Davis, \& McHale, 2005). Studies also suggest that parents may engage in covert monitoring strategies involving such "sneaky" behaviors as checking their adolescents' 
bedrooms and personal belongings for information (Crouter \& Head, 2002). However, evidence supporting parents' use of these additional strategies is scarce. One study did find that adolescents engaged in fewer risk taking behaviors when their fathers received information from spouses; however, there were no other direct links between parents obtaining information from other influential persons and adolescent adjustment (Crouter et al., 2005).

\section{Parental Motivation for Knowledge}

Research regarding parental knowledge stemmed from studies across multiple disciplines, including developmental psychology, clinical psychology, communication studies, epidemiology, and sociology. A primary focus of this body of research has been to determine mechanisms through which parents could prevent children from engaging in a range of problem behaviors including problematic friendships, school-related problem activities, sexual behaviors and substance use (Borawski et al., 2003; Dishion \& McMahon, 1998; Hawk et al., 2012; Keijsers, Frijns, Branje, \& Meeus, 2009; Kerr et al., 2010; Kerr, Stattin, \& Ozdemir, 2012; Tilton-Weaver, Burk, Kerr, \& Stattin, 2013; Stattin \& Kerr, 2000). However, protecting children from harm may be only one motivation for parents' desiring knowledge about their adolescents. Existing research has not considered whether parents have other motivations for wanting information about their adolescents' behaviors. For example, parents may want to gain information in order to maintain a good relationship with their adolescent children, promote emotional well-being or assist with their adolescents' future success.

Although, no known parental monitoring research has investigated different parental knowledge-seeking motivations, theories from communication sciences support the importance of considering the motivations behind information seeking behaviors (Afif \& Weiner, 2004). The Theory of Motivated Information Management (TMIM) posits that individuals experience an 
uncertainty discrepancy in the knowledge they have, which causes anxiety and ultimately motivates various information seeking behaviors to diminish this anxiety (Afifi \& Weiner, 2004). In contrast, the Communication Privacy Management Theory (CPM) provides a framework for understanding an individual's management of information considered private within the boundaries of interpersonal relationships (Petronio, 2002). Petronio (2002) argued that individuals engage in communication privacy maintenance by employing different disclosure and concealment strategies to control information co-owned between relationship partners. Individuals choose communication strategies based on their appraisal of the relationship as well as their motivations regarding the particular type of information (Petronio, 2002). For example, an individual may be motivated to disclose certain information because they want to decrease their vulnerability, they want to hide their true feelings, they want to protect another person, or they want to gain control over a situation (Petronio, 2002). These theories indicate that motivations are a key component of communication processes and that motivation influences the strategies people use to seek or share information. Additionally, research from these theories has demonstrated that motivations are influenced by both individual characteristics and characteristics of a particular relationship.

Much of the empirical support for these communication theories comes from studies of non-hierarchical peer relationships (Afifi \& Weiner, 2004). The hierarchical and familial nature of the parent-child relationship involves both close emotional bonds as well as an inherent power differential. These characteristics may lead to qualitatively different motivations for obtaining information and may also affect the link between motivations and parents' information gathering behaviors. For example, information management within a peer relationship is motivated by an individual's uncertainty discrepancy and desire to decrease uncertainty (Afifi \& Weiner, 2004), 
whereas parents' uncertainty may trigger one of multiple motivations depending on the type of information they are seeking and family dynamics. Beyond striving to keep their adolescents safe, parents also desire a positive relationship with their children (Morris, Cui, \& Steinberg, 2013). Thus, parents' attempts to obtain information about their adolescent may be motivated by a desire to learn more about their adolescent to build and strengthen relationship. Parents also care about their children's emotional well-being (Eisenberg, Cumberland, \& Spinrad, 1998) and may be motivated to learn about their adolescents' lives because they want their children to be happy. Parents are invested in their children's futures and talk with their children about future goals (Wang \& Eccles, 2012); consequently, parents may be motivated to know about their adolescents' lives to assist in promoting a successful future. Additionally, some research indicates that a fundamental goal of parenting is the facilitation of productive members of society including individuals who abide by societal standards and respect the rights of others (Grusec, 2011). Therefore, parents may be motivated to know about their adolescents' whereabouts and activities so they can keep their children out of trouble, protect the welfare of others, or because parents believe that, they simply "need to know." Lastly, parents may worry about how the community views their family or adolescent and may be motivated to know what their adolescent children are doing to ensure the family or adolescent's reputation is respectable.

Domain differences in parents' motivation. Parents' motivations may vary by the specific type of information they are seeking. Some behaviors pose substantially less risk of harming the adolescent (e.g., clothes the adolescent wears; Nucci, 2001). Some behaviors are guided by societal norms and parents' regulations to promote order within a specific social context (e.g., using bad manners), and other behaviors are not harmful to the adolescent but may impede the rights and welfare of others (e.g., lying or cheating; Nucci, 2001; Smetana, 2006). 
Research based on social cognitive domain theory provides a theoretical framework and empirical support for categorizing adolescent behaviors based on domains of social knowledge (Smetana, 2000). According to social domain theory, children's developing comprehension of their social world entails an understanding that different behaviors and interactions with others involve distinct domains of social knowledge: moral, conventional, prudential, and personal. The moral domain pertains to the justice, welfare, and rights of others, whereas the conventional domain includes issues pertaining to societal norms and regulations that promote smooth societal functioning (Smetana, 2000; Smetana, 2011). The prudential domain consists of behaviors that could cause harm to the self (e.g., smoking) and the personal domain consists of behaviors that are outside of moral or conventional concern and are an individual's own prerogative (e.g., clothes they wear; Nucci, 2001; Smetana, 2006; Smetana, 2011).

A great deal of social domain research indicates that parenting beliefs (Cumsille, Darling, Flaherty, \& Martinez, 2006; Nucci, 2001; Smetana, 1988; Smetana, 1995; Smetana, 2006; Smetana \& Asquith, 1994; Smetana, Metzger et al., 2006) and parenting behaviors (Laird \& Marrero, 2010; Smetana, 2000; Smetana \& Daddis, 2002; Tilton-Weaver et al., 2010) differ by the domain of adolescent behaviors. Likewise, parents' motivations for gaining knowledge about different behaviors may parallel domain conceptualizations. For example, parents may very well desire knowledge about prudential issues (e.g., substance use) because they want to protect their adolescent from the harm involved with engaging in those types of behaviors. Whereas, they may wish to know about conventional issues (e.g., manners or language teen uses) because they want to ensure their adolescent is abiding by social regulations and staying out of trouble. Rather than desiring knowledge about schoolwork so they can protect their teen from harm, parents may want knowledge in order to help their child secure a successful future. 
Individual differences in parents' motivations for knowledge. While social domain theory anticipates that parental motivations will differ based on the type of the behavior, there may also be substantial individual variability in parents' motivations for desiring knowledge. Identifying such individual differences in parents' motivations may be especially important for explaining why some parental monitoring research has failed to find a link between parents' behaviors and adolescent outcomes. Individual differences in parental motivations for knowledge may be especially salient for multifaceted adolescent behaviors, which are behaviors that may be interpreted from multiple domains of social knowledge (e.g., peer relationships may be interpreted as personal by an adolescent, but prudential by parents; Smetana, 2006). Interpretations of multifaceted behaviors have been shown to differ based on individuals' experiences, their role in a relationship, and the specific domain-relevant information on which they focus (Smetana; 1988; Smetana, 2000). For instance, adolescent dating may be considered multifaceted because adolescents could think of it as a personal choice while their parents attend to prudential characteristics, such as harm to adolescents (Smetana, 2006). Due to individual differences in conceptualizations of multifaceted behaviors, there may be more variability in parents' motivations for gaining knowledge about these behaviors. Some parents may be focused on the potential harm involved with dating and want to know about dating behaviors so they can protect their adolescent from that harm, whereas other parents may focus on promoting youths' autonomy and desire knowledge about dating behaviors because they want to have a good relationship with their adolescent child.

Parents' beliefs about different adolescent behaviors may influence their motivation for wanting knowledge about their adolescents' involvement. One belief that may affect parents' motivations is the potential harm involved with adolescents' engaging in a behavior (Smetana, 
2011). When a parent believes that engaging in a particular behavior (e.g., attending parties where alcohol is served) will cause their adolescent harm, the parent may be motivated to learn about that behavior to protect their adolescent from impending harm. However, if a parent does not view that behavior as potentially harmful that parent may be motivated to have knowledge in order to ensure the adolescents' happiness or future success. The amount of knowledge parents think they already have about their adolescents may also lead to different motivations for wanting to gain additional information. Parents who know their adolescent is engaging in problematic social behaviors may want to know about peer relationships to protect the teen from harm or keep the adolescent out of trouble. In contrast, parents who do not believe their adolescent is engaging in problematic behaviors may not have protective motivations, but instead may be more strongly motivated to know more about their adolescents' peers because they want to have a good relationship.

Parents' motivations for gaining information about their adolescents may also vary according to characteristics of the adolescent (e.g., age, gender). With age, adolescents spend more time with peers, begin to pull away from their parents and desire more responsibility over their lives (Keijsers \& Poulin, 2013; Koepke \& Denissen, 2012). Based on older adolescents' increased time spent outside the home, parents of older adolescents' may desire knowledge about the adolescents' peers to make sure the adolescent is staying out of trouble whereas parents of younger adolescents may desire information about peers to make sure the younger adolescent is happy and socially active. Previous research suggests that parents engage in more solicitation and control and have greater levels of knowledge for daughters compared to sons, and girls also engage in higher levels of disclosure to parents (Keijsers, Branje, Frijns, Finkenauer, \& Meeus, 2010; Masche, 2010; Racz \& McMahon, 2011; Smetana \& Daddis, 2002; Wang, Dishion, 
Stormshack, \& Willett, 2011). These gender differences may reflect differences in parents' motivations. For instance, parents may want to know about daughters' dating to protect from physical harm or to ensure future success through decreasing the risk of unwanted pregnancies, whereas they may want to make sure their sons are not harming others or ruining their reputations (Jaccard, Dodge, \& Dittus, 2002). In addition, adolescent boys engage in higher levels of externalized problem behaviors such as delinquency (Bongers, Koot, van der Ende, \& Verhulst, 2004), so compared to parents of girls, parents of boys may be more likely to desire knowledge to keep their sons out of trouble.

\section{Links between parents' motivations and their information gathering strategies.}

Parents' conceptualization of their adolescents' behaviors and motivation for wanting knowledge may drive the strategies parents use to obtain knowledge. Parents may rely on very different strategies based on whether they want information to protect their adolescent from physical harm compared to desiring information to maintain a relationship. For example, parents who are motivated to protect may be willing to employ multiple strategies including higher levels of indirect and covert strategies. Parents who desire knowledge to build a relationship may be less likely to engage in indirect strategies and more likely to communicate directly with their teen (e.g., solicitation). Investigating the link between variations in parental knowledge-seeking motivations and information gathering behaviors may provide an initial step in disaggregating inconsistencies found in previous research. There may be certain families in which parent-driven strategies are successful in promoting knowledge and positive youth development. Parents' motivations for wanting knowledge may be an element of those parents' successful efforts, because certain motivations may lead to more appropriate information seeking behaviors in those families. 


\section{Adolescents' Perceptions of Parental Motivation for Knowledge}

Just as parents may have different motivations for wanting information about their adolescents' lives, adolescents may also vary in their interpretation of their parents' motivations for attempting to acquire such knowledge. Adolescents most likely recognize that their parents want to know about their lives for different reasons, such as wanting the teen to be happy, helping them secure a good future, and keeping them out of trouble (Smetana, 1988; Smetana, 2000; Smetana \& Asquith, 1994). However, adolescents' interpretations of their parents' motivations may differ from their parents' actual motivations. As adolescents' autonomy increases, the behaviors they categorize as under their personal jurisdiction expand, and they feel that parents do not need to know about those personal aspects of their lives (Darling, Cumsille, Caldwell, \& Dowdy, 2006; Smetana, Villalobos, Tasopoulos-Chan, Gettman, \& Campione-Barr, 2009; Smetana, Metzger et al., 2006). Subsequently, adolescents may interpret parents’ motivations differently based on whether they believe that their parents have a right to know about that behavior. For example, when youths feel that a behavior is up to them to decide they may perceive their parents as wanting knowledge because they are being overly intrusive or "nosey." However, when adolescents believe that parents have a right to know about an issue, they may report that their parents' want knowledge because they are worried about the adolescent's future or well-being.

Individual differences may emerge in adolescents' perceptions of their parents motivations based on varying adolescent and family characteristics. Research suggests that middle to later adolescence is a time period in which control over the personal domain becomes extremely important to adolescents (Nucci, 2008), so older adolescents may be more likely to perceive parents as wanting knowledge because they are being invasive or "nosey" rather than 
parents desiring knowledge to promote a close relationship with the adolescent. Adolescents' level of engagement in problem behaviors may also affect adolescents' perceptions of their parents' motivations. Adolescents that do not engage in problematic behaviors may attribute more positive motivations to their parents desiring knowledge, rather than feeling that their parents are being nosey.

Adolescents' perceptions of parents' motivations for knowledge may be associated with their choice of information management strategies. Adolescents recognize the consequences of parental knowledge, which may include parents' disapproving of youths' behaviors or punishing adolescents' behaviors (Smetana et al., 2009). Research suggests that adolescents consider the costs and benefits of disclosing information to parents and have reported withholding information to avoid their parents' disapproval or punishment (Marshall et al., 2005; Smetana et al., 2009). Additionally, studies show that withholding information from parents involves more than just non-disclosure or the opposite of end a disclosure continuum (Frijns, Keijsers, Branje, \& Meeus, 2010; Laird \& Marrero, 2010). Adolescent secrecy is comprised of varying strategies through which adolescents actively attempt to keep information from their parents (Laird, Marrero, Melching, \& Kuhn, 2013). For example, adolescents have reported sharing information only after their parents have asked with the reasoning that they are sharing information when their parents want to know (Marshall et al., 2005). Adolescents may also make up a story, lie, or share some information while omitting important details (Cumsille et al., 2010; Laird et al., 2013). Adolescents have also reported keeping information from their parents by avoiding discussions altogether, changing the subject of a conversation, or engaging in more active concealing behaviors such as hiding messages on social networking sites (Babskie \& Metzger, 2015; Darling et al., 2006; Marshall et al., 2005). 
Adolescents' perceptions of their parents' motivations may shed light on additional cognitive processes that are involved in adolescents' use of different information management strategies. Research suggests that decisions to disclose information are directly related to developmental changes in adolescents' beliefs about the legitimacy of parental authority (Cumsille et al., 2010; Darling et al., 2006; Smetana, Metzger et al., 2006). Adolescents report feeling more obligated to disclose information about conventional (e.g., societal rules) and prudential (e.g., substance use) issues, compared to personal issues (e.g., clothes they wear; Smetana, Metzger et al., 2006). Moreover, when youths believe that parents have invaded their privacy they keep more secrets from their parents (Hawk et al., 2012). Thus, adolescents may be more likely to disclose when they believe their parents' want knowledge to promote youths' physical or emotional well-being, whereas perceptions of parents wanting knowledge because they are being nosey may be related to more secretive information management.

\section{The Present Study}

Parental knowledge of adolescents' whereabouts and activities is a key component of positive developmental outcomes (Barber et al., 2005; Crouter \& Head, 2002). A great deal of research has examined the sources that lead to parental knowledge and has consistently supported adolescent disclosure as a stronger predictor of both parental knowledge and adolescent outcomes compared to parents' active monitoring (Keijsers, Branje, VanderValk et al., 2010; Kerr et al., 2010; Masche, 2010). However, findings are inconsistent with respect to the effectiveness of parent-driven information gathering strategies (Fletcher et al., 2004; Keijsers, Branje, Vander Valk et al., 2010; Kerr et al., 2010; Waizenhofer et al., 2004; Wang et al., 2013). Previous research has not investigated why parents want to learn about different behaviors in their adolescents' lives, and such motivations may be related to variations in 
parental information gathering strategies. The first aim of the current study was to examine variability in parental motivations for desiring knowledge about distinct issues in their adolescents' lives, including schoolwork, dating, peer relations, substance use, and conventional issues.

Parents engage in multiple direct (e.g., solicitation) and indirect (e.g., talking to friends' parents) information gathering strategies to facilitate their own knowledge of adolescents' lives (Crouter et al., 2005; Crouter \& Head, 2002; Kerr \& Stattin, 2000), but findings are mixed with regard to the effectiveness of parent-driven strategies (Fletcher et al., 2004; Keijsers, Branje, VanderValk et al., 2010; Metzger et al., 2013; Wang et al., 2013). These inconsistencies may exist because parents' involvement in the process that facilitates parental knowledge is more complex than previously studied. Parental information gathering may be effective based on a combination of the type of knowledge, their motivations for wanting knowledge, and the strategies they utilize to obtain that knowledge. Identifying additional factors such as parental motivations that lead to individual differences in parents' strategy use may be a valuable step in ascertaining when parent-driven strategies do facilitate positive outcomes. Thus, an important goal of the present study was to assess associations between parents' motivations for knowledge and the strategies employed to gain knowledge.

Finally, a great deal of research promotes adolescents' information management as a key predictor of both increased parental knowledge and positive youth development (Darling et al., 2006; Kerr et al., 2010; Marshall et al., 2005; Smetana, 2008). Recent studies highlight the importance of considering adolescents' perceptions of their parents' behaviors as well as the ways in which these perceptions relate to youths' information management (Hawk et al., 2008; Hawk et al., 2012; Kakihara, Tilton-Weaver, Kerr, \& Stattin, 2010; Metzger et al., 2013). The 
third aim of the present study was to investigate adolescents' perceptions of their parents' motivations for knowledge as well as links between adolescents' perceptions of motivation and their use of information management strategies. Accounting for adolescents' perceptions of their parents' motivations may allow us to uncover important information regarding the reasons adolescents utilize different information management strategies. It was expected that variations in adolescents' perceptions of their parents' motivations would be associated with different information management strategies.

\section{Research Questions and Hypotheses}

\section{Research Question 1}

Do parents' motivations for desiring knowledge about their adolescents' behaviors vary for different types of adolescent behaviors (e.g., schoolwork vs. dating)?

Hypothesis 1. Based on previous social domain research (Nucci, 2001; Smetana, 2006), it was expected that parents' motivations for desiring knowledge about different aspects of their adolescents' lives would vary by the type of knowledge, including conventional issues, substance use, schoolwork, peers, identity of boyfriend/girlfriend, dating supervision, and expression of a dating relationship. Thus, it was hypothesized that:

a. Parents would be more likely to be motivated by a desire to protect their adolescents' physical safety when wanting knowledge about substance use, and dating behaviors.

b. Parents would be more likely to be motivated by a desire to promote future success and keep their adolescents out of trouble when wanting knowledge about schoolwork.

c. Parents would be more likely to be motivated to promote their relationship with their adolescent and promote their adolescents' emotional well-being when desiring knowledge about peers. 


\section{Research Question 2}

Are there individual differences in varying parental motivations for gaining knowledge?

Hypothesis 2. Characteristics of the adolescent (e.g., age) and parent (e.g., beliefs) were expected to be associated with different parental motivations for knowledge.

a. It was hypothesized that parents of younger adolescents would be more likely to be motivated to promote emotional well-being, whereas parents of older adolescents would be more likely to be motivated to keep their adolescents out of trouble and protect their adolescents from physical harm, especially with regard to peer relationships and dating.

b. It was hypothesized that parents of adolescent girls would be more likely to be motivated to have knowledge to protect daughters from physical harm and promote emotional well-being, whereas the primary motivation of adolescent boys' parents would be to keep their sons out of trouble, especially with regard to dating.

c. It was hypothesized that parents who believed a behavior is harmful would be more likely to be motivated to gain knowledge to protect their adolescent from harm and to keep their adolescent out of trouble.

d. It was hypothesized that parents who reported knowledge of their adolescents' engagement in problem behaviors would be more likely to be motivated to keep their adolescent out of trouble or protect their adolescent from physical harm.

\section{Research Question 3}

Are different parental motivations for gaining knowledge associated with the strategies parents utilize to seek information about adolescents' behaviors? 
Hypothesis 3. It was expected that parents' would engage in varying information gathering strategies based on their motivations for knowledge. It was hypothesized that:

a. Parents motivated to have knowledge to protect their adolescents' physical safety would be more likely to have distinct rules and engage in higher levels of indirect strategies, solicitation and covert strategies.

b. Parents motivated to have knowledge because they wished to promote their adolescents' emotional well-being would be more likely to engage in higher levels of direct communication with their adolescents (e.g., solicitation).

c. Parents motivated to have knowledge because they wished to facilitate a relationship with their adolescent would primarily solicit information from their adolescent.

\section{Research Question 4}

Do adolescents' perceptions of their parents' motivations for gaining knowledge vary by the type of behavior (e.g., substance use vs. peers)?

Hypothesis 4. Based on previous findings (Hawk et al., 2008; Smetana, 2006), it was hypothesized that:

a. Adolescents would perceive parents' desire to have knowledge about substance use as motivated by parents' wanting to protect their adolescent from harm.

b. Adolescents would perceive parents' desire to have knowledge about peers as motivated by parents being nosey.

\section{Research Question 5}

Are adolescents' perceptions of their parents' motivations for gaining knowledge associated with the information management strategies they utilize? 
Hypothesis 5. It was expected that adolescents' perceptions of why their parents want to know about different issues would be directly related to their engagement in different information management strategies. Thus, it was hypothesized that:

a. Adolescents' perceptions of their parents being motivated to know about the behaviors to protect the adolescent from physical harm, promote emotional wellbeing, or facilitate a relationship would be associated with higher levels of adolescent disclosure.

b. Adolescents' perceptions of their parents being motivated to have knowledge because parents' were being nosey would be associated with more secretive adolescent information management.

\section{Method}

\section{Participants}

Two hundred parents and their adolescent children (ages 13-19) were recruited through public high schools in two Mid-Atlantic States and one Northeastern State. Adolescents enrolled in Social Studies and English classes at their respective high schools were eligible to participate and were asked to recruit one primary caregiver to participate. Siblings were eligible to participate but were not included in this study. Strict procedures were followed to ensure the adolescent data included in this study were from the adolescents for which parents based their answers. Of the 200 recruited parents, one parent was removed due to only answering demographic questions and one parent was removed due to answering demographic questions and then returning to the consent form and opting out of the study. Five parents were removed due to missing a large amount of data, including a majority of the motivation items. Of the 200 recruited adolescents, one adolescent was removed due to only answering demographic variables 
and then opting out of the remainder of the survey. An additional three adolescents were removed due to missing large amounts of data as well as answering both validity questions incorrectly. T-tests were performed to compare analytic samples of $N=193$ parents and $N=196$ adolescents to the recruited sample of 200 parents and 200 adolescents. Results indicated that the analytic samples did not differ on any study variables compared to the recruited sample. In addition, attrition analyses were performed to investigate the demographic characteristics of participants removed from the sample. The four removed adolescents did not differ in age, gender, self-reported GPA or mean levels of problem behaviors compared to the analytic sample. In addition, the seven removed parents did not differ in parent age, parent gender, income, education, adolescent age or adolescent gender compared to the analytic sample.

The analytic sample consisted of 193 parents (ages $30-64, M=45.36, S D=6.31,84 \%$ Female) and 196 adolescents (ages $13-19, M=16.04, S D=1.25,62 \%$ Female). Fifty-one percent of participants were mother-daughter dyads, $33 \%$ were mother-son dyads, $10 \%$ were father-daughter dyads, and $6 \%$ were father-son dyads. Parents were primarily Caucasian/White (91\%), 5\% reported Asian American/Pacific Islander, 2\% reported African American/Black, 2\% Hispanic/Latino, and one parent reported Native American. Most of the adolescents reported Caucasian/White (83\%) ethnicity, 6\% reported Asian American/Pacific Islander, $4 \%$ reported African American/Black, 4\% reported they were biracial, 3\% Hispanic/Latino, and 2\% reported Native American. Ninety-five percent of the parents reported they were the adolescent's biological parent. A majority of parents (74\%) reported they are currently married or living with their romantic partner. Sixty-five percent of mothers and $78 \%$ of fathers reported completing college or a graduate degree. Fifty-three percent of adolescents reported they received Mostly A's and 30\% reported a mixture of A's and B's on their school grades. A majority (69\%) of 
parents reported a yearly household income more than $\$ 50,000$ per year. Additionally, $18 \%$ of parents reported that they were not currently employed. See Table 3 for complete sample demographic information.

\section{Procedure}

Participant recruitment and data collection was completed in several phases at each high school. During the first school visit, adolescents were provided with parental permission and parental consent to contact forms, which were completed by their primary caregivers. The consent to contact form was used to obtain interested parents' email addresses, phone numbers, and mailing addresses. Completed contact and permission forms were collected from the high schools one week after students took them home. Parents who consented to participate in the study were emailed a link to the online parent survey and were given one week to complete the survey. Parents who had not completed the survey by day six were sent reminder emails. Upon completion of the parent survey, parents received $\$ 10$. The second school visit occurred once a substantial number of parents completed the survey, which was approximately one month after the first school visit. During the second school visit, all adolescents with parental consent were recruited to participate. The adolescents then completed informed assent forms followed by the survey, during class time at their respective high school. The adolescents' surveys matched the gender of the parent that completed the parent version of the survey. Thus, all questions pertained to either the adolescents' mother or father depending on the parent who participated. Upon completion of the survey, adolescent participants received a keychain and were entered to win randomly selected $\$ 25, \$ 50$ and $\$ 100$ cash prizes.

\section{Measures}


Adolescent behavior categories. Parental motivation for knowledge, parental knowledge, parental information gathering, and adolescent information management was assessed through 21 behaviors representing seven behavior categories (3-items per category). Behavior categories included conventional issues (i.e., if my child is using bad manners), substance use (i.e., if my child is smoking cigarettes), schoolwork (i.e., if my child is finishing homework or assignments), peer relationships (i.e., who my child's friends are), identity of boyfriend/girlfriend (i.e., who my child's boyfriend/girlfriend is), supervision concerns regarding dating behaviors (i.e., where my child goes with his/her boyfriend/girlfriend), and expression of a dating relationship (i.e., if my child is having sex). Items were chosen from previous social domain research regarding parent-adolescent reasoning and adapted for this study (Daddis \& Randolph, 2010; Daddis \& Smetana, 2005; Smetana, 2000; Smetana, Metzger et al., 2006). Table 1 provides a full list of the adolescent behaviors within the respective behavior category.

Parental motivation for knowledge. Parents and adolescents completed a 21-item measure developed for this study to assess parents' motivations for gaining knowledge about each behavior category in their adolescents' lives. Parents were provided nine reasons (i.e., $I$ want my child to do well in the future) that parents may want to know about issues in their own adolescents' lives (Table 2). Adolescents received the same nine options as parents regarding why their parent may want to know (i.e., my parent wants to me to be happy) with one option reworded to be consistent with the way adolescents' may think (Parent = I just need to know; Adolescent $=$ my parent is nosey, Table 2). Participants were then asked to rank the top three reasons the parent would want to know about each behavior in the respective adolescent's life, regardless of whether the parent already knows. Ranked responses were reverse coded and behaviors within each domain category (e.g., dating relationship) were summed to create 
behavior-specific motivation scores ranging from 0 to 9 , whereby higher scores indicated a motivation for gaining knowledge was chosen more frequently within each category of behavior (See Table 1 for behaviors within each category). This measure was developed through pilot testing with a sample of parents. Detail regarding the pilot study can be found in Appendix E. Directions provided to participants and an example item can be found in Appendix A for the parent-report measure and Appendix B for the adolescent-report measure.

\section{Parent-report measures (Appendix C).}

Demographics. Parents reported their age, gender, relationship to the adolescent, ethnicity, marital status, education level, employment status, occupation, yearly income, their adolescent's age, adolescent's birthdate, adolescents' birth order and adolescent's gender.

Parental knowledge. Adapted from Marshall and colleagues (2005), parents reported how much they know about their adolescents' engagement in the 21 behaviors. Responses were given on a 5-point Likert-type scale ranging from 1 (don't know) to 5 (know a lot). Behaviorspecific knowledge scores were created by averaging responses to the items that represent each behavior category with higher scores indicating more knowledge. Alpha reliability coefficients ranged .74 to .89 .

Harmfulness beliefs. A modified version of Nucci and colleagues (1991) social beliefs inventory assessed the degree of harm parents believe is involved with adolescents' engagement in the 21 behaviors using a 5-point Likert-type scale $(1=$ not harmful at all, $5=$ extremely harmful). Mean scores were computed to create behavior-specific harmfulness scores with higher scores indicating greater harmfulness beliefs. Alpha reliability coefficients ranged from .66 to .88. 
Relationship quality. The relationship satisfaction subscale of the Network of Relationships Inventory (Buhrmester \& Furman, 2008) was used to assess parents' perceptions of their relationship with their adolescent child. The scale consisted of three items for which responses were given on a 5-point Likert-type scale from 1 (hardly at all) to 5 (extremely much). Higher scores indicated a stronger relationship quality $(\alpha=.96)$.

\section{Information gathering strategies.}

Restrictive control. Parents completed a measure assessing the extent to which their family has rules about each adolescent behavior. Consistent with previous work (Smetana, 2000; Smetana \& Daddis, 2002), parents reported on a 5-point Likert-type scale from 1 (no clear rules) to 5 (firm clear rules). Responses were averaged to create behavior-specific subscales and higher scores indicate higher restrictive control. Alpha reliability coefficients ranged from .49 to .88 .

Solicitation. The frequency with which parents ask their adolescents or start conversations about each behavior, was assessed with a modified version of Stattin and Kerr's (2000; Kerr \& Stattin, 2000) solicitation scale. The stem of this measure stated, "How often do you talk to your child or ask about...” Responses were provided on a 5-point Likert-type scale ranging from 1 (almost never) to 5 (almost always). Behavior-specific solicitation scores were computed. Higher scores indicate higher levels of direct parental solicitation. Alpha reliability coefficients ranged from .68 to .92 .

Indirect. Parents reported how frequently they obtain information about each adolescent behavior by asking or talking to other important individuals in the adolescents' life, such as their child's friends, friends' parents, and teachers (i.e., How often do you ask or talk to other people, such as your child's teachers, friends, or friends' parents about...). This measure was adapted from previous research (Cottrell et al., 2007) to be consistent with the solicitation scale and 
provide the same 5-point Likert-type responses $(1=$ almost never; $5=$ almost always $)$. Item responses were averaged to create behavior-specific indirect information gathering scores. Higher scores indicate greater use of indirect strategies. Alpha reliability coefficients ranged from .90 to .95 .

Covert. Eighteen items were adapted from previous research (Cottrell at el., 2007) to assess parents' use of covert monitoring strategies (i.e., read messages on your teen's cell-phone or mobile device) using a 5-point Likert-type scale ranging from 1 (almost never) to 5 (almost always). Higher scores indicate higher levels of covert monitoring $(\alpha=.92)$.

\section{Adolescent-report measures (Appendix D).}

Demographics. Adolescents reported their age, gender, ethnicity, year in school, selfreport GPA, who lives in their home, parents' occupations, and parents' education levels.

\section{Information management strategies.}

Disclosure. Adolescents reported how often they tell their parents about each adolescent behavior without their parents asking, on a measure adapted from previous research (Smetana, Metzger et al., 2006; Tasopoulos-Chan, Smetana, \& Yau, 2009). Disclosure was measured on a 5-point Likert-type scale ranging from 1 (almost never) to 5 (almost always). Adolescents also had the option to respond, "I don't do this;" thus, disclosure was examined only for behaviors that adolescents actually do. Behavior-specific disclosure scores were computed with higher scores indicating more disclosure. Alpha reliability coefficients for complete items ranged from .71 to .89 .

Secrecy. Adolescents were asked to choose the strategy that best described what they typically do when they do not tell their parents everything: tell what parents want, tell only if parent asks, tell some but not all, avoid discussing, lie, or keep it secret. Similar to the disclosure 
measure, adolescents were provided the option to respond "I don't do this," which allowed the assessment of secretive information management regarding behaviors that the adolescents engage in. Similar to procedures used by Rote and Smetana (2015), adolescent responses that endorsed tell some but not all, avoid discussion, lying, and secrecy were coded as 1 (chosen) or 0 (not chosen) to create an adolescent secrecy item. Behavior-specific secrecy scores were created by computing the sum for each category, higher scores indicated more secrecy. Alpha reliability coefficients for complete items ranged from .61 to .95 .

Concealment. Adolescents completed a 13-item measure adapted from previous research (Ledbetter \& Vik, 2012) to assess adolescents' engagement in behaviors that actively conceal information from their parents (e.g., deleting text messages). Responses were provided on a 5point Likert-type scale ranging from 1 (almost never) to 5 (almost always), with higher scores indicating more frequent concealment $(\alpha=.87)$.

\section{Problem behaviors.}

Delinquency. Seven items were adapted from previous research (Ferris, Oosterhoff, \& Metzger, 2013; Miller et al., 2007; Williams et al., 2007) to measure adolescents' engagement in delinquent behaviors in the past 30 days. Consistent with previous studies, adolescents responded on a 4-point Likert-type scale ranging from 1 (never) to 4 (often). Responses were averaged to create a delinquency scale score with higher scores indicating more delinquency $(\alpha=.45)$.

Substance use. Adolescents' substance use was examined using items adapted from previous research (Ferris et al., 2013; Metzger et al., 2009; Moberg \& Hahn, 1991) that measured their use of tobacco products (1-item), marijuana (1-item) and alcohol (1-item) in the past 30 days. Responses were given on a 5-point Likert-type scale $(1=0$ times, $2=1$ or 2 times, $3=3$ to 
9 times, $4=10$ to 19 times, $5=20$ or more times $)$ and averaged to create a substance use score $(\alpha$ $=.62)$.

\section{Data Analysis Strategy}

All analyses were performed separately for parent and adolescent reported data. Hypotheses regarding variability in parental motivations for gaining knowledge were investigated using separate sets of repeated-measures ANOVAs. Separate models were run for each behavior category with motivation identified as the within-subject factor. Individual differences were examined using mixed-model ANOVAs with adolescent age and gender added as covariates. In addition, parental knowledge about each behavior and beliefs about the degree of harm involved with engaging in each behavior were added as covariates to the parent models and adolescent delinquency and substance use were added to the adolescent models. In order to achieve explainable variance, only motivations endorsed by more than $15 \%$ of the sample were included in the mixed-model ANOVAs. When Mauchly's test of sphericity indicated that the assumption of sphericity was violated, significant within-subjects main effects were interpreted using the Greenhouse-Geisser degrees of freedom correction. Follow-up t-tests were performed to explore significant interactions that emerged. When Levene's test for equality of variance indicated violations of the homogeneity of variance assumption, robust tests of significance were interpreted with equal variances not assumed.

Hypotheses regarding associations between parental motivations for gaining knowledge and parents' information gathering and adolescents' information management strategies were examined using structural equation models in SPSS Amos 20. In order to assess associations between variables with adequate variability, only motivations endorsed by more than $30 \%$ of the sample were included in SEM models. If a proposed model provided poor fit to the data, non- 
significant parameters and variables were removed from the model and a chi-square difference test was computed to ensure the reduced model provided a significantly better fit to the data. Significant paths were interpreted upon achieving an adequate fit (CMIN/DF $<3.00, \mathrm{CFI}>.80$, RMSEA < .08). Multi-group models explored whether gender moderated associations between parental motivations and information gathering/management strategies within each behavior category. To test for potential gender moderation, the fit of an unconstrained model that freely estimated adolescent male and female structural paths was compared to the fit of a model that constrained the paths to be equal. When the unconstrained model provided a significantly better fit than the constrained model, critical ratios were investigated to determine which paths differed by gender.

\section{Results}

\section{Data Cleaning and Preliminary Analyses}

Analyses were performed to assess missing data, outliers, and the distribution of all continuous variables in both the parent and adolescent-report data. Seven parents and four adolescents were removed from all analyses due to extreme amounts of missing data, including a majority of the key study variables. Validity questions were built into both the parent and adolescent surveys to identify potentially problematic cases. Three adolescents failed both validity questions but were retained because individual survey responses did not indicate inattentive reporting, and additional analyses indicated that these adolescents were also not multivariate outliers. Nine parents were flagged for failing all three validity questions. Analyses indicated these parents were not multivariate outliers. Individual survey responses were also examined and did not indicate inattentive reporting so these participants were retained in the sample. Additionally, sensitivity analyses were performed to verify these cases did not affect the 
variable distributions. Mahalanobis distance scores were computed for behavior-specific study variables in parent and adolescent-report data to investigate multivariate outliers. One adolescent had multivariate outliers; however, this adolescent was retained after examining individual survey responses and noticing that the adolescent was an outlier due to reporting that the adolescent disclosed and kept secrets about behaviors for which much of the adolescent sample reported, "I don't do this." There were no parents that had multivariate outliers across behaviorspecific variables. Means, standard deviations, and bivariate correlations for key study variables can be found in Tables 5 - 20 .

Additional analyses were performed to examine potential variability caused by differences in parent marital status, recruitment location and adolescents' survey medium. Results revealed that study variables did not vary based on parents' marital status, nor were there significant differences based on whether adolescents completed their surveys on paper (63\%) versus online (37\%). Recruitment location analyses revealed significant location differences in parent and adolescent reports of a few key study variables (Table 4). Parents from West Virginia reported higher levels of solicitation about dating behaviors that concern supervision, more use of covert monitoring strategies and higher levels of peer-related harmfulness beliefs compared to parents from Connecticut. Compared to parents from West Virginia, parents from Connecticut also reported more frequently that they would be motivated to gain knowledge about schoolrelated behaviors in order to ensure adolescents' emotional well-being. Adolescents from Connecticut reported less substance use compared to adolescents from West Virginia. Adolescents from Connecticut reported more school-related disclosure than adolescents from Pennsylvania. With regard to adolescent-reported parental knowledge-seeking motivations, there were no instances in which all three locations differed significantly from each other. There were 
multiple adolescent-reported parental knowledge-seeking motivations for which adolescents from Connecticut reported the motivation less frequently than one of the other schools, which was typically West Virginia.

\section{Research Questions 1 and 2}

(1) Do parents' motivations for desiring knowledge about their adolescents' behaviors vary for different types of adolescent behaviors (e.g., schoolwork vs. dating)?

(2) Are there individual differences in varying parental motivations for gaining knowledge?

\section{Parents’ Motivations for Knowledge: Descriptive Statistics (Table 5)}

Physical safety was the motivation for gaining knowledge about adolescents' behaviors that was chosen the most frequently across all behaviors categories except conventional and school behaviors. More than $90 \%$ of parents chose physical safety as a motivation for gaining knowledge at least once with regard to all behaviors except conventional and school behaviors, for which more than $90 \%$ did not choose physical safety as a motivation. Parents frequently reported also being motivated to keep the adolescent out of trouble, with more than $56 \%$ of parents choosing this motivation at least once across all behavior categories. Future Success was the third most frequently chosen motivation for desiring knowledge, with more than $56 \%$ of parents choosing future success at least once as a motivation for desiring knowledge about all categories of adolescent behaviors except dating identity and dating supervision behaviors. However, across all behavior categories more than $53 \%$ of parents did not choose the family's reputation or just needing to know as motivations for gaining knowledge.

\section{Differences in Parents' Motivations for Knowledge}


A series of repeated measures ANOVAs were performed with parents' motivations for gaining knowledge identified as the within-subject factor. Results showed all ANOVAs were significant, and pairwise comparisons using Bonferonni corrections indicated that parents' knowledge-seeking motivations differed for each behavior category. Main effects, means and standard deviations are presented in Table 21.

Next, individual differences in parents' motivations for gaining knowledge about each behavior category were examined using a series of 2 (adolescent age: 13-15 vs. 16-19) X 2 (adolescent gender: male vs. female) X motivation mixed-model ANOVAs, with parental behavior-specific knowledge and harmfulness beliefs included as covariates. Main effects were qualified by significant harm $\mathrm{X}$ motivation, age $\mathrm{X}$ motivation, and gender $\mathrm{X}$ motivation interactions for the dating expression, dating identity, and dating supervision behavior categories (Table 23). Significant interactions did not emerge for the other four behavior categories.

When considering conventional behaviors, such as the language an adolescent uses outside the home, parents most frequently reported being motivated to gain knowledge in order to ensure their adolescent is being good to others. However, ensuring the adolescent is good to others did not emerge as an important motivator for gaining knowledge in any other behavior categories. Although less frequently, parents also reported being motivated to gain knowledge about conventional behaviors to keep the adolescent out of trouble and to ensure the adolescent has a good reputation. Parents reported being most motivated to gain knowledge about school behaviors to ensure their adolescents' future success. The second and third most frequently chosen motivations for gaining knowledge about school behaviors were ensuring adolescents' emotional well-being and maintaining a good relationship. Physical safety emerged as the most frequently chosen motivation for gaining knowledge about dating expression, dating identity, 
dating supervision, peer, and substance use behaviors. Similarly, keeping the adolescent out of trouble was the second most frequently chosen knowledge-seeking motivation regarding dating expression, dating identity, dating supervision, peer, and substance use behaviors. However, main effects that emerged for parents' motivations for gaining knowledge about dating expression, dating identity, and dating supervision behaviors were moderated by adolescent age, adolescent gender, and parental harmfulness beliefs (see Table 23 for means, standard deviations, and significance tests).

Adolescent age. Significant adolescent age $\mathrm{X}$ motivation interactions emerged for dating expression $\left(F(5.71,1043.77)=2.43, p=.03, \eta^{2}=.01\right)$ and dating identity behaviors $(F(5.20$, $\left.983.21)=2.59, p=.02, \eta^{2}=.01\right)$. Compared to parents of younger adolescents, parents of older adolescents were more frequently motivated to gain knowledge about dating expression and dating identity behaviors to ensure the emotional well-being of their older adolescents. Parents of older adolescents also more frequently reported being motivated to gain knowledge about dating identity behaviors in order to ensure their adolescents are good to others. Parents of younger adolescents, however, more frequently reported they were motivated to gain knowledge about dating expression behaviors because they just needed to know.

Adolescent gender. Significant adolescent gender X motivation interactions emerged for all three dating behavior categories, dating expression $\left(F(5.71,1043.77)=5.06, p<.001, \eta^{2}=\right.$ $.03)$, dating identity $\left(F(5.20,983.21)=5.87, p<.001, \eta^{2}=.03\right)$, and dating supervision $(F(5.09$, $\left.931.05)=6.65, p<.001, \eta^{2}=.04\right)$. Compared to parents of male adolescents, parents of female adolescents more frequently reported being most motivated to gain knowledge about all dating behaviors in order to ensure the physical safety of their daughters. Parents of female adolescents also reported more frequently than parents of male adolescents that they would be motivated to 
gain knowledge about adolescents' dating expression behaviors to ensure their adolescent daughters' have a good reputation. Compared to parents of female adolescents, parents of male adolescents were more frequently motivated to gain knowledge about dating expression behaviors to ensure their adolescent sons were good to others, they more frequently reported being motivated to gain knowledge about dating identity behaviors because they just need to know about their sons' significant other, and they were more motivated to gain knowledge about dating supervision behaviors to keep their sons out of trouble.

Parental harmfulness beliefs. Significant parental harmfulness beliefs X motivation interactions for dating expression $\left(F(5.71,1043.77)=6.44, p<.001, \eta^{2}=.03\right)$ and dating supervision behaviors $\left(F(5.09,931.05)=3.47, p<.01, \eta^{2}=.02\right)$ were explored by using a median split to dichotomize the scale score representing parents beliefs about the amount of harm involved with youth engaging in each behavior and then performing t-tests to explore which parental motivations differed for high harm compared to low harm beliefs. Results indicated that parents with lower harmfulness beliefs about dating expression behaviors more frequently reported that they were motivated to gain knowledge about dating expression behaviors to ensure their adolescents were good to others and their adolescents' emotional wellbeing, compared to parents with higher harmfulness beliefs about dating expression. Compared to parents with lower harmfulness beliefs, parents with higher harmfulness beliefs about dating expression and dating supervision behaviors more frequently reported being motivated to gain knowledge about dating expression and dating supervision behaviors to ensure their adolescent has a good reputation. Parental harmfulness beliefs X motivation interactions were not significant for other the behavior categories.

\section{Research Question 3}


Are different parental motivations for gaining knowledge associated with the strategies parents utilize to seek information about adolescents' behaviors?

\section{Associations between Parental Motivations and Information Gathering Strategies}

Structural equation models were performed for each behavior category with parental motivations for gaining knowledge about the behavior identified as exogenous variables predicting parent-reported family rules, parental solicitation, indirect information seeking, and covert information gathering strategies, while controlling for adolescent age, adolescent gender, parental knowledge of the behavior and relationship quality (Figure 1). Due to minimal missing data $(<1 \%)$, maximum likelihood estimation was used. Variables with significant bivariate correlations were allowed to covary in each the model. Standardized regression coefficients for all direct effects and model fit statistics for parent-report models can be found in Table 25 .

Multi-group models were performed for each behavior category to explore the extent to which paths between parental motivations and information gathering strategies varied based on adolescent gender. Multi-group results presented below are for the models that had a significant chi-square difference test, indicating that the model freely estimating the structural weights of parents of male and parents of female adolescents provided a better fit to the data compared to a model that constrained structural weights to be equal. When multi-group models were significant, critical ratios were examined to discern which associations differed for parents of male and female adolescents.

Conventional. The proposed model provided an adequate fit to the data; however, there were no significant paths between parental motivations for knowledge and parents' information gathering strategies. 
Multi-group results suggested the model that freely estimated male and female adolescents' structural paths provided a good fit to the data $(\mathrm{CMIN} / \mathrm{DF}=1.42, \mathrm{CFI}=.92$, RMSEA $=.05[90 \% \mathrm{CI}=.02, .07])$ and a significantly better fit to the data than a model that constrained parents of male and female adolescents' structural paths to be equal $\left(\Delta \chi^{2}(40)=\right.$ $76.34, p<.001)$. Post-hoc examination of critical ratios indicated that parents' motivation to gain knowledge about conventional behaviors in order to ensure their adolescents' emotional wellbeing was significantly associated with increased rules regarding conventional behaviors $(\beta=$ $.24, p=.04, \mathrm{C} . \mathrm{R} .=-2.14)$ and solicitation about conventional behaviors $(\beta=.33, p=.01, \mathrm{C} . \mathrm{R} .=$ -2.45) for parents of male adolescents, but not parents of female adolescents. Parents' reports of being motivated to gain knowledge about conventional behaviors to maintain a good relationship was significantly associated with increased solicitation of conventional behaviors $(\beta$ $=.37, p=.01$, C.R. $=-2.02$ ) and covert strategies regarding conventional behaviors for parents of male adolescents $(\beta=.46, p=.001$, C.R. $=-3.21)$, but not parents of female adolescents. Parents' reports of being motivated to gain knowledge about conventional behaviors in order to ensure their adolescent has a good reputation were associated with increased rules $(\beta=.38, p=.01$, C.R. $=-2.38)$, solicitation $(\beta=.42, p<.01$, C.R. $=-2.80)$, and covert $(\beta=.41, p<.01$, C.R. $=-$ 2.42) strategies regarding conventional behaviors for parents of male adolescents, but not parents of female adolescents. Finally, parents who were motivated to gain knowledge about conventional behaviors in order to ensure the family's reputation reported increased use of indirect strategies $(\beta=.31, p=.02$, C.R. $=-2.41)$ to learn about conventional behaviors for parents of male adolescents, but not parents of female adolescents. None of the paths that emerged as significant for parents of male adolescents were significant for parents of female adolescents. 
Dating expression. Results revealed that when parents were motivated to gain knowledge about dating expression behaviors because they just need to know they had more rules, solicited more and used more indirect strategies to learn about behaviors that express the dating relationship. Parents' higher frequency of desiring knowledge about dating expression in order to ensure their adolescents' future success was also associated with increased rules, solicitation, and indirect strategies regarding dating expression behaviors. In addition, parents' reports of being motivated to gain knowledge about dating expression to ensure physical safety was associated with increased solicitation of dating expression behaviors and increased use of indirect strategies to learn about dating expression behaviors. Multi-group results indicated the unconstrained model did not provide a significantly better fit compared to a model that constrained parents' of male and female adolescents' structural paths to be equal $\left(\Delta \chi^{2}(40)=\right.$ 53.03, $p=.08$ ), indicating that pathways did not differ for parents of male and female adolescents.

Dating identity. Results indicated that parents' motivations to gain knowledge about the identity of adolescents' significant other to ensure future success were significantly associated with increased parental use of indirect monitoring strategies to learn about dating identity behaviors. In addition, parents' higher frequencies of being motivated to gain knowledge about the identity of an adolescent's significant other to ensure future success and ensure the adolescent has a good reputation were both significantly associated with increased rules regarding the identity of the adolescent's significant other. Multi-group results indicated the unconstrained model did not provide a significantly better fit compared to the model that constrained structural paths to be equal $\left(\Delta \chi^{2}(7)=1.68, p=.98\right)$, which indicated there were no significant gender differences in the structural weights. 
Dating supervision. The proposed model for the dating supervision behavior category provided a poor fit to data. The removal of non-significant paths was unsuccessful in correcting model fit due to non-significant structural weights between parental knowledge-seeking motivations and information gathering strategies. Multi-group models were performed but provided a poor fit to the data; removal of non-significant parameters did not improve the fit. Parents reported being motivated to gain knowledge about dating supervision behaviors in order to protect physical safety and to keep their adolescent out of trouble so frequently that there may not have been enough variability to detect associations between parents motivations and their strategies used to gather information about dating supervision behaviors.

Peers. Results indicated that parents' motivations to gain knowledge about peers in order to ensure adolescents' emotional well-being was associated with increased peer-related parental solicitation and decreased use covert strategies. Parental reports of being motivated to gain knowledge about peers to keep their adolescent out of trouble were significantly associated with increased parental solicitation and use of indirect strategies to gain information about peer relationships. Finally, parents who were motivated to gain knowledge about peers to maintain $a$ good relationship also reported increased peer-related parental solicitation. Multi-group results showed the unconstrained model did not provide a significantly better fit compared to the constrained model $\left(\Delta \chi^{2}(40)=43.54, p=.32\right)$, which indicated there were no significant gender differences in the structural weights.

School. Results indicated that parents' motivations to gain knowledge about school in order to ensure adolescents' emotional well-being were significantly associated with increased solicitation and indirect strategies, and lower levels of covert strategies to learn about school behaviors. Parents motivated to gain knowledge in order to maintain a good relationship had 
significantly fewer rules about school and engaged in more parental solicitation. Finally, when parents reported being motivated to gain knowledge about school in order to keep their adolescents out of trouble and because they just need to know, they engaged in increased parental solicitation about school behaviors. Multi-group results indicated the unconstrained model did not provide a significantly better fit compared to the constrained model $\left(\chi^{2}(36)=46.48, p=.11\right)$, which indicated there were no significant gender differences in the structural weights.

Substance use. Results indicated higher frequencies of desiring knowledge about substance use behaviors because parents just need to know was significantly associated with more parental solicitation and use of indirect strategies to learn about substance use behaviors. Parent-reported motivation to gain knowledge about substance use behaviors in order to maintain a good relationship was significantly associated with decreased rules about substance use. In multi-group analyses, the unconstrained model did not provide a significantly better fit compared the constrained model $\left(\Delta \chi^{2}(3)=7.87, p=.05\right)$, which indicated there were no significant gender differences in the structural weights.

\section{Research Question 4}

Do adolescents' perceptions of their parents' motivations for gaining knowledge vary by the type of behavior (e.g., substance use vs. peers)?

\section{Adolescent-Reported Parental Motivations for Knowledge: Descriptive Statistics (Table 6)}

Keeping the adolescent out of trouble was the parental knowledge-seeking motivation that adolescents' reported most frequently across all behavior categories. More than $66 \%$ of adolescents chose keeping the adolescent out of trouble at least once as their parents' motivation for gaining knowledge about all behavior categories. Physical safety was the second most frequent adolescent-reported parental knowledge-seeking motivation across all behavior 
categories, except conventional and school behaviors. More than $85 \%$ percent of adolescents reported at least once that their parents would want to gain knowledge about dating expression, dating identity, dating supervision, peers, and substance use behaviors in order to protect adolescents' physical safety, but more than $85 \%$ did not choose physical safety as a parental motivation for gaining knowledge about conventional and school behaviors. Additionally, more than $51 \%$ of adolescents reported at least once that their parents would be motivated to gain knowledge about all behaviors in order to ensure the adolescent has a good reputation. Overall, adolescents rarely reported their parents would be motivated to gain knowledge in order to maintain a good relationship, ensure the family's reputation, ensure the adolescent is good to others, or because they were just being nosey.

\section{Differences in Adolescent-Reported Parental Motivations for Knowledge}

A series of repeated measures ANOVAs were performed with adolescent-reported parental motivations for gaining knowledge identified as the within-subject factor. Results showed all ANOVAs were significant, and pairwise comparisons using Bonferonni corrections indicated that adolescents' reports of their parents' motivations for gaining knowledge differed for each behavior category. Main effects, means and standard deviations are presented in Table 22.

Next, individual differences in adolescents' reports of their parents' motivations for gaining knowledge about each behavior category were explored using a series of 2 (adolescent age: $13-15$ vs. 16-19) X 2 (adolescent gender: male vs. female) X motivation mixed-model ANOVAs, with adolescent delinquency and substance use included as covariates. Main effects were qualified by gender X motivation interactions for all behavior categories except school behaviors (Table 24). 
Adolescents most frequently reported their parents would be motivated to gain knowledge about conventional, dating expression, dating supervision, peer, and substance use behaviors in order to keep the adolescent out of trouble, and keeping the adolescent out of trouble was youths' second most frequently reported parental motivation for learning about school behaviors. Physical safety emerged as adolescents' most frequently reported parental knowledge-seeking motivation regarding the identity of adolescents' significant others, however, physical safety was adolescents' second most frequently reported parental motivation for gaining knowledge about dating expression, dating supervision, peer and substance use behaviors. Adolescents' reported their parents would be most motivated to learn about school behaviors in order to ensure future success, while future success also emerged as adolescents third most frequently reported parental motivation for gaining knowledge about substance use behaviors. Ensuring the adolescent has a good reputation emerged as adolescents' second most frequently reported parental motivation for gaining knowledge about conventional and school behaviors, while adolescents' reputation was also adolescents' third most frequently reported motivation for gaining knowledge about dating supervision and peer-related behaviors.

Adolescent gender. There were no significant main effects of gender, however significant gender $\mathrm{X}$ motivation interactions emerged for conventional $(F(4.18,802.63)=6.11, p$ $\left.<.001, \eta^{2}=.03\right)$, dating expression $\left(F(5.88,1128.95)=8.65, p<.001, \eta^{2}=.04\right)$, dating identity $\left(F(5.35,1027.29)=8.71, p<.001, \eta^{2}=.04\right)$, dating supervision $(F(5.17,993.42)=11.23, p<$ $\left..001, \eta^{2}=.06\right), \operatorname{peer}\left(F(5.40,1037.26)=5.19, p<.001, \eta^{2}=.03\right)$ and substance use $(F(3.11$, $\left.596.60)=7.69, p<.001, \eta^{2}=.04\right)$ behaviors. A gender $\mathrm{X}$ motivation interaction was not present for school behaviors. Compared to female adolescents, male adolescents more frequently reported their parents would be motivated to gain knowledge about conventional, dating 
expression, dating identity, dating supervision, peer and substance use behaviors in order to keep the male adolescent out of trouble and to promote future success. Adolescent females reported more frequently than males that their parents would be motivated to gain knowledge about conventional behaviors in order to ensure the adolescent is good to others, but male adolescents reported more frequently that their parents would be more motivated to gain knowledge about dating expression, dating identity, and dating supervision behaviors in order to ensure boys are good to others. Compared to male adolescents, female adolescents reported that their parents would be motivated to learn about dating expression, dating supervision, peers, and substance use behaviors in order to protect their physical safety. Conversely, male adolescents indicated more frequently than female adolescents that parents' would be motivated to gain knowledge about the identity of adolescents' significant others to protect physical safety. Additionally, compared to male adolescents, female adolescents more frequently reported parents would desire knowledge about dating expression, dating identity, and peer behaviors in order to maintain a good relationship. Finally, female adolescents indicated more frequently than male adolescents that their parents would be motivated to learn about peer-related behaviors in order to promote the female adolescents' emotional well-being.

\section{Research Question 5}

Are adolescents' perceptions of their parents' motivations for gaining knowledge associated with the information management strategies they utilize?

\section{Associations between Adolescent-Reported Parental Motivations and Information}

\section{Management Strategies}

Structural equation models were performed for each behavior category with adolescents' reports of their parents' knowledge-seeking motivations identified as exogenous variables 
predicting adolescent-reported disclosure, secrecy, and concealment strategies while controlling for adolescent age, gender, delinquency and substance use (Figure 2). Due to adolescents' ability to report, "I don't do this" for the disclosure and secrecy measures, each behavior-specific structural equation model was performed on the subsample of adolescents who engaged in the behaviors within the respective behavior category. Detail regarding the size of the subsample and demographic differences of the subsample compared to the full analytic sample are reported with the SEM results of each behavior category. When conceptually appropriate, variables were allowed to covary based on modification indices provided by AMOS. Standardized regression coefficients and model fit statistics for adolescent report models can be found in Table 26 .

Similar to parent-report models, multi-group models explored the extent to which structural paths between adolescents' reports of their parents' motivations to gain knowledge and adolescents' information management strategies differed for male and female adolescents. Multigroup results presented below are for the models that had a significant chi-square difference test, indicating that the model freely estimating the structural weights of male and female adolescents provided a better fit to the data compared to a model that constrained structural weights to be equal. When multi-group models were significant, critical ratios were examined to discern which associations differed for male and female adolescents.

Conventional. Eighteen adolescents reported not engaging in the conventional behaviors on the disclosure and secrecy scales for conventional activities, therefore the subsample of adolescents for the conventional behavior category consisted of 178 adolescents. Attrition analyses indicated that the 18 adolescents did not differ in age $(t(194)=1.12, p=.26)$, gender $\left(\chi^{2}(1)=.84, p=.36\right)$, or self-reported GPA $\left(\chi^{2}(5)=5.40, p=.37\right)$ 
After controlling for age, gender, and problem behaviors, results showed that when adolescents' reported their parents would want to gain knowledge about conventional behaviors to keep the adolescent out of trouble, adolescents engaged in increased disclosure and decreased secrecy about their conventional behaviors. When adolescents' felt their parents desired knowledge about conventional activities to promote the adolescent's reputation, promote future success, ensure the family's reputation, and ensure the adolescent is good to others, youth engaged in lower levels of adolescent secrecy about conventional behaviors.

Multi-group analyses indicated the unconstrained model provided a better fit compared to a constrained model $\left(\Delta \chi^{2}(24)=44.26, p=.01\right)$. Critical ratios showed that a higher frequency of adolescent-reported parental motivation to gain knowledge to ensure the adolescent is good to others was significantly associated with more disclosure $(\beta=.40, p<.001$, C.R. $=3.60)$ and less secrecy $(\beta=-.43, p<.001$, C.R. $=-2.40)$ and concealment $(\beta=-.35, p<.01$, C.R. $=-2.99)$ about conventional activities for female adolescents but not male adolescents. Higher frequencies of adolescent-reported parental motivation to learn about conventional activities to promote future success was associated with less secrecy $(\beta=-.36, p<.001$, C.R. $=-2.25)$ and concealment $(\beta=$ $-.34, p<.001$, C.R. $=-3.55)$ about conventional behaviors for female adolescents, but not male adolescents. Finally, when female adolescents felt their parents were motivated to learn about conventional activities to ensure the family's reputation they engaged in less secrecy $(\beta=-.34, p$ $=.001$, C.R. $=-1.98)$ about conventional behaviors, however, this association was not significant for male adolescents.

Dating behavior categories. Forty-five adolescents reported not engaging in dating behaviors on the disclosure and secrecy scales and were removed from the analytic sample for the SEM modeling. SEM models for all three dating behavior categories included a subsample of 
149 adolescents. Attrition analyses indicated adolescents who did not engage in dating behaviors were significantly younger $(M=15.56, \mathrm{SD}=1.27)$ than adolescents who reported engagement in dating behaviors $(\mathrm{M}=16.18, \mathrm{SD}=1.21)$. However, adolescents who did not date were no more or less likely to be male or female $\left(\chi^{2}(1)=3.06, p=.08\right)$ or to a have better self-reported GPA $\left(\chi^{2}(5)=5.22, p=.39\right)$ compared to the adolescents who did engage in dating behaviors.

Dating expression. After controlling for adolescent age, gender, and problem behaviors, results showed adolescents' reports that their parents were motivated to learn about dating expression behaviors to maintain a good relationship were significantly associated with more disclosure and less concealment about dating expression behaviors. Higher frequencies of adolescent-reported parental motivation to gain knowledge about dating expression behaviors because parents were just being nosey was associated with more concealment about dating expression.

For the multi-group model, the unconstrained model provided significantly better fit compared to the constrained model $\left(\Delta \chi^{2}(33)=50.63, p=.03\right)$. Post-hoc critical ratios suggested that when female adolescents, but not males, more frequently reported their parents were motivated to gain knowledge about dating expression behaviors in order to ensure the adolescent has a good reputation they engaged in less secrecy $(\beta=-.36, p=.04$, C.R. $=-2.32)$. For female adolescents, higher frequencies of adolescent-reported parental motivation to learn about dating expression to ensure future success were associated with more disclosure about dating expression behaviors $(\beta=.22, p=.04$, C.R. $=-2.01)$ and higher frequencies of adolescent-reported motivation to maintain a good relationship were associated with less concealment about dating expression behaviors $(\beta=-.41, p=.01, \mathrm{C} . \mathrm{R} .=-2.43)$; however, these associations were not significant for male adolescents. 
Dating identity. Results indicated that when adolescents reported their parents were motivated to gain knowledge about the identity of their significant others to maintain a good relationship and ensure emotional well-being, they engaged in increased disclosure about the dating identity. In addition, higher frequencies of adolescent-reported parental motivation to learn about the identity of significant others because parents are just being nosey was associated with more concealment about the identity of significant others.

For the multi-group analyses, the unconstrained model provided a significantly better fit compared to a constrained model $\left(\Delta \chi^{2}(33)=55.63, p=.01\right)$. Post-hoc critical ratios showed that higher frequencies of adolescent-reported parental knowledge-seeking motivations regarding dating identities because parents were just being nosey were associated with increased concealment for female adolescents $(\beta=.41, p=.01$, C.R. $=2.77)$, but not male adolescents.

Dating supervision. Results revealed that when adolescents reported their parents were motivated to gain knowledge about dating behaviors that cause supervision concerns in order to maintain a good relationship; adolescents engaged in increased disclosure and decreased concealment about dating supervision behaviors. Conversely, higher frequencies of adolescentreported parental motivation to learn about dating supervision because parents were just being nosey were associated with increased adolescent concealment about dating supervision behaviors. Follow up multi-group models indicated that associations did not vary by adolescent gender, as the unconstrained model did not provide a significantly better fit compared the constrained model $\left(\Delta \chi^{2}(9)=8.86, p=.45\right)$.

Peers. All adolescents reported engaging in behaviors within the peer-related behavior category, thus the SEM models included all adolescents from the analytic sample $(N=196)$. Results showed adolescent-reported parental motivation to learn about peers because parents 
were just being nosey was significantly associated with decreased peer-related disclosure and increased peer-related concealment. For the multi-group analyses, the unconstrained model did not provide a significantly better fit than a constrained model $\left(\Delta \chi^{2}(33)=41.48, p=.15\right)$, indicating structural paths did not differ for male and female adolescents.

School. All adolescents reported engaging in behaviors within the school behavior category, therefore all adolescents were retained for the SEM models $(N=196)$. Results showed that higher frequencies of adolescent-reported parental motivation to learn about school-related behaviors in order to promote future success were significantly associated with lower levels of school-related concealment. In addition, when adolescents reported their parents were motivated to learn about school behaviors in order to ensure the family's reputation; youth engage in less school-related disclosure.

Follow up multi-group models showed the unconstrained model provided a significantly better fit compared to a constrained model $\left(\Delta \chi^{2}(27)=53.50, p<.01\right)$. Critical ratios showed higher frequencies of adolescent-reported parental motivation to learn about school to maintain $a$ good relationship was associated with increased school-related disclosure $(\beta=.28, p=.02$, C.R $=2.84)$ and decreased concealment $(\beta=-.39, p<.001$, C.R. $=-3.29)$ for female adolescents, but not males. Higher frequencies of adolescent-reported parental motivation to gain knowledge about school to keep the adolescent out of trouble were also associated with more school-related disclosure $(\beta=.24, p=.05$, C.R. $=2.30)$ and less school-related concealment $(\beta=-.28, p=.02$, C.R. $=-2.55)$ for female adolescents, not male. In addition, when female adolescents, but not male, reported their parents would want knowledge about school in order to ensure the adolescent's reputation; female adolescents engaged in more school-related disclosure $(\beta=.29$, $p=.02)$. Higher frequencies of adolescent-reported parental motivation to gain knowledge about 
school in order to promote future success were associated with less school-related disclosure $(\beta=$ $-.26, p=.03$, C.R. $=2.71)$ for male adolescents, but less school-related concealment $(\beta=-.40, p$ $<.001$, C.R. $=-4.22$ ) for female adolescents. Finally, higher frequencies of adolescent females' reports that their parents would want knowledge about school to ensure emotional well-being were associated with less school-related concealment $(\beta=-.33, p=.01$, C.R. $=-2.56)$ while female adolescents' reports that their parents would be motivated to learn about school to ensure the family's reputation were associated with less school-related secrecy $(\beta=-.32, p=.01$, C.R. $=$ -2.22), neither of which were significant for male adolescents.

Substance use. Many participants reported not engaging in substance use behaviors, which significantly reduced the sample available to test associations for this behavior $(N=69)$. Adolescents who did not use substances were significantly younger $(\mathrm{M}=15.87, \mathrm{SD}=1.27)$ compared to adolescents who reported using substances $(\mathrm{M}=16.33, \mathrm{SD}=1.15)$. However, there were no gender $\left(\chi^{2}(1)=2.33, p=.13\right)$ or self-reported GPA $\left(\chi^{2}(5)=8.31, p=.14\right)$ differences between youth who reported substance use and those who reported no substance use.

This subsample was too small to perform SEM models on the substance use outcomes; alternatively, separate hierarchical regression models were performed for each information management strategy (disclosure, secrecy, and concealment). Adolescent age, gender, delinquency and substance use were entered in step one of each model, and adolescent-reported parental knowledge-seeking motivations were entered in step two predicting the respective information management strategy. For adolescent disclosure, the model accounted for $16.5 \%$ of the variance, $F(10,68)=1.15, p=.34$. The model was not significant and no significant associations were present between motivations and disclosure. For adolescent secrecy, the model accounted for $24 \%$ of the variance in secrecy, $F(10,68)=1.83, p=.08$. Although the full model 
was only marginally significant, an examination of the individual predictors indicated that when adolescents' reported their parents were motivated to learn about substance use in order to maintain a good relationship adolescents engaged in decreased secrecy about substance use behaviors. The adolescent concealment model significantly accounted for $28 \%$ of the variance in concealment, $F(10,68)=2.25, p=.03$. After controlling for the significant effect of adolescent delinquency, higher frequencies of adolescent-reported parental motivation to learn about substance use in order to maintain a good relationship were associated with decreased concealment about substance use behaviors.

\section{Additional Analyses}

Additional correlations were performed to explore associations between parental knowledge-seeking motivations and parental warmth and control. Correlations were performed separately for parent and adolescent-reported variables (see Tables 27 and 28).

Significant correlations for parent-reported variables were most prominent across parentreported motivations for knowledge regarding dating and school-related behaviors. Across all three dating behavior categories, increased parental warmth was associated with a higher frequency of parent-reported motivation to gain knowledge in order to protect physical safety, and a lower frequency of parent-reported motivation to gain knowledge to ensure the adolescent is good to others. For dating identity behaviors, parental control was associated with a higher frequency of parent-reported knowledge-seeking motivation to promote future success. Parental control was also associated with a higher frequency of parents reporting that they would be motivated to gain knowledge about dating supervision behaviors in order to ensure the adolescent has a good reputation. 
Multiple significant correlations emerged between adolescent-reported parental knowledge-seeking motivations and adolescent-reported parental warmth and control. Across all dating behaviors, peer-related behaviors and substance use, adolescent-reported warmth was associated with higher frequencies of adolescents reporting their parents would want knowledge about those behaviors to promote physical safety, emotional well-being, and to maintain a good relationship, and lower frequencies of adolescent-reported parental motivation to ensure the adolescent has a good reputation. Similarly, adolescent-reported control was associated with lower frequencies of adolescent-reported parental knowledge-seeking motivations to promote physical safety, emotional well-being, and to maintain a good relationship, and higher frequencies of adolescent-reported parental knowledge-seeking motivation about those behaviors to ensure the adolescent has a good reputation. Interestingly, across all behaviors except substance use, increased adolescent-reported parental warmth was associated with lower frequencies of adolescent-reported parental motivation to gain knowledge because their parents were just being nosey, and adolescent-reported parental control was associated with higher frequencies of adolescent-reported parental motivation to gain knowledge because their parents were just being nosey.

\section{Discussion}

Extensive research indicates that parental knowledge about their adolescents' whereabouts and activities when away from home facilitates positive youth development (Barber et al., 2005; Crouter \& Head, 2002). However, findings are mixed with regard to the usefulness of parent-driven information seeking behaviors over and above adolescents' own willingness to disclose (Fletcher et al., 2004; Keijsers et al., 2010, Kerr et al., 2010). Utilizing a social domain framework and moving beyond questions of what and how parents garner information, the 
current study investigated why parents want to know about distinct types of adolescent behaviors. The primary goal of the present study was to examine the extent to which parental motivations for seeking knowledge about their adolescents' lives varied based on different types of adolescent behaviors, including conventional, dating, peer, school, and substance use behaviors. The second goal was to assess whether individual differences emerged in parental knowledgeseeking motivations. Next, associations between parents' motivations for gaining knowledge and parents' information gathering or monitoring strategies were examined. Due to the importance of adolescents' own information management, the present study also examined youths' perceptions of their parents' motivations for learning about distinct behaviors as well as how adolescent reports of parental knowledge-seeking motivations influenced their own information management strategies.

Across behaviors, results indicated parents were generally most motivated to learn about their adolescents' activities in order to protect youths' physical safety. However, adolescents' perceptions of the motivation driving their parents' desire to obtain knowledge diverged from parents', as adolescents believed their parents would be most motivated to learn about their behaviors in order to keep the adolescent out of trouble. These findings suggest that parents and adolescents have different vantages when considering the reasoning that motivates parents' information seeking behaviors. Increased variability was present in both parent and adolescentreported parental knowledge-seeking motivation regarding multifaceted behaviors. Although safety was a primary concern of parents', their knowledge-seeking motivations regarding multifaceted dating behaviors were qualified by their own beliefs about the level of harm involved with engaging in dating behaviors, adolescent age and adolescent gender. Adolescent gender differences also qualified adolescent reports of parental motivations to gain knowledge 
across multifaceted behaviors. Additionally, both parent and adolescent reports of parental knowledge-seeking motivations were linked to different information gathering and management strategies. However, the primary motivations of physical safety and keeping the adolescent out of trouble were less strongly linked to knowledge seeking/sharing behaviors, compared to secondary motivations such as promoting future success, ensuring emotional well-being, and maintaining a good relationship. Furthermore, adolescent gender moderated associations between knowledge-seeking motivations and information management for both parent and adolescent-report models. In general, associations between motivations and information management behaviors were stronger for parents of male adolescents across the parent-report models, whereas associations were stronger for female adolescents across the adolescent-report models.

\section{Parental Motivations for Knowledge}

Previous parental monitoring research assumed that parents desired knowledge about their adolescents' whereabouts and activities so they could protect their adolescent children from harm (Racz \& McMahon, 2011). The current results support this assumption when considering the primary motivation reported by parents, as parents most frequently reported physical safety as the motivation behind their desire to gain knowledge about all multifaceted and prudential behaviors. Consistent with research from the social domain perspective (Smetana, 2006), results also revealed that parents' knowledge-seeking motivations varied based on the specific adolescent behavior for which they were trying to gather information. As hypothesized, promoting adolescents' future success was the strongest motivator for seeking knowledge about adolescents' school-related behaviors. Also as expected, parents most frequently reported physical safety as their motivation for seeking knowledge about substance use and dating 
behaviors. Contrary to expectations, however, parents focused on the potential risks involved with peer related behaviors when desiring knowledge about peer relationships. These findings suggest that parents primarily focus on the prudential characteristics of multifaceted behaviors, such as the potential harm involved, when considering why they want knowledge about these behaviors. Parents may be more concerned with their adolescents' physical safety across behaviors because they feel it is their "duty" as parents to protect their children from harm (Grusec, 2011). Other socialization goals, such as ensuring their children comply with societal regulations may be secondary to the protecting their welfare (Grusec, 2011), which is supported by the present findings.

However, parents' knowledge-seeking motivations also varied as a function of adolescent age, gender, and parental harmfulness beliefs. These contextual and psychological variables most strongly influenced parents' motivations for gaining information about their adolescents' dating behaviors. Previous social domain research has conceptualized dating behaviors as multifaceted because reasoning about these behaviors can overlap multiple domains, such as personal and prudential depending on the characteristics of adolescent romantic relationships that are most salient to the individual (Smetana, 2011). Likewise, the present study found that there is more variability in parents' reports of their motivations for obtaining knowledge about multifaceted behaviors depending on the age of the adolescent child, the gender of their child, and the amount of harm they feel is involved with dating behaviors. Contrary to our expectations, parents of older adolescents were more frequently motivated by concerns about adolescents' emotional well-being compared to younger adolescents, particularly with regard to the identity of adolescents' dating partner and expression of the dating relationship. Parents may feel that younger adolescents are not ready for the responsibility that accompanies romantic relationships 
and may believe that their younger adolescents require more guidance (Smetana, 2011). However, parents' of older adolescents' may allow more freedom as a result of older adolescents' developing autonomy and changes that occur in the parent-child relationship that facilitate a more egalitarian relationship with less parental behavioral control in late adolescence (Koepke \& Denissen, 2012). Therefore, parents of older adolescents may be motivated to gain knowledge about dating behaviors to promote their older adolescents' emotional well-being because they trust their older adolescents to make good decisions regarding romantic relationships.

Parents' knowledge-seeking motivations were influenced by the gender of their adolescent in ways that were generally consistent with a priori hypotheses. Across all dating behaviors, parents with adolescent daughters focused more heavily on physical safety compared to parents with adolescent sons. In contrast, parents of adolescent sons reported a wider range of motivations for different types of dating behaviors. For example, when seeking information entailing supervision of dating behaviors, parents with sons reported that they were motivated to keep their sons out of trouble and to protect their sons' physical safety with equal frequency. In contrast, parents of sons reported they were motivated by a "need to know" when seeking information about the identity of the adolescent's significant other. Interestingly, compared to parents of daughters, parents of sons more frequently reported that their desire to know more about expressions of their sons' dating relationship (e.g., holding hands, kissing) was motivated by a desire to make sure their sons were being good to others. These findings suggest that adolescent gender is an important individual factor that parents use when considering their motivations for seeking knowledge about these multifaceted behaviors. Unwanted pregnancies and physical safety concerns are more prominent for girls than boys (Jaccard et al., 2002), which 
may partially explain why parents were overwhelmingly motivated to learn about their daughters' dating behaviors because they wanted to protect their daughters' physical safety. However, when seeking knowledge about adolescent sons' behaviors parents reported desiring to make sure their sons are good to others and are kept out of trouble, which means that parents of adolescent sons primarily focus on more conventional characteristics of these multifaceted behaviors, such as rules. Parents seem to believe their adolescent sons are more likely to cause harm in dating relationships, whereas adolescent daughters are more likely to be harmed. This difference in the way parents think about the dating behaviors of male and female adolescents may be why researchers have found more frequent sex-related parent-adolescent communication with female adolescents compared to male (Lefkowitz, Boone, Sigman, \& Au, 2002). These gendered views may also lead to parents' greater reluctance to permit their adolescent daughters to date (Smetana, 2011). However, the prevalence of health risks involved with dating behaviors, especially sexually transmitted diseases, is similar for male and female adolescents (Centers for Disease Control and Prevention, 2015). It may be beneficial for parenting programs that promote parent-adolescent sex-related communication to inform parents of the similarity in the prevalence of sexual risks for both genders.

Contrary to hypotheses, higher harmfulness beliefs were not linked to parents' motivations to gain information due to physical safety concerns. Harmfulness beliefs did, however, qualify parents' other knowledge-seeking motivations about their adolescents' dating behaviors. For both dating expression (e.g., holding hands) and dating supervision behaviors (e.g., alone with significant other in unsupervised areas), parents with higher harmfulness beliefs more frequently reported being motivated to seek knowledge in order to make sure the adolescent has a good reputation. The social domain perspective traditionally uses parents' 
harmfulness justifications as a way of categorizing prudential behaviors based on the potential health or physical harm that may come to an adolescent (Smetana, 2000). It appears that parents' perceptions of the "harm" involved with dating behaviors extends beyond the health-related and physical safety concerns that domain theorists have traditionally tied to prudential behaviors and includes harm to one's reputation (Smetana, 2006). Parents don't simply want knowledge about dating to protect physical safety, rather they also want to ensure the adolescent's romantic endeavors do not harm the way others view the adolescent. A broader definition of harm may be required to fully understand parents' conceptualizations of the potential harm involved with adolescents' behaviors, as physical harm seems to be just one type of harm that parents consider when asked how harmful they believe a behavior is.

Furthermore, the current study explored whether differential parental knowledge-seeking motivations would be linked to parents' information gathering strategies. Parents' utilize multiple direct and indirect strategies for gaining knowledge about their adolescents' behaviors (Crouter et al., 2005; Kerr \& Stattin, 2000). However, findings are inconsistent with regard to the effectiveness of various parental information gathering strategies (Fletcher et al., 2004; Keijsers et al., 2010; Metzger et al., 2013). Results revealed that parents' motivations do indeed relate to different information seeking strategies, and that these associations between knowledge-seeking motivations vary for different types of adolescent activities and behaviors. Interestingly, parents' motivation to gain knowledge about their adolescents out of concern for their adolescents' safety was only associated with increased solicitation and indirect monitoring with regard to behaviors that express adolescents' dating relationship (e.g., holding hands). This may be because parents' rated physical safety so frequently as a primary knowledge-seeking motivation across behaviors that there was limited variability available to detect associations with parenting behaviors. 
However, although physical safety was the most salient concern for parents when asked why they would want to know about multifaceted and prudential behaviors, parents' actual monitoring behaviors were more strongly associated with other motivations, such as the desire to maintain a relationship, promote their adolescents' emotional well-being, and even promote future success. In fact, parents motivated to learn about their adolescents' behaviors in order to promote emotional well-being engaged in more solicitation and indirect strategies and less covert monitoring for multiple behavior categories, including peer relationships and school behaviors. Similarly, parents motivated by a desire to maintain a relationship with their adolescent also engaged in more solicitation and indirect strategies and reported fewer family rules. Thus, some parents were motivated to maintain a good relationship and were concerned about the adolescent's emotional well-being, and these parents engaged in fewer information gathering strategies that could damage their relationship with their adolescent child. Additionally, these parents exhibited more trust in their adolescent children by providing more behavioral autonomy. Even with highly prudential behaviors such as substance use, some parents had other motivations, besides physical safety, that were linked to their parenting strategies. For example, parents motivated to gain knowledge about substance use behaviors because they wanted to maintain a good relationship with their adolescent children had fewer rules about substance use. Taken together, the parents who are motivated by relational concerns may be the type of parents who promote positive developmental outcomes, through more open communication, trust in adolescents and clear familial expectations (Metzger et al., 2013). A great deal of research supports the importance of authoritative parenting, which includes high levels of warmth and autonomy support, and moderate levels of control, as a parenting characteristic conducive of positive youth development (Morris et al., 2013). The present findings appear to have revealed 
cognitive processes that may be influencing more authoritative parenting behaviors, as the parents who are promoting a supportive family climate may actually be doing so due to more supportive knowledge-seeking motivations. Additional analyses performed in this study, provided even more support for this idea in that increased parental warmth was associated with a greater likelihood that parents' would desire knowledge about multifaceted behaviors in order to promote youths' emotional well-being and a decrease in focus on conventional, or rule related, concerns. Whereas, increased parental control was linked to fewer relational knowledge-seeking motivations and more conventional concerns.

Notable gender differences emerged in the links between parents' motivations and parenting behaviors, primarily with regard to conventional activities. With regard to conventional behaviors, parents' motives were more strongly linked to increased parenting behaviors for parents of male adolescents but not female. Since the conventional behavior category is comprised of behaviors that are socially regulated (Smetana, 2006), the gender difference that emerged may stem from male adolescents' higher likelihood of engaging in problematic social behaviors (Bongers et al., 2004). The present findings suggest that parents think male adolescents are more likely than female adolescents to get into trouble. Consequently, parents engage in more active parental information gathering strategies with their adolescent sons because they want to keep their sons out of trouble.

\section{Adolescents' Perceptions of Parental Motivation for Knowledge}

Previous research endorses the importance of adolescent disclosure in facilitating parental knowledge as well as positive developmental outcomes (Kerr et al., 2010; Marshall et al., 2005, Smetana, 2008). Moreover, recent studies encourage investigations of adolescents' perceptions of their parents' behaviors and how these perceptions influence youths' behavioral 
choices (Hawk et al., 2008, Tilton-Weaver et al., 2010). In addition to investigating variations in parents' motivations for gaining knowledge, this study examined adolescents' perceptions of why their parents want to know about different behaviors. Results revealed that similar to variations in parent-reported knowledge-seeking motivations, adolescents' perceptions of their parents' motivations also varied across different types of adolescent behaviors and activities. Overall, adolescents felt their parents were primarily motivated by a desire to keep the adolescent out of trouble when seeking information about conventional behaviors, dating expression, dating supervision concerns, peers, and substance use. This is contrary to the expectation that adolescents would report their parents would be motivated to obtain knowledge in order to protect their physical safety and also deviates from parents' reports of their primary knowledgeseeking motivation, which was to protect physical safety. According to the social domain perspective, focusing on the rules governing adolescent behaviors is a form of conventional reasoning, whereas physical safety comprises prudential reasoning (Smetana, 2006). Although parents seem to concentrate on the prudential nature of adolescents' behaviors, youth think their parents are focused on the conventional characteristics. In general, this suggests that there may be a fundamental difference in parent and adolescent perceptions of parental knowledge-seeking motivations, which leads adolescents to interpret their parents' behaviors very differently than parents intend. This divergence in parent and adolescent conceptions of parents' knowledgeseeking motivations may partially explain why some parenting research has failed to show positive effects of parental monitoring behaviors on adolescent behavioral outcomes. When adolescents interpret parents' behaviors as being done so to keep them out of trouble but they do not feel they are engaging in behaviors that would get them in trouble, they may feel that parents are being intrusive or over controlling. As previous research shows, youths' perceptions of 
parents as over controlling are linked to more problematic information management strategies and increased risk-taking behaviors (Kakihara et al., 2010; Metzger et al., 2013). Based on Hawk and colleagues' (2008; 2012) work regarding adolescents' perceptions of privacy invasion, we expected some youth to feel that their parents would desire knowledge because they were just being nosey, especially when responding about peer relationships. However, adolescents reported that their parents would want to know because they were nosey at very low levels compared to more altruistic knowledge-seeking motives such as maintaining a good relationship or keeping the adolescent out of trouble. This suggests that even if adolescents disagree with their parents exerting control over multifaceted behaviors, they may recognize that parents are engaging in knowledge-seeking behaviors with good intentions.

Gender differences also emerged in youths' perceptions of their parents' motivations for knowledge. Male and female adolescents' views particularly diverged concerning parents' motivations for gaining knowledge about dating-related behaviors and activities. While female adolescents believed their parents wanted dating-related information due to either relationship maintenance or physical safety concerns, males believed parents wanted such knowledge to ensure the adolescent boys were good to others or to keep them out of trouble. In fact, across all behavior categories male adolescents felt more strongly that their parents were motivated to keep them out of trouble compared to female adolescents. These gender differences were relatively consistent with parents' reports of their own motivations and thus may reflect differences in shared understanding concerning the ways families view dating behaviors for male and female adolescents. The physical consequences of having sex are more apparent for female adolescents than male adolescents, which was evident in both parent and adolescent reports of parents' safety concerns regarding dating behaviors. Previous research suggests that when parents discuss sex 
with their adolescent daughters they tend to focus on the negative consequences (Jaccard et al., 2002). Consistent family communication about unwanted pregnancies and other health risks that accompany sexual involvement may facilitate adolescent girls' recognition of their parents' safety concerns, as parents communicate about sexual risks more frequently with their daughters than their sons (Lefkowitz et al., 2002). In the present findings, female adolescents also believed that parents' desired knowledge about their dating behaviors because their parents wanted to have a good relationship with them. However, this belief did not appear in parents' reports; instead, parents focused almost entirely on the physical safety of their adolescent daughters when considering the reasons they want to know about dating behaviors. Throughout adolescence, female adolescents continue to seek an interdependent relationship with their parents, report more supportive relations with parents, and engage in more dating-related disclosure compared to male adolescents (Daddis \& Randolph, 2010; De Goede et al., 2009; Keijsers \& Poulin, 2013). Female adolescents' perceptions that parents desire dating related knowledge because they want to maintain a good relationship, may explicate existing links between female adolescents' trust in their parents and higher levels of dating-related disclosure (Daddis \& Randolph, 2010). If youth trust their parents and feel their parents are seeking knowledge because they want to have a good relationship, they would likely share more information with parents.

Similar to parent-report models, adolescents' perceptions of parental motivations were related to adolescents' information management strategies. Interestingly, just as parents' physical safety motivations lacked associations with parenting behaviors, adolescents' perceptions of parents' physical safety motives were not associated with information management strategies. In addition, youth frequently reported their parents' would want knowledge in order to keep the adolescent out of trouble, but the links to youths' information management were negligible for 
this knowledge-seeking motivation. Youth may overwhelming recognize these fundamental parental knowledge-seeking motivations, leading to restricted variance for these motivations, and such reduced variability may limit our ability to test associations between adolescents' reports of parental motivations to protect physical safety or keep the adolescent out of trouble and youths' information management strategies.

However, adolescents' beliefs concerning other parental knowledge-seeking motivations were associated with adolescents' information management strategies. Adolescents' beliefs that parents seek knowledge out of concerns for adolescents' emotional well-being were related to increased disclosure, less secrecy, and less concealment. Similarly, youths' beliefs that parents would want knowledge because parents wanted to maintain a good relationship were linked with increased disclosure, less secrecy and less concealment. In contrast, when youth felt their parents wanted knowledge because parents were being "nosey", adolescents reported greater levels of active concealment. This link was prominent for dating and peer related behaviors, which is consistent with previous findings regarding youths' perceptions of these behaviors as personal and outside of parental authority to control (Darling et al., 2006; Smetana, Metzger et al., 2006). Multiple associations between youths' reports of parental knowledge-seeking motivations and youths' information management were qualified by adolescent gender. Contrary to parent-report models, which showed stronger associations between parental motivations and informationseeking behaviors for parents of male adolescents, adolescent-reported parental knowledgeseeking motivations were more strongly linked to female adolescents' information management. Most notably, perceptions of parents' relationship maintenance motivations regarding behaviors that express the dating relationship were only linked to less concealment for female adolescents. Additionally, youths' perceptions of parents desiring knowledge about the identity of their 
romantic partner because parents were being nosey were only linked to increased concealment for female adolescents.

Taken together, these findings indicate that when adolescents' recognize their parents are seeking knowledge for more supportive reasons, youth engaged in more positive information management strategies whereas when they felt parents were being nosey they engaged in more secretive information management. Dating and peer relationships are two multifaceted behavior categories that adolescents may feel more strongly about keeping private, which may be why their perceptions of parents' knowledge-seeking motives as being nosey were linked to more problematic communication processes for these behaviors. This was especially true for female adolescents, who seemed to be more attuned to parents' relationship focused knowledge-seeking motivations. Male adolescents, on the other hand, overwhelmingly reported their parents were motivated to gain knowledge because parents wanted to keep their adolescents out of trouble, leading to little variability in other motivations, which may explain why fewer associations between adolescent-reported motivations and information management emerged for male adolescents. However, these findings may also help to clarify variability in the information management behaviors of males and females. In general, male adolescents tend to disclose less than female adolescents (Keijsers \& Poulin, 2013). According to the present findings, this may be because male and female adolescents have different perceptions of the motivations behind their parents' knowledge-seeking behaviors. Male adolescents felt their parents were just trying to keep them out of trouble and did not recognize other parental concerns, such as emotional well-being. Whereas, female adolescents recognized parents' desire to have a good relationship with them and to make sure they were happy, which was linked to more disclosure. Female adolescents are socialized to be more interdependent which may be why they are more attentive 
of other parental motivations beyond physical safety or keeping the adolescent out of trouble (Smetana, 2011). It may be important for parents to explicitly communicate with their adolescent sons about their knowledge-seeking motivations, as this may help male adolescents recognize parents' desire to maintain a good relationship and their concerns regarding youths' emotional well-being, while also facilitating adolescent disclosure.

\section{Limitations and Future Directions}

The present study's findings should be interpreted in light of its limitations. The crosssectional, correlational design of this study prevents discussions of directional family processes. Analyses examining associations between knowledge-seeking motivations and information gathering/management strategies identified motivations as predictors of the strategies parents and adolescents use to manage parental knowledge, but it is also possible that parents' and adolescents' communicative strategies influence parents' motivations and adolescents' perceptions of their parents' motivations. Adolescents' information management strategies and their assessment of parents' attempts to gain information may be highly influenced by whether or not adolescents are actually engaged in different types of activities. Future research should examine parental motivations as well as adolescents' perceptions of knowledge-seeking motivations in longitudinal designs as well as consider the influence adolescents' behaviors have on knowledge-seeking motives. The present study also did not consider the influence parenting behaviors may have on adolescents' perceptions of their parents' motivations. Overly restrictive parenting may facilitate youths perceiving parents as wanting knowledge because they are being nosey and in turn relate to more secretive information management (Hawk et al., 2012; Metzger et al., 2013). Future research should consider direct links between parenting behaviors and youths' perceptions of the motives behind those behaviors. 
This study recruited families through students in high school classrooms, which may have subjected the data to selection bias. Students were tasked with recruiting one parent to participate with them, which may be one reason the present sample was comprised almost entirely of adolescents who received mostly B's or higher in school grades (85\%) and engaged in very few problem behaviors. Only $36 \%(N=69)$ of adolescents in the analytic sample reported using substances. The fact that the current sample reported lower levels of problem behaviors and delinquency may also explain the extremely low reliability of the delinquency $(\alpha=.45)$ and substance use $(\alpha=.62)$ measures, which could have been driven by reduced variability in these measures. Future research should seek to recruit adolescents who engage in higher levels of problem behaviors in order to assess the extent to which parents' motivations vary when their adolescents are involved with problematic behaviors.

Recruitment within the high school classrooms also limited our sample to including mostly adolescents ages 14 to 19 , and this restricted range may have reduced the ability of the present study to detect age differences. Future research should seek to recruit younger adolescents in order to investigate variability in parental motivations associated with developmental changes that occur during adolescence. One such developmental change that may influence parental motivations for gaining knowledge is parents' and adolescents' beliefs about parental authority. Additionally, a majority of the present sample consisted of mother-adolescent dyads (84\%), $51 \%$ of which were mother-daughter dyads. This limits our ability to generalize present findings to fathers. Mothers' and fathers' motivations for knowledge may differ, especially when considering behaviors in the dating and peer relationship categories, as previous research shows mothers tend to know more about their adolescents activities and youth tend to disclose more to mothers than fathers (Smetana, Metzger et al., 2006; Waizenhofer et al., 2004). 
Preliminary analyses explored differences in mothers' and fathers' knowledge-seeking motivations and revealed that mothers more frequently report being motivated to learn about dating supervision behaviors in order to protect the adolescent's reputation, $t(64.39)=-3.26, p<$ .01. Future researchers should investigate the role of parent gender in the variability of parental motivations for knowledge as well as adolescents' perceptions of their parents' motivations. Future research should also consider recruiting more mother-son, father-daughter, and father-son dyads.

Other family characteristics not included in this study may explain variability in parental knowledge-seeking motivations, especially variability within behavior categories. Additional correlations were performed to explore associations between parent and adolescents' reports of parental knowledge-seeking motivations and parental warmth and control. These correlations promote the importance of including additional family context variables in future research, especially with adolescent-report of parents' knowledge-seeking motivations. Parental authority beliefs and parental attitudes about the effectiveness of parenting behaviors may also influence initial knowledge-seeking motivations as well as links between motives and parenting behaviors. The uncertainty management theory from communication studies suggests that information gathering behaviors are just one category of strategies people use to manage information when they are uncertain of their own knowledge, however, there are times when people are uncertain of their knowledge but do not want to know more (Brashers, 2001). Consequently, people also engage in various avoidance techniques in order to decrease uncertainty by remaining unknowledgeable (Brashers, 2001). With regard to parent-adolescent relationships, there may be some behaviors that certain parents are motivated to avoid gaining knowledge about. The present study did not include a response option for parents to report that they "do not want to know" 
about these behaviors. Future research may benefit from adding this response option to the knowledge-seeking motivation scale, as parents who do not want knowledge may engage in very different parental monitoring strategies, if any at all, compared to parents who are motivated to gain knowledge. Some adolescents may also think that their parents don't want to know about certain behaviors, which may be linked to different adolescent information management strategies. Additionally, adolescents' parental authority beliefs and trust in their parents may be influential factors that future research should consider (Borawski et al., 2003; Daddis \& Randolph, 2010; Smetana, Metzger et al., 2006). Finally, the current study was limited to investigations of whether different parental motivations for gaining knowledge exist and initial explorations of links between parental motivations and information gathering/management strategies. Future research should examine the larger role parental motivations may play in shaping the family processes involved in facilitating positive youth development by assessing links between knowledge-seeking motivations, parenting strategies, and developmental outcomes.

In conclusion, this study was the first to consider the extent to which parents have other motivations for desiring knowledge about adolescents' activities beyond protecting their children from physical harm. Although physical safety and keeping the adolescent out of trouble were primary motivations behind parent and adolescent-reported knowledge-seeking motivations, they had less of an influence on both parental information gathering and adolescent information management strategies compared to motivations promoting emotional well-being and relationship maintenance. Findings support the importance of moving beyond the assumption that parents engage in information gathering strategies primarily because they want to protect their children from harm and urge researchers to consider other parental knowledge-seeking 
motivations, such as emotional well-being and future success. Present findings also indicated that parents and adolescents have divergent views regarding parents' core motivations for seeking knowledge, as parents focused on the prudential aspects of keeping youth safe from harm while adolescents focused on parents' desiring knowledge to keep adolescents out of trouble, which involves more conventional reasoning. Gender differences emerged throughout all models indicating important differences in parents' and adolescents' perceptions of parental knowledgeseeking motivations based on the gender of the adolescent. Findings urge researchers to consider the influence different knowledge-seeking motivations have on family communication processes as well as how parental knowledge-seeking motivations vary for different types of families. 


\section{References}

Afifi, W. A., \& Weiner, J. L. (2004). Toward a theory of motivated information management. Communication Theory, 14, 167-190. doi: 10.1111/j.1468-2885.2004.tb00310.x

Anderson, R., \& Branstetter, S. (2012). Adolescents, parents, and monitoring: A review of constructs with attention to process and theory. Journal of Family Theory \& Review, 4, 119. doi: 10.1111/j.1756-2589.2011.00112.x

Babskie, E., \& Metzger, A. (2015). Associations among adolescents' cyber-specific beliefs and information management strategies. Unpublished manuscript.

Barber, B. K., Stolz, H. E., \& Olsen, J. A. (2005). Parental support, psychological control, and behavioral control: Assessing relevance, across time, culture, and method. Monographs of the Society for Research in Child Development, 70, 1-137.

Borawski, E. A., Ievers-Landis, C. E., Lovegreen, L. D., \& Trapl, E. S. (2003). Parental monitoring, negotiated unsupervised time, and parental trust: The role of parenting practices in adolescent health risk behaviors. Journal of Adolescent Health, 33, 60-70. doi:10.1016/S1054-139X(03)00100-9

Bongers, I. L., Koot, H. M., van der Ende, J., \& Verhulst, F. C. (2004). Developmental trajectories of externalizing behaviors in childhood and adolescence. Child Development, 75(5), 1523-1537. doi: 10.1111/j.1467-8624.2004.00755.x

Branstetter, S. A., \& Furman, W. (2013). Buffering effect of parental monitoring knowledge and parent-adolescent relationships on consequences of adolescent substance use. Journal of Child and Family Studies, 22(2), 192-198. doi:10.1007/s10826-012-9568-2

Brashers, D. E. (2001). Communication and uncertainty management. Journal of Communication, 51(3), 477-497. doi:10.1111/j.1460-2466.2001.tb02892.x 
Buhrmester, D. \& Furman, W. (2008). The Network of Relationships Inventory: Relationship Qualities Version. Unpublished measure, University of Texas at Dallas.

Byrne, B. M. (2004). Testing for multigroup invariance using AMOS graphics: A road less traveled. Structural Equation Modeling: A Multidisciplinary Journal, 11(2), 272-300. doi: 10.1207/s15328007sem1102_8

Collins, A. W., \& Steinberg, L. (2006). Adolescent development in interpersonal context. In W. Damon (Series ed.) \& N. Eisenberg, (Vol. Ed.), Handbook of child psychology. Vol. 3 Social, emotional, and personality development (6 ${ }^{\text {th }}$ ed., pp. 1003-1067). New York: Wiley.

Cottrell, S. A., Branstetter, S., Cottrell, L., Harris, C. V., Rishel, C., \& Stanton, B. F. (2007). Development and validation of a parental monitoring instrument: Measuring how parents monitor adolescents' activities and risk behaviors. The Family Journal, 15(4), 328-335. doi:10.1177/1066480707303748

Centers for Disease Control and Prevention (2015). Sexually Transmitted Disease Surveillance 2014. Atlanta: U.S. Department of Health and Human Services. Retrieved from: http://www.cdc.gov/std/stats

Crouter, A. C., Bumpus, M. F., Davis, K. D., \& McHale, S. M. (2005). How do parents learn about adolescents' experiences? Implications for parental knowledge and adolescent risky behavior. Child Development, 76, $869-882$.

Crouter, A. C., \& Head, M. R. (2002). Parental monitoring and knowledge of children. In M. H. Bornstein (Ed.), Handbook of Parenting: Vol. 3: Being and Becoming a Parent (2nd ed., pp. 461-483). Mahwah, NJ: Erlbaum. 
Crouter, A. C., Manke, B. A., \& McHale, S. M. (1995). The family context of gender intensification in early adolescence. Child Development, 66, 317-329. doi: $10.2307 / 1131580$

Cumsille, P., Darling, N., \& Martinez, M. L. (2010). Shading the truth: Adolescents' decisions to avoid issues, disclose, or lie to parents. Journal of Adolescence, 33, 285-296. doi: 10.1016/j.adolescence.2009.10.008

Daddis, C., \& Randolph, D. (2010). Dating and disclosure: Adolescent management of information regarding romantic involvement. Journal of Adolescence, 33(2), 309-320. doi:10.1016/j.adolescence.2009.05.002

Daddis, C., \& Smetana, J. (2005). Middle-class African American families' expectations for adolescents’ behavioral autonomy. International Journal of Behavioral Development, 29, 371-381. doi: 10.1080/01650250500167053

Darling, N., Cumsille, P., Caldwell, L. L., \& Dowdy, B. (2006). Predictors of adolescents' disclosure to parents and perceived parental knowledge: Between- and within- person differences. Journal of Youth and Adolescence, 35, 667-678. doi: 10.1007/s10964-0069058-1

De Goede, I. H. A., Branje, S. J. T., \& Meeus, W. H. J. (2009). Developmental changes in adolescents' perceptions of relationships with their parents. Journal of Youth and Adolescence, 38, 75-88. doi: 10.1007/s10964-008-9286-7

Dishion, T. J., \& McMahon, R. J. (1998). Parental monitoring and the prevention of child and adolescent problem behavior: A conceptual and empirical formulation. Clinical Child and Family Psychology Review, 1(1), 61-75. doi: 10.1023/A:1021800432380 
Eisenberg, N., Cumberland, A., \& Spinrad, T. L. (1998). Parental socialization of emotion. Psychological Inquiry, 9, 241-273. doi: 10.1207/s15327965pli0904_1

Ferris, K. A., Oosterhoff, B., \& Metzger, A. (2013). Organized activity involvement among rural youth: Gender differences in associations between activity type and developmental outcomes. Journal of Research in Rural Education, 28(15), 1-16.

Fletcher, A. C, Darling, N., \& Steinberg, L. (1995). Parental monitoring and peer influences on adolescent substance use. In J. McCord (Ed.) Coercion and punishment in long-term perspectives (pp. 259-271). New York: Cambridge University Press.

Fletcher, A. C., Steinberg, L., \& Williams-Wheeler, M. (2004). Parental influences on adolescent problem behavior: Revisiting Stattin and Kerr. Child Development, 75(3), 781-796. doi:10.1111/j.1467-8624.2004.00706.x

Frijns, T., Keijsers, L., Branje, S., \& Meeus, W. (2010). What parents don't know and how it may affect their children: Qualifying the disclosure-adjustment link. Journal of Adolescence, 33, 261-270. doi:10.1016/j.adolescence.2009.05.010

Grusec, J. E. (2011). Socialization processes in the family: Social and emotional development. Annual Review of Psychology, 62, 243-269. doi: 10.1146/annurev.psych.121208.131650

Hawk, S. T., Hale III, W. W., Raaijmakers, Q. A. W., \& Meeus, W. (2008). Adolescents' perceptions of privacy invasion in reaction to parental solicitation and control. The Journal of Early Adolescence, 28, 583-608. doi: 10.1177/0272431608317611

Hawk, S. T., Keijsers, L., Frijns, T., Hale, W., Branje, S., \& Meeus, W. (2012). "I Still Haven't Found What I'm Looking For": Parental Privacy Invasion Predicts Reduced Parental Knowledge. Developmental Psychology. doi: 10.1037/a0029484 
Jaccard, J., Dodge, T., \& Dittus, P. (2002). Parent-adolescent communication about sex and birth control: A conceptual framework. New Directions for Child \& Adolescent Development, 2002, 9-42.

Keijsers, L., Branje, S. J. T., Frijns, T., Finkenauer, C., \& Meeus, W. (2010). Gender differences in keeping secrets from parents in adolescence. Developmental Psychology, 46(1), 293298. doi: $10.1037 / \mathrm{a} 0018115$

Kakihara, F., Tilton-Weaver, L., Kerr, M., Stattin, H. (2010). The relationship of parental control to youth adjustment: Do youths' feelings about their parents play a role? Journal of Youth and Adolescence, 39, 1442-1456. doi: 10.1007/s10964-009-9479-8

Keijsers, L., Branje, S. T., VanderValk, I. E., \& Meeus, W. (2010). Reciprocal effects between parental solicitation, parental control, adolescent disclosure, and adolescent delinquency. Journal of Research on Adolescence, 20, 88-113. doi:10.1111/j.1532-7795.2009.00631.x

Keijsers, L., Frijns, T., Branje, S. J. T., \& Meeus, W. (2009). Developmental links of adolescent disclosure, parental solicitation, and control with delinquency: Moderation by parental support. Developmental Psychology, 45, 1314-1327. doi: 10.1037/a0016693

Keijsers, L., \& Poulin, F. (2013). Developmental changes in parent-child communication throughout adolescence. Developmental Psychology, 49(12), 2301-2308. doi:10.1037/a0032217

Kerr, M., \& Stattin, H. (2000). What parents know, how they know it, and several forms of adolescent adjustment: Further support for a reinterpretation of monitoring. Developmental Psychology, 36, 366-380. doi: 10.1037//0012-1649.36.3.366 
Kerr, M., Stattin, H., \& Burk, W. J. (2010). A reinterpretation of parental monitoring in longitudinal perspective. Journal of Research on Adolescence, 20(1), 39-64. doi: 10.1111/j.1532-7795.2009.00623.x

Kerr, M., Stattin, H., \& Özdemir, M. (2012). Perceived parenting style and adolescent adjustment: Revisiting directions of effects and the role of parental knowledge. Developmental Psychology, 48(6), 1540-1553. doi: 10.1037/a0027720

Kiesner, J., Poulin, F., \& Dishion, T. J. (2010). Adolescent substance use with friends: Moderating and mediating effects of parental monitoring and peer activity contexts. Merrill-Palmer Quarterly, 56(4), 529-556. doi: 10.1353/mpq.2010.0002

Kline, R. B. (2011). Principles and practice of structural equation modeling (3rd ed.). New York, NY: Guilford Press.

Koepke, S., \& Denissen, J. J. A. (2012). Dynamics of identity development and separationindividuation in parent-child relationships during adolescence and emerging adulthood-a conceptual integration. Developmental Review, 32, 67-88. doi: 10.1016/j.dr.2012.01.001

Laird, R. D., Marrero, M. D., Melching, J. A., \& Kuhn, E. S. (2013). Information management strategies in early adolescence: Developmental change in use and transactional associations with psychological adjustment. Developmental Psychology, 49(5), 928-937. doi: $10.1037 / \mathrm{a} 0028845$

Laird, R. D., Marrero, M. D., \& Sentse, M. (2010). Revisiting parental monitoring: Evidence that parental solicitation can be effective when needed most. Journal of Youth and Adolescence, 39(12), 1431-1441. doi: 10.1007/s10964-009-9453-5 
Ledbetter, A. M., \& Vik, T. A. (2012). Parental invasive behaviors and emerging adults' privacy defenses: Instrument development and validation. Journal of Family Communication, 12(3), 227-247. doi:10.1080/15267431.2012.686943

Lefkowitz, E. S., Boone, T. L., Sigman, M., \& Kit-fong Au, T. (2002). He said, she said: Gender differences in mother-adolescent conversations about sexuality. Journal of Research on Adolescence, 12(2), 217-242. doi:10.1111/1532-7795.00032

Little, T.D. (2013). Longitudinal Structural Equation Modeling. The Guilford Press: New York.

Marshall, S. K., Tilton-Weaver, L. C., \& Bosdet, L. (2005). Information management: Considering adolescents' regulation of parental knowledge. Journal of Adolescence, 28, 633-647. doi: 10.1016/j.adolescence.2005.08.008

Masche, J. G. (2010). Explanation of normative declines in parents' knowledge about their adolescent children. Journal of Adolescence, 33, 271-284. doi: 10.1016/j.adolescence.2009.08.002

Metzger, A., Crean, H. F., \& Forbes-Jones, E. L. (2009). Patterns of organized activity participation in urban, early adolescents. Journal of Early Adolescence, 29, 426-442. doi:10.1177/0272431608322949

Metzger, A., Ice, C., \& Cottrell, L. (2012). But I trust my teen: Parents' attitudes and response to a parental monitoring intervention. AIDS Research \& Treatment, 2012, 1-10. doi: $10.1155 / 2012 / 396163$

Metzger, A., Wakschlag, L. S., Anderson, R., Darfler, A., Price, J., Flores, Z., \& Mermelstein, R. (2013). Information management strategies within conversations about cigarette smoking: Parenting correlates and longitudinal associations with teen smoking. Developmental Psychology, 49(8), 1565-1578. doi:10.1037/a0030720 
Miller, K. E., Melnick, M. J., Barnes, G. M., Sabo, D., \& Farrell, M. P. (2007). Athletic involvement and adolescent delinquency. Journal of Youth and Adolescence, 36(5), 711723. doi:10.1007/s10964-006-9123-9

Moberg, D. P., \& Hahn, L. (1991). The adolescent drug involvement scale. Journal of Child \& Adolescent Substance Abuse, 2(1), 75-88.

Morris, A. S., Cui, L., \& Steinberg, L. (2013). Parenting research and themes: What we have learned and where to go next. In R. E. Larzelere, A. Morris, A. W. Harrist (Eds.), Authoritative parenting: Synthesizing Nurturance and Discipline for Optimal Child Development (pp. 35-58). Washington, DC: American Psychological Association. doi:10.1037/13948-003

Nucci, L. P. (2001). Education in the Moral Domain. Cambridge: Cambridge University Press.

Nucci, L. P. (2008). Nice is not Enough: Facilitating Moral Development. New York: Pearson.

Nucci, L.P., Guerra, N., \& Lee, J. (1991). Adolescent judgments of the personal, prudential, and normative aspects of drug usage. Developmental Psychology, 27, 841-848.

Petronio, S. (2002). SUNY Series in Communication Studies: Boundaries of privacy: Dialectics of disclosure. Albany: State University of New York Press.

Petronio, S. (2010). Communication privacy management theory: What do we know about family privacy regulation? Journal of Family Theory and Review, 2, 175-196. doi:10.1111/j.1756-2589.2010.00052.x

Racz, S., \& McMahon, R. J. (2011). The relationship between parental knowledge and monitoring and child and adolescent conduct problems: A 10-year update. Clinical Child and Family Psychology Review, 14(4), 377-398. doi:10.1007/s10567-011-0099-y 
Reyna, V. F., \& Farley, F. (2006). Risk and Rationality in Adolescent Decision Making: Implications for Theory, Practice, and Public Policy. Psychological Science in the Public Interest, 7(1), 1-44. doi:10.1111/j.1529-1006.2006.00026.

Smetana, J. G. (1988). Adolescents' and parents' conceptions of parental authority. Child Development, 59, 321-335.

Smetana, J. G. (1995). Parenting styles and conceptions of parental authority during adolescence. Child Development, 66, 299-316.

Smetana, J. G. (2000). Middle-class African American adolescents' and parents' conceptions of parental authority and parenting practices: A longitudinal investigation. Child Development, 71, 1672-1686. doi: 10.1111/1467-8624.00257

Smetana, J. G. (2006). Social-cognitive domain theory: Consistencies and variations in children's moral and social judgments. In M. Killen, J. G. Smetana (Eds.), Handbook of moral development (pp. 119-153). Mahwah, NJ: Lawrence Erlbaum Associates.

Smetana, J. G. (2008). “It's 10 o'clock: Do you know where your children are?” Recent advances in understanding parental monitoring and adolescents' information management. Child Development Perspectives, 2, 19-25. doi: 10.1111/j.17508606.2008.00036.x

Smetana, J. G. (2011). Adolescent, Families, and Social Development: How Teens Construct Their Worlds. United Kingdom: Wiley-Blackwell.

Smetana, J. G., \& Asquith, P. (1994). Adolescents' and parents' conceptions of parental authority and adolescent autonomy. Child Development, 65, 1147-1162.

Smetana, J. G., Campione-Barr, N., \& Daddis, C. (2004). Longitudinal development of family decision making: Defining healthy behavioral autonomy for middle-class African 
American adolescents. Child Development, 75(5), 1418-1434. doi:10.1111/j.14678624.2004.00749.x

Smetana, J. G., Campione-Barr, N., \& Metzger, A. (2006). Adolescent development in interpersonal and societal contexts. In S. T. Fiske, A. E. Kazdin, D. L. Schacter (Eds.), Annual review of psychology (Vol 57) (pp. 255-284). Palo Alto, CA: Annual Reviews.

Smetana, J. G., \& Daddis, C. (2002). Domain-specific antecedents of parental psychological control and monitoring: The role of parenting beliefs and practices. Child Development, 73, 563-580. doi: 10.1111/1467-8624.00424

Smetana, J. G., Metzger, A., Gettman, D. C., \& Campione-Barr, N. (2006). Disclosure and secrecy in adolescent-parent relationships. Child Development, 77(1), 201-217. doi: 10.1111/j.1467-8624.2006.00865.x

Smetana, J. G., Villalobos, M., Tasopoulos-Chan, M., Gettman, D. C., \& Campione-Barr, N. (2009). Early and middle adolescents' disclosure to parents about activities in different domains. Journal of Adolescence, 32, 693-713. doi: 10.1016/j.adolescence.2008.06.010

Soenens, B., Vansteenkiste, M., Luyckx, K., \& Goossens, L. (2006). Parenting and adolescent problem behavior: an integrated model with adolescent self-disclosure and perceived parental knowledge as intervening variables. Developmental Psychology, 42, 305-318. doi: 10.1037/0012-1649.42.2.305

Stattin, H., \& Kerr, M. (2000). Parental monitoring: A reinterpretation. Child Development, 71(4), 1072-1085. doi: 10.1111/1467-8624.00210

Tilton-Weaver, L. C., Burk, W. J., Kerr, M., \& Stattin, H. (2013). Can parental monitoring and peer management reduce the selection or influence of delinquent peers? Testing the 
question using a dynamic social network approach. Developmental Psychology, 49(11), 2057-2070. doi:10.1037/a0031854

Tilton-Weaver, L., Kerr, M., Pakalniskeine, V., Tokic, A., Salihovic, S., \& Stattin, H. (2010). Open up or close down: How do parental reactions affect youth information management? Journal of Adolescence, 33, 333-346.

doi:10.1016/j.adolescence.2009.07.011

Tasopoulos-Chan, M., Smetana, J. G., \& Yau, J. P. (2009). How much do I tell thee? Strategies for managing information to parents among American adolescents from Chinese, Mexican, and European backgrounds. Journal of Family Psychology, 23(3), 364-374. doi:10.1037/a0015816

Waizenhofer, R. N., Buchanan, C. M., \& Jackson-Newsom, J. (2004). Mothers' and fathers' knowledge of adolescents' daily activities: Its sources and its links with adolescent adjustment. Journal of Family Psychology, 18, 348-360. doi:10.1037/0893-3200.18.2.348

Wang, M., \& Eccles, J. S. (2012). Social support matters: Longitudinal effects of social support on three dimensions of school engagement from middle to high school. Child Development, 83(3), 877-895. doi:10.1111/j.1467-8624.2012.01745.x

Wang, M. T., Dishion, T. J., Stormshack, E. A., \& Willett, J. B. (2011). Trajectories of family management practices and early adolescent behavioral outcomes. Developmental Psychology, 47 (5), 1324-1341. doi: 10.1037/a0024026

Wang, B., Stanton, B., Li, X., Cottrell, L., Deveaux, L., \& Kaljee, L. (2013). The influence of parental monitoring and parent-adolescent communication on Bahamian adolescent risk involvement: A three-year longitudinal examination. Social Science \& Medicine, 97, 161169. doi:10.1016/j.socscimed.2013.08.013 
Weintraub, K. J., \& Gold, M. (1991). Monitoring and delinquency. Criminal Behavior and Mental Health, 1, 268-281.

Williams, J. H., Van Dorn, R. A., Ayers, C. D., Bright, C. L., Abbott, R. D., \& Hawkins, J. D. (2007). Understanding race and gender differences in delinquent acts and alcohol and marijuana use: A developmental analysis of initiation. Social Work Research, 31(2), 7181. doi:10.1093/swr/31.2.71 
Table 1

Adolescent Behavior Categories

\section{Conventional}

the type of language teen uses away from home

if teen is using bad manners away from home

if teen is talking back or being rude to teachers

\section{Substance Use}

if teen is smoking cigarettes

if teen is drinking alcohol

if teen is doing drugs

\section{Schoolwork}

if teen is not doing well on schoolwork or tests

if teen is finishing homework or assignments

how teen is doing in different school subjects

\section{Peers}

who teen's friends are

if teen is hanging out with friends parents don't like

where teen goes with his/her friends

\section{Dating - Identity of Boyfriend/Girlfriend}

who teen's boyfriend/girlfriend is

who teen's boyfriend/girlfriend's family is

the kind of person teen's boyfriend/girlfriend is

\section{Dating - Expression of Relationship}

if teen is having sex

if teen is holding hands with his/her boyfriend/girlfriend

if teen is kissing his/her boyfriend/girlfriend

\section{Dating - Supervision Concerns}

where teen is going with his/her boyfriend/girlfriend

if teen is in unsupervised areas (e.g., bedroom) with boyfriend/girlfriend

if teen is home alone with his/her boyfriend/girlfriend 
Table 2

Parental Motivations for Knowledge

\section{Parent Report}

I want my teen to be happy.

I want my teen to be physically safe.

I want to keep my teen out of trouble.

I want my teen to do well in the future.

I want to have a good relationship with my teen.

I want my teen to be good to others.

I want my teen to represent our family well.

I want my teen to have a good reputation.

\section{Adolescent Report}

My parent wants me to be happy.

My parent wants me to be physically safe.

My parent wants to keep me out of trouble.

My parent wants me to do well in the future.

My parent wants to have a good relationship with me.

My parent wants me to be good to others.

My parent wants me to represent our family well.

My parent wants me to have a good reputation.

My parent is nosey 
Table 3

Parent and Adolescent Demographic Statistics

\begin{tabular}{|c|c|c|c|c|c|c|}
\hline & \multicolumn{3}{|c|}{ Parent } & \multicolumn{3}{|c|}{ Adolescent } \\
\hline & $\mathrm{M}(\mathrm{SD})$ & Range & $\%$ & $\mathrm{M}(\mathrm{SD})$ & Range & $\%$ \\
\hline Age & $45(6.3)$ & $30-64$ & & $16(1.25)$ & $14-19$ & - \\
\hline Gender & & & $84 \%$ Female & & & $62 \%$ Female \\
\hline \multicolumn{7}{|l|}{ Relation to Adolescent } \\
\hline Birth Parent & & & $94 \%$ & & & \\
\hline Adoptive Parent & & & $4 \%$ & & & \\
\hline Stepparent & & & $1 \%$ & & & \\
\hline Other & & & $1 \%$ & & & \\
\hline \multicolumn{7}{|l|}{ Ethnicity } \\
\hline Caucasian/White & & & $91 \%$ & & & $83 \%$ \\
\hline African American/Black & & & $2 \%$ & & & $4 \%$ \\
\hline Hispanic & & & $2 \%$ & & & $3 \%$ \\
\hline Asian American/Pacific Islander & & & $5 \%$ & & & $6 \%$ \\
\hline Native American & & & $1 \%$ & & & $2 \%$ \\
\hline Biracial & & & - & & & $4 \%$ \\
\hline \multicolumn{7}{|l|}{ Adolescent Grades } \\
\hline Mostly As & & & - & & & $53 \%$ \\
\hline Some As and Bs & & & - & & & $28 \%$ \\
\hline Mostly Bs & & & - & & & $4 \%$ \\
\hline Some Bs and Cs & & & - & & & $11 \%$ \\
\hline Mostly Cs & & & - & & & $3 \%$ \\
\hline Some Cs and Ds & & & - & & & $2 \%$ \\
\hline \multicolumn{7}{|l|}{ Parent Marital Status } \\
\hline Married or civil union & & & $73 \%$ & & & \\
\hline Divorced & & & $16 \%$ & & & \\
\hline Separated & & & $4 \%$ & & & \\
\hline Widowed & & & $1 \%$ & & & \\
\hline Living with partner & & & $1 \%$ & & & \\
\hline Never Married & & & $5 \%$ & & & \\
\hline \multicolumn{7}{|l|}{ Parent Education } \\
\hline Completed High School & & & $14 \%$ & & & \\
\hline Some College & & & $19 \%$ & & & \\
\hline Completed College/Technical & & & & & & \\
\hline School & & & $52 \%$ & & & \\
\hline Graduate Degree & & & $15 \%$ & & & \\
\hline \multicolumn{7}{|l|}{ Family Income } \\
\hline$<25,000$ & & & $11 \%$ & & & \\
\hline$\$ 25,000-\$ 50,000$ & & & $18 \%$ & & & \\
\hline$\$ 50,000-\$ 100,000$ & & & $38 \%$ & & & \\
\hline
\end{tabular}


$>\$ 100,000$

$30 \%$

Parent Employment

$82 \%$ Employed 
Table 4

Location Differences in Study Variables by Parent and Adolescent Report

Parent Location Differences

\begin{tabular}{lcccc}
\hline & $\begin{array}{c}\text { West Virginia } \\
(n=64)\end{array}$ & $\begin{array}{c}\text { Pennsylvania } \\
(n=62)\end{array}$ & $\begin{array}{c}\text { Connecticut } \\
(n=67)\end{array}$ & F test \\
\hline $\begin{array}{l}\text { Motivations } \\
\text { School }\end{array}$ & & & & \\
$\quad$ Emotional Well-Being & $1.70(2.02)^{*}$ & $2.00(2.48)$ & $2.90(2.52)^{*}$ & $F(2,192)=4.57, p=.01$ \\
$\quad \begin{array}{l}\text { Behaviors } \\
\quad \text { Date Supervision Solicitation }\end{array}$ & $4.01(1.21)^{*}$ & $3.79(1.20)$ & $3.40(1.45)^{*}$ & $F(2,192)=3.77, p=.03$ \\
$\quad$ Covert Strategies & $1.95(.71)^{*}$ & $1.78(.69)$ & $1.65(.66)^{*}$ & $F(2,190)=3.23, p=.04$ \\
$\quad$ Peer Harmfulness Beliefs & $3.58(.83)^{*}$ & $3.49(.85)$ & $3.19(.98)^{*}$ & $F(2,188)=3.43, p=.03$ \\
\hline
\end{tabular}

Adolescent Location Differences

$\begin{array}{cccc}\begin{array}{c}\text { West Virginia } \\ (n=67)\end{array} & \begin{array}{c}\text { Pennsylvania } \\ (n=63)\end{array} & \begin{array}{c}\text { Connecticut } \\ (n=66)\end{array} & F \text { test }\end{array}$

\section{Motivations}

Dating Expression

Physical Safety

$\begin{array}{llll}2.66(2.29) * & 4.00(2.58) * & 4.48(2.60) & F(2,195)=9.58, p<.001 \\ 2.22(2.65)^{*} & 1.19(1.92)^{*} & 1.76(2.27) & F(2,195)=3.26, p=.04\end{array}$

Maintain Relationship

$F(2,195)=3.26, p=.04$

Dating Identity

Good to Others

$1.06(1.43)^{*} \quad .70(1.47)$

$.50(.90)^{*} \quad F(2,195)=3.22, p=.04$

Dating Supervision

Keep out of Trouble

$6.40(2.35)$

$6.92(1.85)^{*}$

$5.82(2.49)^{*}$

$F(2,195)=3.87, p=.02$

Peer Behaviors

Adolescent's Reputation

$2.52(2.02)^{*} \quad 2.32(2.09)$

$1.41(1.64)^{*} \quad F(2,195)=6.28, p<.01$

School

Adolescent's Reputation

$3.18(2.04)$

$3.68(2.39)^{*}$

$2.48(2.10)^{*}$

$F(2,195)=4.94, p=.01$

Substance Use

Keep out of Trouble

$6.75(2.18) * \quad 6.35(2.06)$

$5.73(2.27)^{*}$

$F(2,195)=3.71, p=.03$

Adolescent's Reputation

$2.36(2.10)^{*} \quad 2.38(2.30)$

$1.45(1.87)^{*}$

$F(2,195)=4.18, p=.02$

Future Success

$2.27(2.29)$

$1.97(1.85)^{*}$

$2.98(2.03)^{*}$

$F(2,195)=4.15, p=.02$

Physical Safety

$5.19(2.89)^{*} \quad 5.71(2.89)$

$6.58(2.72)^{*}$

$F(2,195)=4.02, p=.02$

\section{Behaviors}

Substance Use

$1.21(.46)^{*}$

$1.13(.29)$

$1.05(.12)^{*}$

$F(2,194)=3.89, p=.02$

School Disclosure

$3.80(1.13) \quad 3.63(1.12)^{*}$

$4.15(.99)^{*} \quad F(2,195)=3.91, p=.02$

Note. * Indicate significant differences at Bonferonni corrected p-values 
Table 5

Descriptive Statistics for Parent-Report Variables

\begin{tabular}{|c|c|c|c|c|c|c|c|c|c|c|c|c|c|c|c|c|c|c|c|c|c|}
\hline & \multicolumn{3}{|c|}{ Conventional } & \multicolumn{3}{|c|}{ Dating Expression } & \multicolumn{3}{|c|}{ Dating Identity } & \multicolumn{3}{|c|}{ Dating Supervision } & \multicolumn{3}{|c|}{ Peers } & \multicolumn{3}{|c|}{ School } & \multicolumn{3}{|c|}{ Substance Use } \\
\hline & M & SD & Range & M & $\mathrm{SD}$ & Range & M & $\mathrm{SD}$ & Range & M & $\mathrm{SD}$ & Range & M & SD & Range & M & $\mathrm{SD}$ & Range & M & SD & Range \\
\hline $\begin{array}{l}\text { Physical } \\
\text { Safety }\end{array}$ & .21 & .96 & $0-9$ & 4.85 & 2.89 & $0-9$ & 5.98 & 3.11 & $0-9$ & 6.83 & 2.72 & $0-9$ & 6.62 & 2.61 & $0-9$ & .13 & .84 & $0-9$ & 7.30 & 2.49 & $0-9$ \\
\hline $\begin{array}{l}\text { Keep out of } \\
\text { Trouble }\end{array}$ & 2.90 & 2.55 & $0-9$ & 2.77 & 2.49 & $0-9$ & 3.04 & 2.56 & $0-9$ & 4.95 & 2.57 & $0-9$ & 4.07 & 2.47 & $0-9$ & 2.07 & 2.51 & $0-9$ & 4.34 & 2.53 & $0-9$ \\
\hline $\begin{array}{l}\text { Future } \\
\text { Success }\end{array}$ & 2.52 & 2.26 & $0-9$ & 1.38 & 1.81 & $0-9$ & 1.22 & 1.83 & $0-9$ & 1.23 & 1.84 & $0-7$ & 1.66 & 1.96 & $0-9$ & 8.03 & 1.84 & $0-9$ & 2.47 & 2.30 & $0-9$ \\
\hline $\begin{array}{l}\text { Emotional } \\
\text { Well-Being }\end{array}$ & .49 & 1.30 & $0-9$ & 2.40 & 2.28 & $0-9$ & 2.75 & 2.45 & $0-9$ & .61 & 1.31 & $0-9$ & 1.73 & 2.16 & $0-9$ & 2.21 & 2.40 & $0-9$ & .57 & 1.54 & $0-9$ \\
\hline $\begin{array}{l}\text { Maintain } \\
\text { Relationship }\end{array}$ & 1.03 & 2.07 & $0-9$ & 2.75 & 2.81 & $0-9$ & 2.17 & 2.42 & $0-9$ & 1.38 & 2.12 & $0-9$ & 1.74 & 2.24 & $0-9$ & 2.17 & 2.46 & $0-9$ & 1.49 & 2.27 & $0-9$ \\
\hline $\begin{array}{l}\text { Good } \\
\text { Person }\end{array}$ & 6.26 & 2.94 & $0-9$ & .85 & 1.67 & $0-9$ & .46 & 1.07 & $0-7$ & .26 & .88 & $0-6$ & .75 & 1.30 & $0-6$ & .24 & .98 & $0-8$ & .04 & .26 & $0-3$ \\
\hline $\begin{array}{l}\text { Teen's } \\
\text { Reputation }\end{array}$ & 2.57 & 2.30 & $0-9$ & 1.56 & 1.89 & $0-7$ & .94 & 1.52 & $0-6$ & 1.22 & 1.74 & $0-7$ & .87 & 1.57 & $0-8$ & 1.20 & 1.89 & $0-7$ & .63 & 1.27 & $0-8$ \\
\hline $\begin{array}{l}\text { Family's } \\
\text { Reputation }\end{array}$ & 1.41 & 1.92 & $0-7$ & .38 & 1.13 & $0-8$ & .37 & .85 & $0-5$ & .26 & .78 & $0-4$ & .23 & .70 & $0-5$ & .72 & 1.48 & $0-6$ & .20 & .79 & $0-8$ \\
\hline $\begin{array}{l}\text { Need to } \\
\text { Know }\end{array}$ & .88 & 2.01 & $0-9$ & 1.30 & 2.35 & $0-9$ & 1.31 & 2.33 & $0-9$ & 1.52 & 2.44 & $0-9$ & .60 & 1.51 & $0-9$ & 1.48 & 2.40 & $0-9$ & 1.25 & 2.29 & $0-9$ \\
\hline Knowledge & 4.26 & .78 & $1.33-5$ & 4.32 & .95 & $1-5$ & 4.35 & .98 & $1-5$ & 4.62 & .72 & $1.33-5$ & 4.46 & .62 & $2-5$ & 4.58 & .54 & $3-5$ & 4.72 & .58 & $1-5$ \\
\hline $\begin{array}{l}\text { Harmfulness } \\
\text { Beliefs }\end{array}$ & 3.85 & .89 & $1-5$ & 2.73 & .80 & $1-5$ & 2.93 & .98 & $1-5$ & 3.62 & 1.04 & $1-5$ & 3.42 & .90 & $1-5$ & 4.01 & .84 & $1-5$ & 4.77 & .55 & $1-5$ \\
\hline Rules & 4.64 & .52 & $2.33-5$ & 3.72 & 1.05 & $1-5$ & 3.67 & 1.15 & $1-5$ & 4.50 & .85 & $1-5$ & 4.08 & .87 & $1-5$ & 4.43 & .64 & $1.67-5$ & 4.91 & .26 & $3-5$ \\
\hline Solicitation & 3.77 & .97 & $1-5$ & 3.10 & 1.22 & $1-5$ & 3.61 & 1.18 & $1-5$ & 3.73 & 1.31 & $1-5$ & 4.09 & .76 & $1.67-5$ & 4.54 & .55 & $3-5$ & 3.58 & 1.36 & $1-5$ \\
\hline Indirect & 2.32 & 1.26 & $1-5$ & 1.80 & 1.10 & $1-5$ & 2.27 & 1.22 & $1-5$ & 2.10 & 1.25 & $1-5$ & 2.49 & 1.23 & $1-5$ & 2.80 & 1.19 & $1-5$ & 1.99 & 1.25 & $1-5$ \\
\hline Covert & 1.79 & .70 & $1-4.29$ & & & & & & & & & & & & & & & & & & \\
\hline $\begin{array}{l}\text { Relationship } \\
\text { Quality }\end{array}$ & 4.31 & .66 & $2-5$ & & & & & & & & & & & & & & & & & & \\
\hline
\end{tabular}

Note. Covert strategies and relationship quality did not have behavior specific subscales. 


\section{Table 6}

Descriptive Statistics for Adolescent-Report Variables

\begin{tabular}{|c|c|c|c|c|c|c|c|c|c|c|c|c|c|c|c|c|c|c|c|c|c|}
\hline & \multicolumn{3}{|c|}{$\begin{array}{c}\text { Conventional } \\
(\mathrm{N}=178)\end{array}$} & \multicolumn{3}{|c|}{$\begin{array}{c}\text { Dating Expression } \\
(\mathrm{N}=149)\end{array}$} & \multicolumn{3}{|c|}{$\begin{array}{c}\text { Dating Identity } \\
(\mathrm{N}=149)\end{array}$} & \multicolumn{3}{|c|}{$\begin{array}{c}\text { Dating Supervision } \\
(\mathrm{N}=149)\end{array}$} & \multicolumn{3}{|c|}{$\begin{array}{c}\text { Peers } \\
(\mathrm{N}=196)\end{array}$} & \multicolumn{3}{|c|}{$\begin{array}{c}\text { School } \\
(N=196)\end{array}$} & \multicolumn{3}{|c|}{$\begin{array}{c}\text { Substance Use } \\
(\mathrm{N}=69)\end{array}$} \\
\hline & $\mathrm{M}$ & SD & Range & $\mathrm{M}$ & $\mathrm{SD}$ & Range & $\mathrm{M}$ & $\mathrm{SD}$ & Range & $\mathrm{M}$ & SD & Range & $\mathrm{M}$ & $\mathrm{SD}$ & Range & $\mathrm{M}$ & SD & Range & $\mathrm{M}$ & SD & Range \\
\hline $\begin{array}{l}\text { Physical } \\
\text { Safety }\end{array}$ & .43 & 1.27 & $0-8$ & 3.70 & 2.60 & $0-9$ & 4.69 & 3.05 & $0-9$ & 5.19 & 2.81 & $0-9$ & 4.58 & 2.59 & $0-9$ & .23 & .92 & $0-8$ & 5.83 & 2.88 & $0-9$ \\
\hline $\begin{array}{l}\text { Keep out of } \\
\text { Trouble }\end{array}$ & 4.66 & 2.65 & $0-9$ & 3.79 & 2.33 & $0-9$ & 4.34 & 2.47 & $0-9$ & 6.37 & 2.28 & $0-9$ & 6.50 & 2.29 & $0-9$ & 2.13 & 2.17 & $0-9$ & 6.28 & 2.20 & $0-9$ \\
\hline $\begin{array}{l}\text { Future } \\
\text { Success }\end{array}$ & 1.48 & 1.79 & $0-9$ & 1.09 & 1.64 & $0-9$ & 1.01 & 1.71 & $0-9$ & 1.03 & 1.80 & $0-9$ & .87 & 1.57 & $0-9$ & 7.63 & 1.97 & $0-9$ & 2.41 & 2.10 & $0-9$ \\
\hline $\begin{array}{l}\text { Emotional } \\
\text { Well-Being }\end{array}$ & .27 & 1.02 & $0-9$ & 2.33 & 2.12 & $0-9$ & 2.85 & 2.52 & $0-9$ & .78 & 1.32 & $0-8$ & 1.27 & 1.60 & $0-7$ & 1.79 & 2.22 & $0-9$ & .24 & .83 & $0-8$ \\
\hline $\begin{array}{l}\text { Maintain } \\
\text { Relationship }\end{array}$ & .31 & 1.12 & $0-9$ & 1.73 & 2.33 & $0-9$ & 1.57 & 2.21 & $0-9$ & .82 & 1.60 & $0-8$ & .88 & 1.59 & $0-9$ & 1.40 & 1.99 & $0-9$ & .38 & 1.23 & $0-9$ \\
\hline $\begin{array}{l}\text { Good to } \\
\text { Others }\end{array}$ & 4.06 & 2.66 & $0-9$ & .89 & 1.56 & $0-8$ & .76 & 1.31 & $0-6$ & .49 & 1.08 & $0-5$ & .64 & 1.14 & $0-7$ & .21 & .84 & $0-9$ & .13 & .74 & $0-9$ \\
\hline $\begin{array}{l}\text { Teen's } \\
\text { Reputation }\end{array}$ & 4.34 & 2.37 & $0-9$ & 1.94 & 2.19 & $0-9$ & 1.45 & 1.93 & $0-9$ & 1.95 & 2.04 & $0-8$ & 2.08 & 1.97 & $0-8$ & 3.11 & 2.22 & $0-8$ & 2.06 & 2.13 & $0-9$ \\
\hline $\begin{array}{l}\text { Family's } \\
\text { Reputation }\end{array}$ & 2.09 & 2.11 & $0-9$ & .44 & 1.16 & $0-9$ & .52 & 1.20 & $0-8$ & .53 & 1.09 & $0-7$ & .44 & 1.05 & $0-8$ & 1.16 & 1.79 & $0-8$ & .53 & 1.24 & $0-9$ \\
\hline $\begin{array}{l}\text { Need to } \\
\text { Know }\end{array}$ & .59 & 1.42 & $0-9$ & 2.02 & 2.61 & $0-9$ & .93 & 1.93 & $0-9$ & .98 & 1.91 & $0-9$ & .96 & 1.93 & $0-9$ & .58 & 1.52 & $0-9$ & .29 & 1.15 & $0-9$ \\
\hline Disclosure & 2.87 & 1.45 & $1-5$ & 3.52 & 1.14 & $1-5$ & 3.52 & 1.14 & $1-5$ & 3.52 & 1.14 & $1-5$ & 4.18 & .94 & $1-5$ & 3.87 & 1.08 & $1-5$ & 2.49 & 1.68 & $1-5$ \\
\hline Secrecy & .97 & 1.05 & $0-3$ & 2.21 & 2.41 & $0-9$ & 2.21 & 2.41 & $0-9$ & 2.21 & 2.41 & $0-9$ & .79 & .98 & $0-3$ & .65 & 1.02 & $0-3$ & .86 & 1.02 & $0-3$ \\
\hline Concealment & 1.54 & .63 & $1-5$ & & & & & & & & & & & & & & & & & & \\
\hline Delinquency & 1.07 & .14 & $1-1.71$ & & & & & & & & & & & & & & & & & & \\
\hline $\begin{array}{l}\text { Substance } \\
\text { Use }\end{array}$ & 1.15 & .41 & $1-4$ & & & & & & & & & & & & & & & & & & \\
\hline
\end{tabular}

Note. Adolescent concealment, delinquency and substance use did not have behavior-specific subscales. 


\section{Table 7}

Conventional Behaviors: Bivariate Correlations between Parent-Report Variables

\begin{tabular}{|c|c|c|c|c|c|c|c|c|c|c|c|c|c|c|c|c|c|}
\hline & 2 & 3 & 4 & 5 & 6 & 7 & 8 & 9 & 10 & 11 & 12 & 13 & 14 & 15 & 16 & 17 & 18 \\
\hline 1. Adolescent Age & -.09 & -.10 & -.09 & -.09 & -.02 & -.14 & -.03 & -.12 & -.08 & -.03 & -.02 & -.02 & -.06 & -.03 & -.07 & -.05 & -.06 \\
\hline 2. Adolescent Gender & - & -.14 & -.04 & -.13 & -.08 & -.06 & -.00 & -.01 & -.08 & -.07 & -.13 & -.09 & $.19 * *$ & -.03 & -.06 & $-.15^{*}$ & -.04 \\
\hline 3. Physical Safety & & - & -.03 & -.08 & $.18^{*}$ & -.01 & $-.21 * *$ & $-.16^{*}$ & -.10 & -.01 & -.03 & -.02 & -.00 & -.02 & -.13 & -.05 & -.03 \\
\hline 4. Keep out of Trouble & & & - & $-.19 * *$ & -.03 & $-.17 *$ & $-.17 *$ & -.13 & $-.24 * *$ & $-.15^{*}$ & -.02 & -.02 & -.01 & -.11 & -.07 & -.00 & -.06 \\
\hline 5. Future Success & & & & - & -.07 & -.08 & $-.18^{*}$ & -.12 & $-.22 * *$ & -.03 & -.09 & -.01 & -.03 & -.02 & -.01 & -.10 & -.02 \\
\hline 6. Emotional Well-Being & & & & & - & -.10 & -.03 & $-.18^{*}$ & -.13 & -.05 & -.04 & -.01 & -.07 & -.02 & -.05 & -.03 & -.12 \\
\hline 7. Maintain Relationship & & & & & & - & $-.25 * *$ & $-.26 * *$ & -.07 & -.10 & -.06 & -.11 & -.10 & -.04 & -.12 & -.06 & -.03 \\
\hline 8. Good to Others & & & & & & & - & $-.16^{*}$ & $-.22 * *$ & $-.31 * *$ & -.05 & -.07 & -.02 & -.02 & -.13 & -.05 & -.05 \\
\hline 9. Adolescents' Reputation & & & & & & & & - & -.03 & $-.21 * *$ & -.00 & -.05 & -.02 & -.08 & -.02 & -.01 & -.06 \\
\hline 10. Family's Reputation & & & & & & & & & - & -.12 & -.14 & -.01 & -.08 & -.11 & -.01 & -.00 & -.02 \\
\hline 11. Need to Know & & & & & & & & & & - & -.00 & -.12 & -.05 & -.07 & -.12 & $.15^{*}$ & -.07 \\
\hline 12. Knowledge & & & & & & & & & & & - & -.00 & $.36 * *$ & $.25^{* *}$ & -.12 & -.01 & -.09 \\
\hline 13. Harmfulness Beliefs & & & & & & & & & & & & - & -.03 & $.24 * *$ & -.03 & -.14 & -.09 \\
\hline 14. Relationship Quality & & & & & & & & & & & & & - & $.18^{*}$ & -.07 & -.03 & -.14 \\
\hline 15. Rules & & & & & & & & & & & & & & - & $.26^{* *}$ & $.21^{* *}$ & -.11 \\
\hline 16. Solicitation & & & & & & & & & & & & & & & - & $.51 * *$ & $.20 * *$ \\
\hline 17. Indirect & & & & & & & & & & & & & & & & - & $.42 * *$ \\
\hline 18. Covert & & & & & & & & & & & & & & & & & - \\
\hline
\end{tabular}

Note. $* p<.05, * * p<.01$ 
Table 8

Dating Expression Behaviors: Bivariate Correlations between Parent-Report Variables

\begin{tabular}{|c|c|c|c|c|c|c|c|c|c|c|c|c|c|c|c|c|c|}
\hline & 2 & 3 & 4 & 5 & 6 & 7 & 8 & 9 & 10 & 11 & 12 & 13 & 14 & 15 & 16 & 17 & 18 \\
\hline 1. Adolescent Age & -.09 & -.08 & -.03 & .05 & $.15^{*}$ & -.06 & .10 & .06 & .03 & -.13 & .01 & $-.19 * *$ & .06 & -.03 & -.05 & -.04 & -.06 \\
\hline 2. Adolescent Gender & - & $.27 * *$ & -.03 & .03 & -.07 & -.07 & $-.42 * *$ & .14 & .05 & -.06 & $.19 * *$ & .14 & $.19 * *$ & $.23 * *$ & .10 & .02 & -.04 \\
\hline 3. Physical Safety & & - & .03 & -.09 & $-.15^{*}$ & $-.36^{* *}$ & $-.17 *$ & -.14 & -.07 & $-.25 * *$ & .00 & .07 & .04 & .09 & .08 & .00 & -.03 \\
\hline 4. Keep out of Trouble & & & - & .00 & $-.28 * *$ & $-.30 * *$ & -.10 & -.13 & -.13 & -.03 & .03 & $.17 *$ & -.06 & .12 & .10 & .02 & .05 \\
\hline 5. Future Success & & & & - & $-.19 * *$ & $-.18 *$ & -.10 & -.02 & .05 & $-.15^{*}$ & -.02 & .11 & -.03 & $.20 * *$ & .08 & $.25^{* *}$ & .04 \\
\hline 6. Emotional Well-Bein & & & & & - & -.02 & .12 & $-.18^{*}$ & -.13 & $-.18^{*}$ & -.09 & $-.29 * *$ & .13 & $-.31 * *$ & $-.22 * *$ & $-.25 * *$ & $-.22 * *$ \\
\hline 7. Maintain Relationship & & & & & & - & -.13 & $-.17 *$ & $-.21 * *$ & .04 & .11 & $-.21 * *$ & -.01 & -.13 & .00 & -.04 & -.06 \\
\hline 8. Good to Others & & & & & & & - & $-.18^{*}$ & -.01 & -.10 & -.14 & $-.19 *$ & -.07 & $-.28 * *$ & $-.15 *$ & -.09 & -.05 \\
\hline 9. Adolescent's Reputati & & & & & & & & - & $.27 * *$ & -.14 & .01 & $.17 *$ & .00 & $.15^{*}$ & .00 & .11 & $.17 *$ \\
\hline 10. Family's Reputation & & & & & & & & & - & -.08 & -.04 & .11 & .04 & .08 & .00 & .09 & $.20 * *$ \\
\hline 11. Need to Know & & & & & & & & & & - & -.03 & $.22 * *$ & .03 & $.15^{*}$ & $.18^{*}$ & $.20 * *$ & .05 \\
\hline 12. Knowledge & & & & & & & & & & & - & .11 & $.31 * *$ & $.26^{* *}$ & $.35 * *$ & .11 & -.07 \\
\hline 13. Harmfulness Beliefs & & & & & & & & & & & & - & -.04 & $.46^{* *}$ & $.24 * *$ & $.26 * *$ & $.26 * *$ \\
\hline 14. Relationship Quality & & & & & & & & & & & & & - & .10 & $.15^{*}$ & .03 & -.14 \\
\hline 15. Rules & & & & & & & & & & & & & & - & $.57 * *$ & $.39 * *$ & $.27 * *$ \\
\hline 16. Solicitation & & & & & & & & & & & & & & & - & $.57 * *$ & $.31 * *$ \\
\hline 17. Indirect & & & & & & & & & & & & & & & & - & $.42 * *$ \\
\hline 18. Covert & & & & & & & & & & & & & & & & & - \\
\hline
\end{tabular}

Note. ${ }^{*} p<.05, * * p<.01$ 
Table 9

Dating Identity Behaviors: Bivariate Correlations between Parent-Report Variables

\begin{tabular}{|c|c|c|c|c|c|c|c|c|c|c|c|c|c|c|c|c|c|}
\hline & 2 & 3 & 4 & 5 & 6 & 7 & 8 & 9 & 10 & 11 & 12 & 13 & 14 & 15 & 16 & 17 & 18 \\
\hline 1. Adolescent Age & -.09 & $-.19 * *$ & .01 & .13 & $.15^{*}$ & -.01 & .08 & -.06 & .04 & -.04 & .04 & -.10 & .06 & .01 & .06 & .03 & -.06 \\
\hline 2. Adolescent Gender & - & $.32 * *$ & .01 & -.06 & -.09 & -.07 & -.13 & -.05 & -.02 & $-.17 *$ & .11 & $.16^{*}$ & $.19 * *$ & $.24 * *$ & .12 & .02 & -.04 \\
\hline 3. Physical Safety & & - & .13 & -.10 & $-.23 * *$ & $-.37 * *$ & $-.19 * *$ & $-.17 *$ & $-.28 * *$ & $-.36 * *$ & .08 & .00 & $.22 * *$ & .07 & .09 & .09 & -.07 \\
\hline 4. Keep out of Trouble & & & - & -.07 & $-.37 * *$ & $-.35 * *$ & -.07 & $-.15^{*}$ & -.11 & $-.16^{*}$ & $-.17 *$ & .05 & -.09 & .04 & .05 & .02 & $.17^{*}$ \\
\hline 5. Future Success & & & & - & -.13 & -.11 & -.08 & -.13 & .07 & -.09 & -.04 & .10 & -.05 & $.16^{*}$ & .08 & .12 & .01 \\
\hline 6. Emotional Well-Bei & & & & & - & .11 & -.07 & -.06 & $-.16^{*}$ & $-.18 *$ & .08 & -.10 & .09 & $-.18 *$ & -.12 & -.12 & $-.18^{*}$ \\
\hline 7. Maintain Relationsh & & & & & & - & -.03 & $-.16^{*}$ & -.02 & -.01 & .14 & -.08 & .01 & -.03 & .05 & .09 & .05 \\
\hline 8. Good to Others & & & & & & & - & -.02 & .10 & -.03 & -.04 & $-.15^{*}$ & -.08 & -.12 & -.08 & -.08 & .00 \\
\hline 9. Adolescent's Reputa & & & & & & & & - & $.27 * *$ & .01 & -.04 & .05 & -.12 & .11 & -.02 & -.02 & .04 \\
\hline 10. Family's Reputatio & & & & & & & & & - & .09 & -.02 & -.04 & -.10 & .00 & .01 & .02 & .03 \\
\hline 11. Need to Know & & & & & & & & & & - & -.11 & .14 & -.04 & .01 & .02 & .04 & .04 \\
\hline 12. Knowledge & & & & & & & & & & & - & .02 & $.34 * *$ & $.20 * *$ & $.32 * *$ & $.16^{*}$ & -.09 \\
\hline 13. Harmfulness Belief & & & & & & & & & & & & - & -.07 & $.30 * *$ & $.160 *$ & .12 & .10 \\
\hline 14. Relationship Qualit & & & & & & & & & & & & & - & $.15^{*}$ & .12 & .05 & -.14 \\
\hline 15. Rules & & & & & & & & & & & & & & - & $.55^{* *}$ & $.37 * *$ & $.24 * *$ \\
\hline 16. Solicitation & & & & & & & & & & & & & & & - & $.52 * *$ & $.21 * *$ \\
\hline 17. Indirect & & & & & & & & & & & & & & & & - & $.39 * *$ \\
\hline 18. Covert & & & & & & & & & & & & & & & & & - \\
\hline
\end{tabular}

Note. $* p<.05, * * p<.01$ 
Table 10

Dating Supervision Behaviors: Bivariate Correlations between Parent-Report Variables

\begin{tabular}{|c|c|c|c|c|c|c|c|c|c|c|c|c|c|c|c|c|c|}
\hline & 2 & 3 & 4 & 5 & 6 & 7 & 8 & 9 & 10 & 11 & 12 & 13 & 14 & 15 & 16 & 17 & 18 \\
\hline 1. Adolescent Age & -.09 & -.09 & .07 & .08 & .11 & -.12 & .10 & .06 & .07 & -.09 & $-.21 * *$ & -.13 & .06 & -.03 & .04 & .08 & -.06 \\
\hline 2. Adolescent Gender & - & $.33 * *$ & $-.17 *$ & -.07 & .05 & -.04 & $-.19 * *$ & .08 & -.13 & -.12 & $.26^{* *}$ & .10 & $.19 * *$ & .09 & .07 & -.01 & -.04 \\
\hline 3. Physical Safety & & - & $-.20 * *$ & -.14 & -.06 & $-.19 * *$ & $-.24 * *$ & -.08 & $-.16^{*}$ & $-.31 * *$ & .11 & -.06 & $.15^{*}$ & .02 & .03 & -.01 & -.09 \\
\hline 4. Keep out of Trouble & & & - & -.02 & $-.17 *$ & $-.32 * *$ & -.06 & -.09 & $-.19 * *$ & -.09 & $-.15^{*}$ & $.15^{*}$ & -.06 & .06 & .08 & .06 & .04 \\
\hline 5. Future Success & & & & - & -.03 & $-.16^{*}$ & .05 & $-.20 * *$ & .03 & $-.20 * *$ & $-.22 * *$ & -.04 & -.06 & -.06 & -.07 & $.14^{*}$ & .02 \\
\hline 6. Emotional Well-Bei & & & & & - & -.02 & .02 & $-.15^{*}$ & .01 & -.03 & .02 & -.09 & .11 & -.06 & .03 & -.05 & $-.16^{*}$ \\
\hline 7. Maintain Relationsh & & & & & & - & -.04 & -.14 & .01 & -.10 & .09 & $-.15^{*}$ & -.07 & $-.18^{*}$ & -.06 & -.03 & -.02 \\
\hline 8. Good to Others & & & & & & & - & -.06 & $.15^{*}$ & -.11 & -.01 & -.08 & .00 & -.06 & .00 & .11 & .11 \\
\hline 9. Adolescent's Reputa & & & & & & & & - & .03 & $-.15^{*}$ & .13 & $.20 * *$ & -.01 & $.17 *$ & .14 & .05 & .09 \\
\hline 10. Family's Reputatio & & & & & & & & & - & -.12 & -.01 & -.11 & -.02 & .02 & -.01 & .01 & .05 \\
\hline 11. Need to Know & & & & & & & & & & - & -.10 & .08 & .02 & .07 & .03 & .04 & .05 \\
\hline 12. Knowledge & & & & & & & & & & & - & .11 & $.23 * *$ & $.23^{* *}$ & $.20 * *$ & -.01 & .01 \\
\hline 13. Harmfulness Belief & & & & & & & & & & & & - & -.14 & $.52 * *$ & $.25 * *$ & $.15^{*}$ & $.24 * *$ \\
\hline 14. Relationship Qualit & & & & & & & & & & & & & - & -.05 & .08 & .03 & -.14 \\
\hline 15. Rules & & & & & & & & & & & & & & - & $.43^{* *}$ & $.21 * *$ & $.20 * *$ \\
\hline 16. Solicitation & & & & & & & & & & & & & & & - & $.50 * *$ & $.23 * *$ \\
\hline 17. Indirect & & & & & & & & & & & & & & & & - & $.40 * *$ \\
\hline 18. Covert & & & & & & & & & & & & & & & & & - \\
\hline
\end{tabular}

Note. $* p<.05, * * p<.01$ 
Table 11

Peer Behaviors: Bivariate Correlations between Parent-Report Variables

\begin{tabular}{|c|c|c|c|c|c|c|c|c|c|c|c|c|c|c|c|c|c|}
\hline & 2 & 3 & 4 & 5 & 6 & 7 & 8 & 9 & 10 & 11 & 12 & 13 & 14 & 15 & 16 & 17 & 18 \\
\hline 1. Adolescent Age & -.09 & -.11 & .06 & .10 & .01 & -.02 & -.03 & .08 & .02 & .01 & .07 & -.04 & .06 & -.05 & -.09 & -.04 & -.06 \\
\hline 2. Adolescent Gender & - & .02 & -.02 & $-.16^{*}$ & $.19 * *$ & -.03 & .00 & -.03 & .00 & -.11 & $.20 * *$ & .03 & $.19 * *$ & .11 & .13 & -.03 & -.04 \\
\hline 3. Physical Safety & & - & -.06 & $-.22 * *$ & $-.15^{*}$ & $-.21 * *$ & $-.15^{*}$ & $-.19 * *$ & $-.20 * *$ & $-.19 * *$ & -.02 & -.02 & .05 & -.05 & -.01 & .06 & -.04 \\
\hline 4. Keep out of Trouble & & & - & $-.24 * *$ & $-.26 * *$ & $-.31 * *$ & $-.20 * *$ & -.02 & -.11 & -.01 & -.03 & $.17 *$ & -.02 & .00 & .06 & .08 & .09 \\
\hline 5. Future Success & & & & - & -.13 & -.11 & -.04 & -.01 & .10 & -.09 & -.12 & -.05 & -.08 & .01 & -.06 & -.01 & .00 \\
\hline 6. Emotional Well-Beiı & & & & & - & -.06 & .03 & $-.18 *$ & .06 & -.10 & .04 & -.04 & .12 & -.11 & .07 & -.06 & $-.15^{*}$ \\
\hline 7. Maintain Relationsh & & & & & & - & .03 & $-.18 *$ & $-.15^{*}$ & -.11 & .11 & .02 & -.05 & .06 & .07 & .02 & .02 \\
\hline 8. Good to Others & & & & & & & - & -.11 & .05 & .02 & .01 & .02 & -.01 & .11 & .06 & .07 & -.07 \\
\hline 9. Adolescent's Reputa & & & & & & & & - & .14 & -.08 & -.01 & -.04 & .02 & .07 & .02 & .03 & -.02 \\
\hline 10. Family's Reputatior & & & & & & & & & - & -.04 & .04 & -.02 & .07 & .05 & .00 & -.05 & .06 \\
\hline 11. Need to Know & & & & & & & & & & - & .00 & -.02 & .04 & .08 & .05 & .00 & -.03 \\
\hline 12. Knowledge & & & & & & & & & & & - & -.08 & $.44 * *$ & $.24 * *$ & $.34 * *$ & -.07 & $-.17 *$ \\
\hline 13. Harmfulness Belief & & & & & & & & & & & & - & -.10 & $.44 * *$ & $.26^{* *}$ & $.29 * *$ & $.22 * *$ \\
\hline 14. Relationship Qualit & & & & & & & & & & & & & - & $.15^{*}$ & $.23 * *$ & .00 & -.14 \\
\hline 15. Rules & & & & & & & & & & & & & & - & $.55^{* *}$ & $.25^{* *}$ & $.19 * *$ \\
\hline 16. Solicitation & & & & & & & & & & & & & & & - & $.44 * *$ & $.18^{*}$ \\
\hline 17. Indirect & & & & & & & & & & & & & & & & - & $.42 * *$ \\
\hline 18. Covert & & & & & & & & & & & & & & & & & - \\
\hline
\end{tabular}

Note. ${ }^{*} p<.05, * * p<.01$ 
Table 12

School Behaviors: Bivariate Correlations between Parent-Report Variables

\begin{tabular}{|c|c|c|c|c|c|c|c|c|c|c|c|c|c|c|c|c|c|}
\hline & 2 & 3 & 4 & 5 & 6 & 7 & 8 & 9 & 10 & 11 & 12 & 13 & 14 & 15 & 16 & 17 & 18 \\
\hline 1. Adolescent Age & -.09 & -.10 & -.02 & -.01 & .08 & $-.15^{*}$ & .09 & .09 & .10 & .00 & -.01 & .03 & .06 & -.02 & -.12 & -.03 & -.06 \\
\hline 2. Adolescent Gender & - & .04 & -.06 & -.10 & .12 & .08 & .00 & .03 & .05 & $-.16^{*}$ & $.18^{*}$ & -.06 & $.19 * *$ & -.04 & .04 & -.10 & -.04 \\
\hline 3. Physical Safety & & - & .07 & $-.27 * *$ & -.11 & -.03 & $.19 * *$ & -.02 & -.01 & -.08 & .00 & -.01 & -.05 & .00 & .03 & $.18^{*}$ & $.19 * *$ \\
\hline 4. Keep out of Trouble & & & - & .00 & $-.24 * *$ & $-.36 * *$ & .05 & -.10 & $-.21 * *$ & -.09 & -.09 & .02 & $-.18^{*}$ & .08 & .09 & .01 & $.15^{*}$ \\
\hline 5. Future Success & & & & - & -.04 & $-.31 * *$ & $-.30 * *$ & -.01 & -.03 & -.08 & .00 & .07 & .06 & .07 & -.08 & -.04 & .01 \\
\hline 6. Emotional Well-Beir & & & & & - & -.03 & -.08 & $-.24 * *$ & $-.16^{*}$ & $-.20 * *$ & .06 & .01 & $.27 * *$ & -.01 & .10 & .05 & $-.21 * *$ \\
\hline 7. Maintain Relationshi & & & & & & - & -.08 & $-.29 * *$ & -.11 & -.11 & $.18^{*}$ & $-.15^{*}$ & .05 & $-.25 * *$ & .13 & .06 & -.04 \\
\hline 8. Good to Others & & & & & & & - & -.03 & .03 & -.13 & -.08 & -.01 & .00 & .00 & -.10 & -.03 & .05 \\
\hline 9. Adolescent's Reputa & & & & & & & & - & .09 & $-.21 * *$ & -.01 & .09 & -.10 & .11 & -.13 & .03 & .02 \\
\hline 10. Family's Reputation & & & & & & & & & - & $-.15^{*}$ & $-.18^{*}$ & -.01 & -.05 & .06 & $-.25 * *$ & -.05 & -.06 \\
\hline 11. Need to Know & & & & & & & & & & - & -.08 & .05 & .04 & .01 & .09 & .04 & .00 \\
\hline 12. Knowledge & & & & & & & & & & & - & .01 & $.31 * *$ & .12 & $.34 * *$ & .00 & -.12 \\
\hline 13. Harmfulness Belief & & & & & & & & & & & & - & .08 & $.34 * *$ & .11 & .14 & .11 \\
\hline 14. Relationship Qualit & & & & & & & & & & & & & - & .06 & $.23 * *$ & -.07 & -.14 \\
\hline 15. Rules & & & & & & & & & & & & & & - & $.35 * *$ & .13 & .13 \\
\hline 16. Solicitation & & & & & & & & & & & & & & & - & $.30 * *$ & .10 \\
\hline 17. Indirect & & & & & & & & & & & & & & & & - & $.31 * *$ \\
\hline 18. Covert & & & & & & & & & & & & & & & & & - \\
\hline
\end{tabular}

Note. $* p<.05, * * p<.01$ 
Table 13

Substance Use Behaviors: Bivariate Correlations between Parent-Report Variables

\begin{tabular}{|c|c|c|c|c|c|c|c|c|c|c|c|c|c|c|c|c|c|}
\hline & 2 & 3 & 4 & 5 & 6 & 7 & 8 & 9 & 10 & 11 & 12 & 13 & 14 & 15 & 16 & 17 & 18 \\
\hline 1. Adolescent Age & -.09 & .02 & -.04 & .10 & .09 & -.09 & .01 & .02 & -.05 & -.02 & -.08 & -.03 & .06 & -.03 & -.08 & .03 & -.06 \\
\hline 2. Adolescent Gender & - & .03 & .01 & -.10 & .12 & .00 & .07 & .09 & .08 & -.14 & .06 & .00 & $.19 * *$ & -.05 & -.03 & -.10 & -.04 \\
\hline 3. Physical Safety & & - & $-.15^{*}$ & -.08 & .04 & $-.40 * *$ & -.12 & -.08 & $-.21 * *$ & $-.36 * *$ & .04 & $.14^{*}$ & .12 & -.01 & .00 & -.03 & -.04 \\
\hline 4. Keep out of Trouble & & & - & $-.31 * *$ & $-.19 * *$ & $-.20 * *$ & $-.16^{*}$ & -.10 & .00 & -.11 & -.04 & .02 & -.05 & .08 & .09 & .05 & .05 \\
\hline 5. Future Success & & & & - & -.06 & $-.20 * *$ & .05 & -.13 & .01 & $-.16^{*}$ & -.07 & .02 & -.10 & .14 & -.10 & .00 & -.04 \\
\hline 6. Emotional Well-Being & & & & & - & $-.15^{*}$ & $.31 * *$ & -.14 & .03 & $-.15^{*}$ & .04 & .04 & .10 & -.01 & -.13 & -.12 & $-.16^{*}$ \\
\hline 7. Maintain Relationship & & & & & & - & .01 & -.08 & -.07 & .03 & .03 & -.11 & .04 & $-.16^{*}$ & .03 & .04 & .02 \\
\hline 8. Good to Others & & & & & & & - & .03 & .04 & -.05 & -.05 & .01 & .01 & -.05 & -.04 & -.10 & .00 \\
\hline 9. Adolescent's Reputatic & & & & & & & & - & .09 & -.10 & -.02 & -.05 & .00 & -.02 & .11 & .05 & .02 \\
\hline 10. Family's Reputation & & & & & & & & & - & .07 & -.05 & -.04 & -.07 & .06 & .01 & $.15^{*}$ & $.26 * *$ \\
\hline 11. Need to Know & & & & & & & & & & - & -.04 & -.09 & .02 & -.04 & $.15^{*}$ & $.20 * *$ & .02 \\
\hline 12. Knowledge & & & & & & & & & & & - & -.06 & $.28 * *$ & $.15^{*}$ & $.15^{*}$ & -.05 & -.09 \\
\hline 13. Harmfulness Beliefs & & & & & & & & & & & & - & .04 & .08 & -.05 & -.07 & .00 \\
\hline 14. Relationship Quality & & & & & & & & & & & & & - & .13 & $.15^{*}$ & .03 & -.14 \\
\hline 15. Rules & & & & & & & & & & & & & & - & $.18^{*}$ & .10 & .13 \\
\hline 16. Solicitation & & & & & & & & & & & & & & & - & $.47 * *$ & $.28 * *$ \\
\hline 17. Indirect & & & & & & & & & & & & & & & & - & $.40 * *$ \\
\hline 18. Covert & & & & & & & & & & & & & & & & & - \\
\hline
\end{tabular}

Note. ${ }^{*} p<.05, * * p<.01$ 
Table 14

Conventional Behaviors: Bivariate Correlations between Adolescent-Report Variables

\begin{tabular}{|c|c|c|c|c|c|c|c|c|c|c|c|c|c|c|c|}
\hline & 2 & 3 & 4 & 5 & 6 & 7 & 8 & 9 & 10 & 11 & 12 & 13 & 14 & 15 & 16 \\
\hline 1. Adolescent Age & -.10 & .13 & .00 & -.05 & -.02 & -.07 & .06 & -.01 & -.04 & -.05 & .07 & -.09 & -.13 & .03 & $.19 *$ \\
\hline 2. Adolescent Gender & - & -.10 & $-.20 * *$ & $-.19 *$ & $-.21 * *$ & -.02 & $.31 * *$ & .03 & -.09 & -.01 & .08 & -.04 & -.05 & $-.16^{*}$ & -.06 \\
\hline 3. Physical Safety & & - & .12 & -.04 & $.31 * *$ & $.35^{* *}$ & $-.27 * *$ & $-.22 * *$ & -.09 & $.24 * *$ & -.04 & $.17 *$ & .13 & $.17 *$ & -.06 \\
\hline 4. Keep out of Trouble & & & - & -.09 & -.12 & -.14 & $-.35 * *$ & $-.28 * *$ & $-.23 * *$ & -.05 & .13 & .00 & .04 & .12 & -.02 \\
\hline 5. Future Success & & & & - & $.26 * *$ & .11 & $-.15 *$ & -.14 & -.13 & -.03 & .00 & -.09 & -.08 & -.04 & .03 \\
\hline 6. Emotional Well-Being & & & & & - & $.44 * *$ & -.05 & $-.23 * *$ & .01 & $.40 * *$ & .05 & .03 & -.02 & -.02 & -.09 \\
\hline 7. Maintain Relationship & & & & & & - & -.02 & -.15 & .03 & $.21 * *$ & .06 & .13 & -.03 & -.02 & -.09 \\
\hline 8. Good to Others & & & & & & & - & -.10 & -.14 & $-.27 * *$ & .09 & -.11 & $-.16^{*}$ & -.08 & .03 \\
\hline 9. Adolescent's Reputation & & & & & & & & - & -.05 & -.15 & -.05 & -.07 & .00 & -.09 & .07 \\
\hline 10. Family's Reputation & & & & & & & & & - & .12 & -.12 & -.05 & .09 & .05 & .08 \\
\hline 11. Being Nosey & & & & & & & & & & - & -.14 & .12 & $.37 * *$ & .12 & -.07 \\
\hline 12. Disclosure & & & & & & & & & & & - & $-.15^{*}$ & $-.26 * *$ & $-.15 *$ & -.11 \\
\hline 13. Secrecy & & & & & & & & & & & & - & $.21 * *$ & .06 & .00 \\
\hline 14. Concealment & & & & & & & & & & & & & - & $.28 * *$ & .01 \\
\hline 15. Delinquency & & & & & & & & & & & & & & - & $.38^{* *}$ \\
\hline 16. Substance Use & & & & & & & & & & & & & & & - \\
\hline
\end{tabular}

Note. $* p<.05, * * p<.01$ 
Table 15

Dating Expression Behaviors: Bivariate Correlations between Adolescent-Report Variables

\begin{tabular}{|c|c|c|c|c|c|c|c|c|c|c|c|c|c|c|c|}
\hline & 2 & 3 & 4 & 5 & 6 & 7 & 8 & 9 & 10 & 11 & 12 & 13 & 14 & 15 & 16 \\
\hline 1. Adolescent Age & -.09 & -.08 & .07 & .02 & -.14 & .00 & .01 & .02 & .01 & .04 & .00 & .10 & $-.19 *$ & .04 & $.18 *$ \\
\hline 2. Adolescent Gender & - & $.19 *$ & $-.19 *$ & $-.21 * *$ & .04 & $.30 * *$ & $-.39 * *$ & .04 & -.10 & -.08 & $.23 * *$ & .02 & -.06 & $-.21 *$ & -.06 \\
\hline 3. Physical Safety & & - & -.07 & -.13 & -.02 & -.02 & -.11 & $-.22 * *$ & $-.17 *$ & $-.25 * *$ & .14 & -.08 & -.04 & -.12 & -.16 \\
\hline 4. Keep out of Trouble & & & - & .13 & $-.44 * *$ & $-.29 * *$ & .00 & .05 & .05 & -.15 & -.08 & -.04 & .01 & .04 & -.06 \\
\hline 5. Future Success & & & & - & -.13 & -.04 & $.21 *$ & -.04 & $.16^{*}$ & $-.17 *$ & .06 & -.06 & -.08 & -.04 & -.15 \\
\hline 6. Emotional Well-Being & & & & & - & $.26^{* *}$ & .03 & $-.24 * *$ & .02 & -.12 & .12 & -.04 & -.16 & -.02 & .09 \\
\hline 7. Maintain Relationship & & & & & & - & -.06 & $-.24 * *$ & .00 & $-.20 *$ & $.35^{* *}$ & -.07 & $-.23 * *$ & -.10 & -.06 \\
\hline 8. Good to Others & & & & & & & - & .06 & .15 & -.12 & -.02 & .09 & .03 & -.05 & .09 \\
\hline 9. Adolescent's Reputatio & & & & & & & & - & $.25 * *$ & .04 & -.05 & .03 & .08 & .07 & .12 \\
\hline 10. Family's Reputation & & & & & & & & & - & .06 & -.01 & -.06 & .12 & -.05 & -.08 \\
\hline 11. Being Nosey & & & & & & & & & & - & $-.26 * *$ & $.18^{*}$ & $.30 * *$ & $.25^{* *}$ & .01 \\
\hline 12. Disclosure & & & & & & & & & & & - & $-.43 * *$ & $-.39 * *$ & $-.40 * *$ & $-.24 * *$ \\
\hline 13. Secrecy & & & & & & & & & & & & - & $.28 * *$ & $.17 *$ & .15 \\
\hline 15. Delinquency & & & & & & & & & & & & & & - & $.40 * *$ \\
\hline 16. Substance Use & & & & & & & & & & & & & & & - \\
\hline
\end{tabular}

Note. $* p<.05, * * p<.01$ 
Table 16

Dating Identity Behaviors: Bivariate correlations between adolescent-report variables

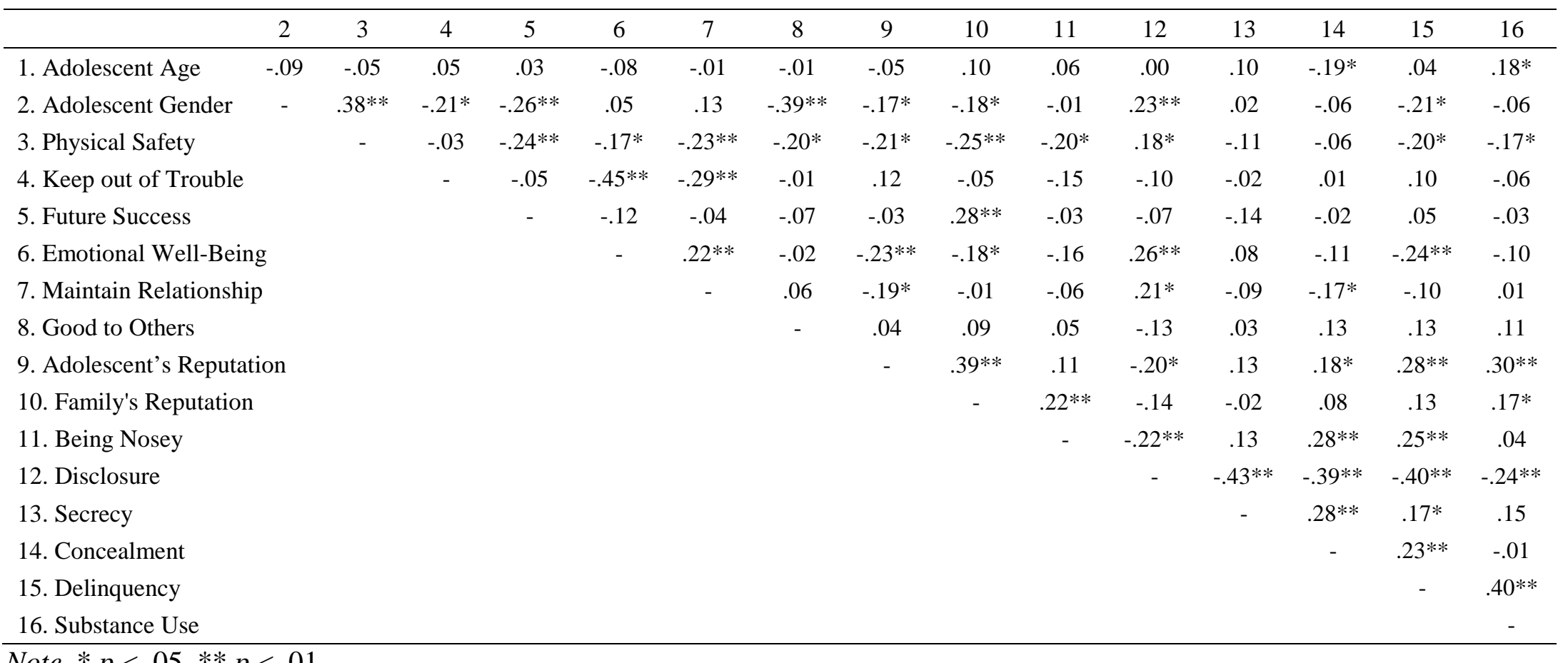

Note. $* p<.05, * * p<.01$ 
Table 17

Dating Supervision Behaviors: Bivariate Correlations between Adolescent-Report Variables

\begin{tabular}{|c|c|c|c|c|c|c|c|c|c|c|c|c|c|c|c|}
\hline & 2 & 3 & 4 & 5 & 6 & 7 & 8 & 9 & 10 & 11 & 12 & 13 & 14 & 15 & 16 \\
\hline 1. Adolescent Age & -.09 & -.09 & .01 & .00 & -.07 & .05 & -.09 & -.01 & .03 & .09 & .00 & .10 & $-.19 *$ & .04 & $.18 *$ \\
\hline 2. Adolescent Gender & - & $.35^{* *}$ & $-.19 *$ & $-.28 * *$ & -.09 & .08 & $-.41 * *$ & .10 & $-.23 * *$ & -.01 & $.23 * *$ & .02 & -.06 & $-.21 *$ & -.06 \\
\hline 3. Physical Safety & & - & -.14 & $-.35 * *$ & -.13 & -.06 & -.16 & $-.16^{*}$ & $-.36^{* *}$ & $-.26 * *$ & $.16^{*}$ & -.07 & $-.17 *$ & -.11 & -.08 \\
\hline 4. Keep out of Trouble & & & - & $-.21 *$ & $-.38 * *$ & $-.45^{* *}$ & -.12 & .11 & .02 & $-.22 * *$ & -.07 & -.11 & .10 & .06 & .02 \\
\hline 5. Future Success & & & & - & $.22 * *$ & .05 & $.21^{*}$ & $-.17 *$ & $.18^{*}$ & -.04 & -.06 & -.10 & -.09 & .05 & .01 \\
\hline \multicolumn{3}{|c|}{ 6. Emotional Well-Being } & & & - & $.40 * *$ & $.27 * *$ & $-.20 *$ & .12 & $.20 *$ & .03 & .14 & -.04 & .01 & .10 \\
\hline \multicolumn{3}{|l|}{ 7. Maintain Relationship } & & & & - & .03 & $-.26 * *$ & .08 & .15 & $.17 *$ & .00 & $-.18 *$ & -.01 & .06 \\
\hline \multicolumn{3}{|l|}{ 8. Good to Others } & & & & & - & $-.17 *$ & .06 & $.17 *$ & -.06 & .01 & .07 & .04 & .03 \\
\hline \multicolumn{3}{|c|}{ 9. Adolescent's Reputation } & & & & & & - & .06 & -.15 & .02 & -.03 & .11 & -.06 & -.01 \\
\hline \multicolumn{3}{|l|}{ 10. Family's Reputation } & & & & & & & - & .15 & -.10 & .07 & $.18^{*}$ & .01 & -.04 \\
\hline \multicolumn{3}{|l|}{ 11. Being Nosey } & & & & & & & & - & $-.16^{*}$ & $.19^{*}$ & $.33 * *$ & $.23 * *$ & .03 \\
\hline \multicolumn{3}{|l|}{ 12. Disclosure } & & & & & & & & & - & $-.43 * *$ & $-.39 * *$ & $-.40 * *$ & $-.24 * *$ \\
\hline \multicolumn{3}{|l|}{ 13. Secrecy } & & & & & & & & & & - & $.28 * *$ & $.17 *$ & .15 \\
\hline \multicolumn{3}{|l|}{ 15. Delinquency } & & & & & & & & & & & & - & $.40 * *$ \\
\hline \multicolumn{3}{|l|}{ 16. Substance Use } & & & & & & & & & & & & & - \\
\hline
\end{tabular}

Note. $* p<.05, * * p<.01$ 
Table 18

Peer Behaviors: Bivariate Correlations between Adolescent-Report Variables

\begin{tabular}{|c|c|c|c|c|c|c|c|c|c|c|c|c|c|c|c|}
\hline & 2 & 3 & 4 & 5 & 6 & 7 & 8 & 9 & 10 & 11 & 12 & 13 & 14 & 15 & 16 \\
\hline 1. Adolescent Age & -.10 & -.02 & .03 & .00 & $-.20 * *$ & .02 & .01 & .03 & .09 & .00 & -.06 & .12 & -.10 & .04 & $.19 * *$ \\
\hline 2. Adolescent Gender & - & $.14^{*}$ & $-.26 * *$ & $-.27 * *$ & $.18^{*}$ & $.21 * *$ & -.09 & -.06 & $-.15^{*}$ & .00 & $.26^{* *}$ & -.07 & -.04 & $-.16^{*}$ & -.06 \\
\hline 3. Physical Safety & & - & $-.22 * *$ & $-.17 *$ & -.04 & -.09 & -.12 & $-.16^{*}$ & $-.23 * *$ & $-.37 * *$ & .13 & -.08 & -.03 & -.10 & -.14 \\
\hline 4. Keep out of Trouble & & & - & -.08 & $-.42 * *$ & $-.35^{* *}$ & -.02 & .10 & -.07 & $-.15^{*}$ & -.04 & -.03 & .01 & .10 & .03 \\
\hline 5. Future Success & & & & - & -.09 & -.05 & .03 & $-.17 *$ & .14 & -.05 & -.03 & -.02 & -.02 & .04 & .02 \\
\hline 6. Emotional Well-Being & & & & & - & $.30 * *$ & .09 & $-.23 * *$ & -.03 & .07 & .11 & .00 & -.07 & -.04 & -.08 \\
\hline 7. Maintain Relationship & & & & & & - & $.16^{*}$ & $-.19 * *$ & .09 & .04 & $.18^{*}$ & -.03 & $-.16^{*}$ & -.06 & -.04 \\
\hline 8. Good to Others & & & & & & & - & -.04 & .12 & .04 & .10 & .03 & -.07 & -.05 & -.04 \\
\hline 9. Adolescent's Reputatic & & & & & & & & - & $.15^{*}$ & -.09 & $-.16^{*}$ & .02 & .08 & .11 & $.27 * *$ \\
\hline 10. Family's Reputation & & & & & & & & & - & $.24 * *$ & $-.25 * *$ & $.15^{*}$ & .12 & .03 & .02 \\
\hline 11. Being Nosey & & & & & & & & & & - & $-.21 * *$ & .13 & $.29 * *$ & .10 & -.02 \\
\hline 12. Disclosure & & & & & & & & & & & - & $-.32 * *$ & $-.34 * *$ & $-.31 * *$ & $-.19 * *$ \\
\hline 13. Secrecy & & & & & & & & & & & & - & $.21 * *$ & .12 & .04 \\
\hline 15. Delinquency & & & & & & & & & & & & & & - & $.38 * *$ \\
\hline 16. Substance Use & & & & & & & & & & & & & & & - \\
\hline
\end{tabular}

Note. $* p<.05, * * p<.01$ 
Table 19

School Behaviors: Bivariate Correlations between Adolescent-Report Variables

\begin{tabular}{|c|c|c|c|c|c|c|c|c|c|c|c|c|c|c|c|}
\hline & 2 & 3 & 4 & 5 & 6 & 7 & 8 & 9 & 10 & 11 & 12 & 13 & 14 & 15 & 16 \\
\hline 1. Adolescent Age & -.10 & .08 & .08 & .03 & -.08 & -.03 & .01 & -.13 & .05 & .04 & $-.28 * *$ & .11 & -.10 & .04 & $.19 * *$ \\
\hline 2. Adolescent Gender & - & -.09 & $-.18^{*}$ & .02 & .07 & $.17 *$ & $-.17 *$ & -.07 & -.10 & -.01 & $.25^{* *}$ & -.02 & -.04 & $-.16^{*}$ & -.06 \\
\hline 3. Physical Safety & & - & $.17 *$ & $-.40 * *$ & .06 & .13 & $.50 * *$ & -.08 & $.17 *$ & $.34 * *$ & -.05 & .08 & .14 & .02 & -.06 \\
\hline 4. Keep out of Trouble & & & - & $-.20 * *$ & $-.30 * *$ & $-.25 * *$ & $.17 *$ & -.09 & $-.16^{*}$ & -.04 & -.07 & .00 & .04 & $.15^{*}$ & $.16^{*}$ \\
\hline 5. Future Success & & & & - & $-.21 * *$ & $-.15^{*}$ & $-.22 * *$ & .07 & -.14 & $-.29 * *$ & -.04 & .01 & $-.16^{*}$ & .01 & .09 \\
\hline 6. Emotional Well-Being & & & & & - & $.37 * *$ & .10 & $-.48 * *$ & $-.21 * *$ & -.04 & $.15^{*}$ & -.03 & -.11 & -.05 & -.13 \\
\hline 7. Maintain Relationship & & & & & & - & .13 & $-.39 * *$ & $-.24 * *$ & .02 & .11 & -.06 & $-.17 *$ & -.06 & -.03 \\
\hline 8. Good to Others & & & & & & & - & .05 & $.18^{*}$ & $.32 * *$ & -.08 & $.14^{*}$ & .12 & .12 & .04 \\
\hline 9. Adolescent's Reputatior & & & & & & & & - & $.18^{*}$ & -.12 & -.02 & .07 & .12 & -.02 & .00 \\
\hline 10. Family's Reputation & & & & & & & & & - & .09 & $-.20 * *$ & -.05 & $.19 * *$ & -.01 & -.09 \\
\hline 11. Being Nosey & & & & & & & & & & - & -.08 & .07 & $.21 * *$ & .08 & .04 \\
\hline 12. Disclosure & & & & & & & & & & & - & -.07 & $-.22 * *$ & $-.21 * *$ & $-.25 * *$ \\
\hline 13. Secrecy & & & & & & & & & & & & - & .13 & .05 & .10 \\
\hline 14. Concealment & & & & & & & & & & & & & - & $.30 * *$ & .03 \\
\hline 15. Delinquency & & & & & & & & & & & & & & - & $.38 * *$ \\
\hline 16. Substance Use & & & & & & & & & & & & & & & - \\
\hline
\end{tabular}

Note. $* p<.05, * * p<.01$ 
Table 20

Substance Use Behaviors: Bivariate Correlations between Adolescent-Report Variables

\begin{tabular}{|c|c|c|c|c|c|c|c|c|c|c|c|c|c|c|c|}
\hline & 2 & 3 & 4 & 5 & 6 & 7 & 8 & 9 & 10 & 11 & 12 & 13 & 14 & 15 & 16 \\
\hline 1. Adolescent Age & -.17 & .14 & .06 & .05 & -.07 & -.09 & .10 & $-.28 *$ & .00 & -.09 & .05 & .07 & -.18 & -.10 & $.24 *$ \\
\hline 2. Adolescent Gender & - & $.39 * *$ & $-.38 * *$ & -.23 & .14 & .15 & -.15 & -.10 & -.12 & .00 & .10 & $.25 *$ & -.04 & -.12 & -.06 \\
\hline 3. Physical Safety & & - & $-.37 * *$ & -.19 & -.01 & $-.32 * *$ & $-.35 * *$ & $-.30 *$ & -.19 & -.20 & -.03 & .19 & .06 & -.12 & -.07 \\
\hline 4. Keep out of Trouble & & & - & $-.25 *$ & -.11 & -.06 & .20 & .16 & -.03 & -.23 & -.03 & -.12 & -.10 & .21 & .17 \\
\hline 5. Future Success & & & & - & -.02 & -.10 & -.04 & $-.30 *$ & -.06 & .08 & -.13 & -.07 & .11 & .01 & -.09 \\
\hline 6. Emotional Well-Bei & & & & & - & $.32 * *$ & -.08 & -.21 & -.05 & -.08 & .02 & -.11 & -.09 & .03 & .13 \\
\hline 7. Maintain Relationsh & & & & & & - & -.01 & -.03 & -.13 & .00 & .23 & -.23 & $-.25^{*}$ & .03 & .17 \\
\hline 8. Good to Others & & & & & & & - & .15 & .11 & -.12 & .08 & .11 & -.17 & .08 & .09 \\
\hline 9. Adolescent's Reputa & ion & & & & & & & - & -.11 & -.14 & .01 & -.19 & .01 & .12 & .14 \\
\hline 10. Family's Reputatio & & & & & & & & & - & -.15 & .13 & .02 & -.07 & -.15 & -.10 \\
\hline 11. Being Nosey & & & & & & & & & & - & -.12 & $.29 *$ & $.44 * *$ & .09 & -.07 \\
\hline 12. Disclosure & & & & & & & & & & & - & $-.42 * *$ & $-.38 * *$ & -.18 & .16 \\
\hline 13. Secrecy & & & & & & & & & & & & - & $.36^{* *}$ & .15 & .05 \\
\hline 14. Concealment & & & & & & & & & & & & & - & $.35 * *$ & -.06 \\
\hline 15. Delinquency & & & & & & & & & & & & & & - & $.40^{* *}$ \\
\hline 16. Substance Use & & & & & & & & & & & & & & & - \\
\hline
\end{tabular}

Note. $* p<.05, * * p<.01$ 
Table 21

Parent-Reported Differences in Parental Knowledge-Seeking Motivations by Behavior Category

\begin{tabular}{|c|c|c|c|c|c|c|c|c|c|c|c|}
\hline & $\begin{array}{c}\text { Physical } \\
\text { Safety }\end{array}$ & $\begin{array}{l}\text { Keep out } \\
\text { of Trouble }\end{array}$ & $\begin{array}{l}\text { Future } \\
\text { Success }\end{array}$ & $\begin{array}{l}\text { Emotional } \\
\text { Well-Being }\end{array}$ & $\begin{array}{c}\text { Maintain } \\
\text { Relationship }\end{array}$ & $\begin{array}{l}\text { Good } \\
\text { Person }\end{array}$ & $\begin{array}{c}\text { Teen's } \\
\text { Reputation }\end{array}$ & $\begin{array}{c}\text { Family's } \\
\text { Reputation }\end{array}$ & $\begin{array}{l}\text { Need to } \\
\text { Know }\end{array}$ & $\begin{array}{c}\text { Main } \\
\text { Effects }\end{array}$ & $\eta^{2}$ \\
\hline Conventional & $\begin{array}{c}.21^{\mathrm{b}} \\
(.96)\end{array}$ & $\begin{array}{l}2.90^{\mathrm{c}} \\
(2.55)\end{array}$ & $\begin{array}{l}2.52^{c} \\
(2.26)\end{array}$ & $\begin{array}{l}.49^{\mathrm{bd}} \\
(1.30)\end{array}$ & $\begin{array}{l}1.03^{\mathrm{de}} \\
(2.07)\end{array}$ & $\begin{array}{c}6.26^{\mathrm{a}} \\
(2.94)\end{array}$ & $\begin{array}{l}2.57^{\mathrm{c}} \\
(2.30)\end{array}$ & $\begin{array}{l}1.41^{\mathrm{e}} \\
(1.92)\end{array}$ & $\begin{array}{c}.88^{\mathrm{de}} \\
(2.01)\end{array}$ & $133.65 * * *$ & .41 \\
\hline $\begin{array}{l}\text { Dating } \\
\text { Expression }\end{array}$ & $\begin{array}{l}4.85^{\mathrm{d}} \\
(2.89)\end{array}$ & $\begin{array}{c}2.77^{b} \\
(2.49)\end{array}$ & $\begin{array}{l}1.38^{\mathrm{ac}} \\
(1.81)\end{array}$ & $\begin{array}{c}2.28^{b} \\
(2.28)\end{array}$ & $\begin{array}{c}2.75^{b} \\
(2.81)\end{array}$ & $\begin{array}{c}.85^{\mathrm{ae}} \\
(1.67)\end{array}$ & $\begin{array}{l}1.56^{\mathrm{c}} \\
(1.89)\end{array}$ & $\begin{array}{r}.38^{\mathrm{e}} \\
(1.13)\end{array}$ & $\begin{array}{l}1.30^{\mathrm{ac}} \\
(2.35)\end{array}$ & $63.75 * * *$ & .25 \\
\hline $\begin{array}{l}\text { Dating } \\
\text { Identity }\end{array}$ & $\begin{array}{l}5.99^{\mathrm{d}} \\
(3.11)\end{array}$ & $\begin{array}{c}3.04^{\mathrm{b}} \\
(2.56)\end{array}$ & $\begin{array}{l}1.22^{c} \\
(1.83)\end{array}$ & $\begin{array}{c}2.75^{b} \\
(2.45)\end{array}$ & $\begin{array}{l}2.17^{\mathrm{b}} \\
(2.42)\end{array}$ & $\begin{array}{r}.46^{\mathrm{a}} \\
(1.07)\end{array}$ & $\begin{array}{r}.94^{\mathrm{c}} \\
(1.53)\end{array}$ & $\begin{array}{l}.37^{\mathrm{a}} \\
(.85)\end{array}$ & $\begin{array}{l}1.31^{\mathrm{c}} \\
(2.33)\end{array}$ & $117.56 * * *$ & .38 \\
\hline $\begin{array}{l}\text { Dating } \\
\text { Supervision }\end{array}$ & $\begin{array}{l}6.83^{d} \\
(2.72)\end{array}$ & $\begin{array}{l}4.95^{\mathrm{b}} \\
(2.57)\end{array}$ & $\begin{array}{l}1.23^{\mathrm{c}} \\
(1.84)\end{array}$ & $\begin{array}{r}.61^{\mathrm{a}} \\
(1.31)\end{array}$ & $\begin{array}{l}1.38^{\mathrm{c}} \\
(2.12)\end{array}$ & $\begin{array}{l}.26^{\mathrm{a}} \\
(.88)\end{array}$ & $\begin{array}{l}1.22^{\mathrm{c}} \\
(1.74)\end{array}$ & $\begin{array}{l}.26^{\mathrm{a}} \\
(.78)\end{array}$ & $\begin{array}{l}1.52^{\mathrm{c}} \\
(2.44)\end{array}$ & $240.28 * * *$ & .56 \\
\hline Peers & $\begin{array}{l}6.62^{d} \\
(2.61)\end{array}$ & $\begin{array}{l}4.07^{\mathrm{c}} \\
(2.47)\end{array}$ & $\begin{array}{c}1.66^{\mathrm{b}} \\
(1.96)\end{array}$ & $\begin{array}{l}1.73^{b} \\
(2.16)\end{array}$ & $\begin{array}{l}1.74^{\mathrm{b}} \\
(2.24)\end{array}$ & $\begin{array}{c}.75^{\mathrm{a}} \\
(1.30)\end{array}$ & $\begin{array}{c}.87^{\mathrm{a}} \\
(1.57)\end{array}$ & $\begin{array}{l}.23^{\mathrm{e}} \\
(.70)\end{array}$ & $\begin{array}{c}.60^{\mathrm{ae}} \\
(1.51)\end{array}$ & $198.13 * * *$ & .51 \\
\hline School & $\begin{array}{l}.13^{\mathrm{a}} \\
(.84)\end{array}$ & $\begin{array}{l}2.07^{\mathrm{b}} \\
(2.50)\end{array}$ & $\begin{array}{l}8.03^{\mathrm{d}} \\
(1.84)\end{array}$ & $\begin{array}{l}2.21^{\mathrm{b}} \\
(2.40)\end{array}$ & $\begin{array}{l}2.17^{b} \\
(2.46)\end{array}$ & $\begin{array}{l}.24^{\mathrm{a}} \\
(.98)\end{array}$ & $\begin{array}{l}1.20^{\mathrm{ce}} \\
(1.89)\end{array}$ & $\begin{array}{c}.72^{\mathrm{e}} \\
(1.48)\end{array}$ & $\begin{array}{l}1.48^{\mathrm{bc}} \\
(2.40)\end{array}$ & $256.26 * * *$ & .57 \\
\hline $\begin{array}{l}\text { Substance } \\
\text { Use }\end{array}$ & $\begin{array}{l}7.30^{\mathrm{f}} \\
(2.49)\end{array}$ & $\begin{array}{l}4.34^{\mathrm{c}} \\
(2.53)\end{array}$ & $\begin{array}{c}2.47^{\mathrm{g}} \\
(2.30)\end{array}$ & $\begin{array}{l}.57^{\text {be }} \\
(1.54)\end{array}$ & $\begin{array}{l}1.49^{\mathrm{d}} \\
(2.27)\end{array}$ & $\begin{array}{l}.04^{\mathrm{a}} \\
(.26)\end{array}$ & $\begin{array}{r}.63^{\mathrm{e}} \\
(1.27)\end{array}$ & $\begin{array}{l}.20^{\mathrm{ab}} \\
(.79)\end{array}$ & $\begin{array}{l}1.25^{\mathrm{de}} \\
(2.29)\end{array}$ & $269.70 * * *$ & .58 \\
\hline
\end{tabular}

Note. Means with different superscripts significantly differ at Bonferroni-adjusted $p$ values. *** $p<.001$ 
Table 22

Adolescent-Reported Differences in Parental Knowledge-Seeking Motivations by Behavior Category

\begin{tabular}{|c|c|c|c|c|c|c|c|c|c|c|c|}
\hline & $\begin{array}{l}\text { Keep out } \\
\text { of Trouble }\end{array}$ & $\begin{array}{c}\text { Teen's } \\
\text { Reputation }\end{array}$ & $\begin{array}{l}\text { Good } \\
\text { Person }\end{array}$ & $\begin{array}{l}\text { Future } \\
\text { Success }\end{array}$ & $\begin{array}{c}\text { Physical } \\
\text { Safety }\end{array}$ & $\begin{array}{l}\text { Maintain } \\
\text { Relationship }\end{array}$ & $\begin{array}{l}\text { Emotional } \\
\text { Well-Being }\end{array}$ & $\begin{array}{c}\text { Family's } \\
\text { Reputation }\end{array}$ & $\begin{array}{l}\text { Being } \\
\text { Nosey }\end{array}$ & $\begin{array}{c}\text { Main } \\
\text { Effects }\end{array}$ & $\eta^{2}$ \\
\hline Conventional & $\begin{array}{l}4.66^{\mathrm{a}} \\
(2.65)\end{array}$ & $\begin{array}{l}4.34^{\mathrm{a}} \\
(2.37)\end{array}$ & $\begin{array}{l}4.06^{\mathrm{a}} \\
(2.66)\end{array}$ & $\begin{array}{c}1.48^{\mathrm{b}} \\
(1.79)\end{array}$ & $\begin{array}{l}0.43^{\mathrm{c}} \\
(1.27)\end{array}$ & $\begin{array}{l}0.31^{\mathrm{c}} \\
(1.12)\end{array}$ & $\begin{array}{l}0.27^{\mathrm{c}} \\
(1.02)\end{array}$ & $\begin{array}{l}2.09^{b} \\
(2.11)\end{array}$ & $\begin{array}{l}0.59^{c} \\
(1.42)\end{array}$ & $167.53 * * *$ & .46 \\
\hline $\begin{array}{l}\text { Dating } \\
\text { Expression }\end{array}$ & $\begin{array}{c}3.79^{\mathrm{a}} \\
(2.33)\end{array}$ & $\begin{array}{c}1.94^{\mathrm{b}} \\
(2.19)\end{array}$ & $\begin{array}{c}0.89^{c} \\
(1.56)\end{array}$ & $\begin{array}{l}1.09^{\mathrm{cd}} \\
(1.64)\end{array}$ & $\begin{array}{l}3.70^{\mathrm{a}} \\
(2.60)\end{array}$ & $\begin{array}{l}1.73^{\mathrm{bd}} \\
(2.33)\end{array}$ & $\begin{array}{l}2.33^{b} \\
(2.12)\end{array}$ & $\begin{array}{c}0.44^{\mathrm{e}} \\
(1.16)\end{array}$ & $\begin{array}{l}2.02^{b} \\
(2.61)\end{array}$ & $54.91 * * *$ & .22 \\
\hline $\begin{array}{l}\text { Dating } \\
\text { Identity }\end{array}$ & $\begin{array}{l}4.34^{\mathrm{a}} \\
(2.47)\end{array}$ & $\begin{array}{c}1.45^{\mathrm{b}} \\
(1.93)\end{array}$ & $\begin{array}{l}0.76^{\mathrm{cd}} \\
(1.31)\end{array}$ & $\begin{array}{l}1.01^{b d} \\
(1.71)\end{array}$ & $\begin{array}{l}4.69^{\mathrm{a}} \\
(3.05)\end{array}$ & $\begin{array}{c}1.57^{\mathrm{b}} \\
(2.21)\end{array}$ & $\begin{array}{c}2.85^{\mathrm{e}} \\
(2.52)\end{array}$ & $\begin{array}{l}0.52^{\mathrm{c}} \\
(1.20)\end{array}$ & $\begin{array}{l}0.93^{b c} \\
(1.93)\end{array}$ & $99.81 * * *$ & .34 \\
\hline $\begin{array}{l}\text { Dating } \\
\text { Supervision }\end{array}$ & $\begin{array}{c}6.37^{\mathrm{a}} \\
(2.28)\end{array}$ & $\begin{array}{c}1.95^{\mathrm{b}} \\
(2.04)\end{array}$ & $\begin{array}{l}0.49^{c} \\
(1.08)\end{array}$ & $\begin{array}{c}1.03^{\mathrm{d}} \\
(1.80)\end{array}$ & $\begin{array}{l}5.19^{\mathrm{e}} \\
(2.81)\end{array}$ & $\begin{array}{l}0.82^{\mathrm{cd}} \\
(1.60)\end{array}$ & $\begin{array}{l}0.78^{\mathrm{cd}} \\
(1.32)\end{array}$ & $\begin{array}{c}0.53^{\mathrm{c}} \\
(1.09)\end{array}$ & $\begin{array}{l}0.98^{\mathrm{cd}} \\
(1.91)\end{array}$ & $255.61 * * *$ & .57 \\
\hline Peers & $\begin{array}{c}6.50^{\mathrm{a}} \\
(2.29)\end{array}$ & $\begin{array}{c}2.08^{b} \\
(1.97)\end{array}$ & $\begin{array}{l}0.64^{\mathrm{ef}} \\
(1.14)\end{array}$ & $\begin{array}{l}0.87^{\mathrm{df}} \\
(1.57)\end{array}$ & $\begin{array}{l}4.58^{c} \\
(2.59)\end{array}$ & $\begin{array}{l}0.88^{\mathrm{df}} \\
(1.59)\end{array}$ & $\begin{array}{l}1.27^{\mathrm{d}} \\
(1.6)\end{array}$ & $\begin{array}{c}0.44^{\mathrm{e}} \\
(1.05)\end{array}$ & $\begin{array}{l}0.96^{\mathrm{df}} \\
(1.93)\end{array}$ & $243.96 * * *$ & .56 \\
\hline School & $\begin{array}{l}2.13^{\mathrm{a}} \\
(2.17)\end{array}$ & $\begin{array}{l}3.11^{\mathrm{b}} \\
(2.22)\end{array}$ & $\begin{array}{l}0.21^{\mathrm{c}} \\
(0.84)\end{array}$ & $\begin{array}{l}7.63^{d} \\
(1.97)\end{array}$ & $\begin{array}{l}0.23^{c} \\
(0.92)\end{array}$ & $\begin{array}{l}1.40^{\mathrm{ae}} \\
(1.99)\end{array}$ & $\begin{array}{l}1.79^{\mathrm{ae}} \\
(2.22)\end{array}$ & $\begin{array}{l}1.16^{\mathrm{e}} \\
(1.79)\end{array}$ & $\begin{array}{c}0.58_{\mathrm{f}} \\
(1.52)\end{array}$ & $295.29 * * *$ & .60 \\
\hline Substance Use & $\begin{array}{l}6.28^{\mathrm{a}} \\
(2.20)\end{array}$ & $\begin{array}{l}2.06^{\mathrm{b}} \\
(2.13)\end{array}$ & $\begin{array}{l}0.13^{\mathrm{c}} \\
(0.74)\end{array}$ & $\begin{array}{l}2.41^{\mathrm{b}} \\
(2.1)\end{array}$ & $\begin{array}{l}5.83^{\mathrm{a}} \\
(2.88)\end{array}$ & $\begin{array}{l}0.38^{\mathrm{cd}} \\
(1.23)\end{array}$ & $\begin{array}{l}0.24^{\mathrm{cd}} \\
(0.83)\end{array}$ & $\begin{array}{l}0.53^{\mathrm{d}} \\
(1.24)\end{array}$ & $\begin{array}{l}0.29^{\mathrm{cd}} \\
(1.15)\end{array}$ & $353.85 * * *$ & .65 \\
\hline
\end{tabular}

Note. Means with different superscripts significantly differ at Bonferroni-adjusted $p$ values. *** $p<.001$ 
Table 23

Significant Individual Differences in Parent-Reported Motivations by Behavior Category

\begin{tabular}{lccc}
\hline & $\begin{array}{c}\text { Low Harm } \\
\text { Beliefs }\end{array}$ & $\begin{array}{c}\text { High Harm } \\
\text { Beliefs }\end{array}$ & \\
\cline { 2 - 3 } & $\mathrm{M}(\mathrm{SD})$ & $\mathrm{M}(\mathrm{SD})$ & $T$ - statistic \\
\hline
\end{tabular}

\section{Dating Expression}

Good to Others

Emotional Well-Being

Adolescent's Reputation

Dating Supervision

\begin{tabular}{cccc} 
Adolescent's Reputation & $1.23(1.75)$ & $1.92(2.00)$ & $t(174.21)=-2.76, p<.01$ \\
\hline & Male & Female & \\
\cline { 2 - 3 } & $\mathrm{M}(\mathrm{SD})$ & $\mathrm{M}(\mathrm{SD})$ & $T$ - statistic \\
\hline
\end{tabular}

\section{Dating Expression}

Good to Others

Physical Safety

Adolescent's reputation

\section{Dating Identity}

Need to Know

Physical Safety

\section{Dating Supervision}

\begin{tabular}{lccc} 
Keep out of trouble & $5.51(2.71)$ & 4.61 (2.43) & $t(142.34)=2.35, p=.02$ \\
Physical Safety & $5.69(3.00)$ & $7.54(2.27)$ & $t(124.68)=-4.55, p<.001$ \\
\cline { 1 - 2 } & Younger & Older & $T$ - statistic \\
\cline { 1 - 2 } & M (SD) & M (SD) & . \\
\hline
\end{tabular}

\section{Dating Expression}

Emotional Well-Being

Need to Know

$1.84(2.09)$
$1.75(2.70)$

$2.77(2.33)$

$t(169.87)=-2.86, p<.01$

$1.01(2.07)$

$t(128.38)=2.02, p=.04$

\section{Dating Identity}

Emotional Well-Being

Good to Others
1.84 (2.09)

$.60(1.34)$
$2.76(2.33)$

$t(189.07)=-3.46, p<.01$

$1.01(1.83)$ 
Table 24

Significant Individual Differences in Adolescent-Reported Motivations by Behavior Category

\begin{tabular}{|c|c|c|c|}
\hline & Male & Female & \\
\hline & $\mathrm{M}(\mathrm{SD})$ & $\mathrm{M}(\mathrm{SD})$ & $T$ - statistic \\
\hline \multicolumn{4}{|l|}{ Conventional } \\
\hline Keep out of trouble & $5.38(2.82)$ & $4.23(2.45)$ & $t(137.93)=2.90, p<.01$ \\
\hline Good to Others & $3.08(2.21)$ & $4.66(2.74)$ & $t(179.01)=-4.41, p<.001$ \\
\hline Future Success & $2.84(2.15)$ & $1.27(1.51)$ & $t(116.55)=1.99, p=.049$ \\
\hline \multicolumn{4}{|l|}{ Dating Expression } \\
\hline Keep out of trouble & $4.34(2.48)$ & $3.46(2.19)$ & $t(139.41)=2.51, p=.01$ \\
\hline Good to Others & $1.65(2.02)$ & $.43(0.95)$ & $t(92.97)=4.85, p<.001$ \\
\hline Future Success & $1.55(1.98)$ & $.80(1.32)$ & $t(112.79)=2.89, p<.01$ \\
\hline Physical Safety & $2.76(2.34)$ & $4.28(2.59)$ & $t(166.59)=-4.24, p<.001$ \\
\hline Maintain Relationship & $.91(1.70)$ & $2.24(2.52)$ & $t(191.87)=-4.41, p<.001$ \\
\hline \multicolumn{4}{|l|}{ Dating Identity } \\
\hline Keep out of trouble & $5.01(2.52)$ & $3.93(2.35)$ & $t(145.77)=2.98, p<.001$ \\
\hline Good to Others & $1.76(2.10)$ & $1.27(1.81)$ & $t(94.08)=4.56, p<.001$ \\
\hline Future Success & $1.35(1.69)$ & $.39(.82)$ & $t(100.67)=2.92, p<.01$ \\
\hline Physical Safety & $1.51(2.21)$ & $.70(1.23)$ & $t(161.60)=-5.27, p<.001$ \\
\hline Maintain Relationship & $3.32(2.76)$ & $5.52(2.93)$ & $t(175.70)=-2.32, p=.02$ \\
\hline \multicolumn{4}{|l|}{ Dating Supervision } \\
\hline Keep out of trouble & $6.91(2.39)$ & $6.05(2.17)$ & $t(142.61)=2.52, p=.01$ \\
\hline Good to Others & $1.04(1.48)$ & $.16(.51)$ & $t(83.90)=4.98, p<.001$ \\
\hline Future Success & $1.69(2.18)$ & $.63(1.38)$ & $t(108.82)=3.74, p<.001$ \\
\hline Physical Safety & $3.84(2.65)$ & $6.02(2.58)$ & $t(150.84)=-5.63, p<.001$ \\
\hline Family's Reputation & $.82(1.44)$ & $.34(.77)$ & $t(98.77)=2.65, p=.01$ \\
\hline \multicolumn{4}{|l|}{ Peers } \\
\hline Keep out of trouble & $7.27(2.15)$ & $6.03(2.26)$ & $t(160)=3.83, p<.001$ \\
\hline Future Success & $1.41(2.01)$ & $.54(1.13)$ & $t(101.49)=3.40, p<.01$ \\
\hline Physical Safety & $4.11(2.57)$ & $4.86(2.58)$ & $t(154.73)=-1.99, p=.049$ \\
\hline Maintain Relationship & $.45(1.21)$ & $1.14(1.74)$ & $t(190.49)=-3.29, p<.01$ \\
\hline Emotional Well-Being & $.91(1.34)$ & $1.49(1.71)$ & $t(181.65)=-2.68, p=.01$ \\
\hline \multicolumn{4}{|l|}{ Substance Use } \\
\hline Keep out of trouble & $7.04(1.94)$ & $5.81(2.23)$ & $t(170.80)=4.06, p<.001$ \\
\hline Physical Safety & $4.93(2.88)$ & $6.37(2.75)$ & $t(148.48)=-3.44, p<.01$ \\
\hline
\end{tabular}


Table 25

Standardized Regression Weights and Fit Statistics for Parent-Report Models

\begin{tabular}{|c|c|c|c|c|}
\hline & \multirow[b]{2}{*}{ Beta } & \multicolumn{3}{|c|}{ Fit Indices } \\
\hline & & CMIN/DF & CFI & RMSEA $(90 \% \mathrm{CI})$ \\
\hline Conventional & & 1.53 & .93 & $.05(.03, .08)$ \\
\hline Knowledge $\rightarrow$ Rules & $.23 * *$ & & & \\
\hline Gender $\rightarrow$ Indirect & $-.15 *$ & & & \\
\hline Dating Expression & & 1.90 & .93 & $.07(.05, .09)$ \\
\hline Gender $\rightarrow$ Rules & $.13^{*}$ & & & \\
\hline Knowledge $\rightarrow$ Rules & $.22 * *$ & & & \\
\hline Knowledge $\rightarrow$ Solicitation & $.33 * *$ & & & \\
\hline Adolescent's Reputation $\rightarrow$ Rules & $.17 *$ & & & \\
\hline Adolescent's Reputation $\rightarrow$ Indirect & $.21 *$ & & & \\
\hline Need to Know $\rightarrow$ Rules & $.24 * *$ & & & \\
\hline Need to Know $\rightarrow$ Solicitation & $.27 * *$ & & & \\
\hline Need to Know $\rightarrow$ Indirect & $.32 * *$ & & & \\
\hline Physical Safety $\rightarrow$ Solicitation & $.22 *$ & & & \\
\hline Physical Safety $\rightarrow$ Indirect & $.20^{*}$ & & & \\
\hline Future Success $\rightarrow$ Rules & $.22 *$ & & & \\
\hline Future Success $\rightarrow$ Solicitation & $.16^{*}$ & & & \\
\hline Future Success $\rightarrow$ Indirect & $.33 * *$ & & & \\
\hline Dating Identity & & 1.75 & .91 & $.06(.02, .10)$ \\
\hline Gender $\rightarrow$ Rules & $.24 * *$ & & & \\
\hline Knowledge $\rightarrow$ Rules & $.18^{*}$ & & & \\
\hline Adolescent's Reputation $\rightarrow$ Rules & $.13^{*}$ & & & \\
\hline Future Success $\rightarrow$ Indirect & $.15^{*}$ & & & \\
\hline Future Success $\rightarrow$ Rules & $.20 * *$ & & & \\
\hline Dating Supervision & & 2.65 & .86 & $.09(.07, .12)$ \\
\hline Peers & & 1.17 & .98 & $.03(.00, .06)$ \\
\hline Age $\rightarrow$ Solicitation & $-.13 *$ & & & \\
\hline Knowledge $\rightarrow$ Rules & $.20 *$ & & & \\
\hline Knowledge $\rightarrow$ Solicitation & $.29 * *$ & & & \\
\hline Knowledge $\rightarrow$ covert & $-.16^{*}$ & & & \\
\hline Emotional Well-Being $\rightarrow$ Solicitation & $.17^{*}$ & & & \\
\hline Emotional Well-Being $\rightarrow$ Covert & $-.20 *$ & & & \\
\hline Keep out of Trouble $\rightarrow$ Solicitation & $.26 *$ & & & \\
\hline Keep out of Trouble $\rightarrow$ Indirect & $.24 *$ & & & \\
\hline Maintain Relationship $\rightarrow$ Solicitation & $.19 *$ & & & \\
\hline School & & 1.92 & .90 & $.07(.04, .09)$ \\
\hline Knowledge $\rightarrow$ Rules & $.17 *$ & & & \\
\hline
\end{tabular}


Knowledge $\rightarrow$ Solicitation $\quad .29 * *$

Emotional Well-Being $\rightarrow$ Solicitation $\quad .19^{*}$

Emotional Well-Being $\rightarrow$ Indirect $\quad .19^{*}$

Emotional Well-Being $\rightarrow$ Covert $\quad-.20 *$

Keep out of Trouble $\rightarrow$ Solicitation $\quad .28 * *$

Maintain Relationship $\rightarrow$ Rules $\quad-.30 * *$

Maintain Relationship $\rightarrow$ Solicitation $\quad .20 *$

Need to Know $\rightarrow$ Solicitation .19*

\section{Substance Use}

Maintain Relationship $\rightarrow$ Rules

Need to Know $\rightarrow$ Solicitation

Need to Know $\rightarrow$ Indirect
$.72 \quad 1.00 \quad .00(.00, .08)$

$-.16^{*}$

$.16^{*}$

$.21 * *$

Note. $* p<.05, * * p<.01$ 
Table 26

Standardized Regression Weights and Fit Statistics for Adolescent-Report Models

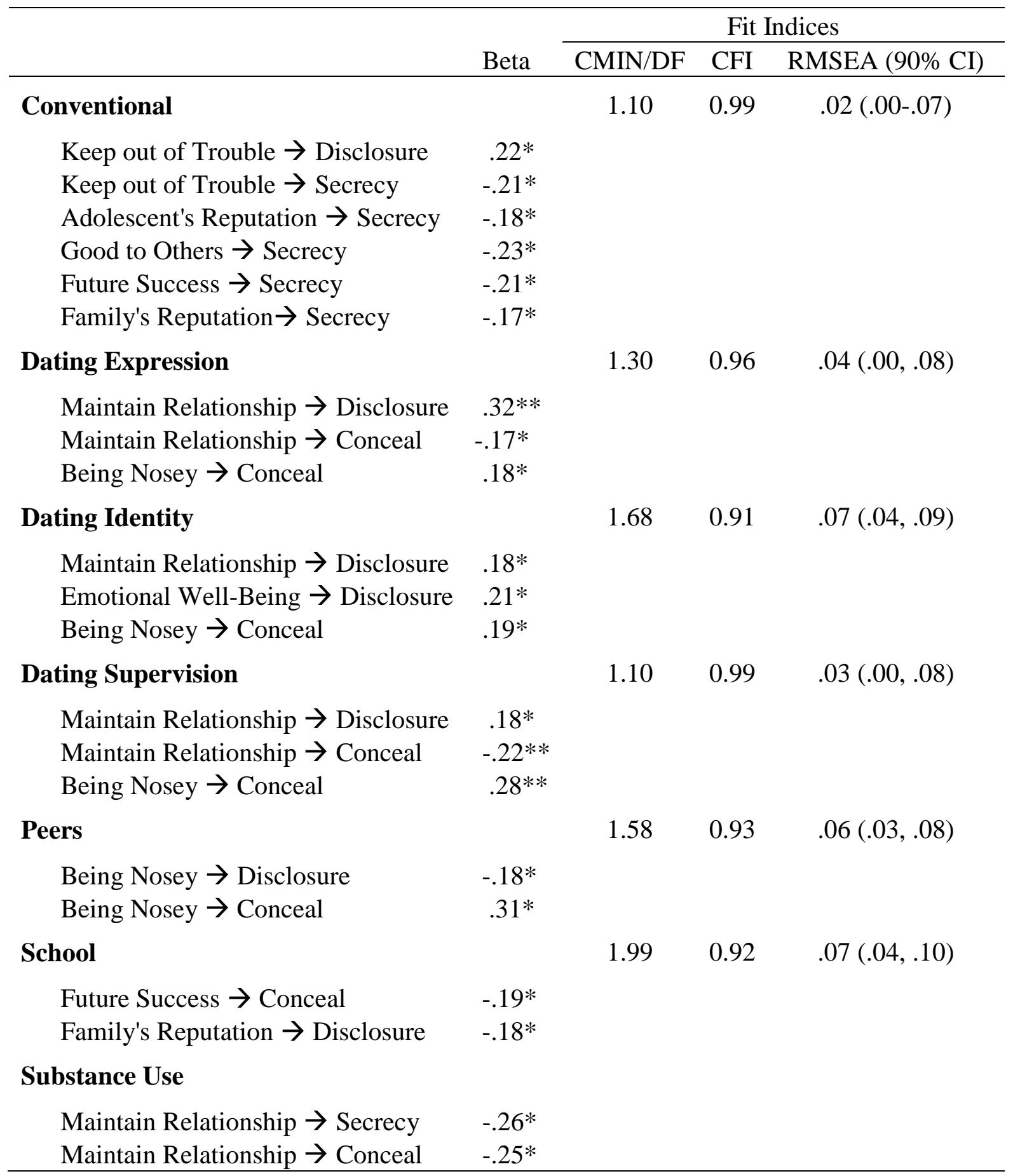

Note. No fit indices are provided for Substance Use due to regression analyses, ${ }^{*} p<.05$, $* * p<.01$ 
Table 27

Bivariate Correlations between Parent-Reported Knowledge-Seeking Motivations and Warmth and Control

\begin{tabular}{|c|c|c|c|c|c|c|c|c|c|c|c|c|c|c|}
\hline & \multicolumn{2}{|c|}{ Conventional } & \multicolumn{2}{|c|}{$\begin{array}{c}\text { Dating } \\
\text { Expression }\end{array}$} & \multicolumn{2}{|c|}{$\begin{array}{l}\text { Dating } \\
\text { Identity }\end{array}$} & \multicolumn{2}{|c|}{$\begin{array}{c}\text { Dating } \\
\text { Supervision }\end{array}$} & \multicolumn{2}{|c|}{ Peers } & \multicolumn{2}{|c|}{ School } & \multicolumn{2}{|c|}{ Substance Use } \\
\hline & Warmth & Control & Warmth & Control & Warmth & Control & Warmth & Control & Warmth & Control & Warmth & Control & Warmth & Control \\
\hline Physical Safety & .11 & .03 & $.16 *$ & .00 & $.21 * *$ & .02 & $.18 *$ & -.03 & -.03 & .10 & .08 & .11 & .08 & -.02 \\
\hline $\begin{array}{l}\text { Keep out of } \\
\text { Trouble }\end{array}$ & -.04 & -.01 & .03 & .06 & -.07 & .06 & -.01 & .08 & .02 & .00 & -.06 & .06 & .02 & .02 \\
\hline Future Success & -.04 & .10 & .00 & -.02 & .01 & $.15^{*}$ & -.03 & .04 & -.08 & .07 & .05 & .03 & $-.15^{*}$ & .05 \\
\hline $\begin{array}{l}\text { Emotional } \\
\text { Well-Being }\end{array}$ & .02 & .06 & -.08 & -.04 & .04 & -.12 & .09 & -.13 & .07 & $-.17 *$ & $.16^{*}$ & -.01 & -.06 & -.06 \\
\hline $\begin{array}{l}\text { Maintain } \\
\text { Relationship }\end{array}$ & .11 & -.07 & .01 & -.10 & .11 & -.10 & .04 & -.07 & .03 & .02 & .12 & $-.16 *$ & .04 & -.05 \\
\hline Good to Others & .01 & -.07 & $-.23 * *$ & .00 & $-.23 * *$ & -.08 & $-.15 *$ & -.07 & .13 & -.01 & $-.15 *$ & .00 & -.03 & .08 \\
\hline $\begin{array}{l}\text { Adolescent's } \\
\text { Reputation }\end{array}$ & .08 & -.01 & .04 & .02 & -.10 & .05 & -.06 & $.14^{*}$ & -.04 & -.08 & -.06 & -.02 & .11 & -.04 \\
\hline $\begin{array}{l}\text { Family's } \\
\text { Reputation }\end{array}$ & -.14 & -.01 & .00 & .01 & -.10 & .02 & $-.22 * *$ & .00 & -.07 & .02 & -.07 & .05 & .01 & .08 \\
\hline Need to Know & .01 & .13 & .07 & .14 & -.07 & .10 & .01 & .03 & -.02 & .08 & -.05 & .09 & .04 & .10 \\
\hline
\end{tabular}


Table 28

Bivariate Correlations between Adolescent-Reported Parental Knowledge-Seeking Motivations and Warmth and Control

\begin{tabular}{|c|c|c|c|c|c|c|c|c|c|c|c|c|c|c|}
\hline & \multicolumn{2}{|c|}{ Conventional } & \multicolumn{2}{|c|}{$\begin{array}{c}\text { Dating } \\
\text { Expression }\end{array}$} & \multicolumn{2}{|c|}{$\begin{array}{l}\text { Dating } \\
\text { Identity }\end{array}$} & \multicolumn{2}{|c|}{$\begin{array}{c}\text { Dating } \\
\text { Supervision }\end{array}$} & \multicolumn{2}{|c|}{ Peers } & \multicolumn{2}{|c|}{ School } & \multicolumn{2}{|c|}{ Substance Use } \\
\hline & Warmth & Control & Warmth & Control & Warmth & Control & Warmth & Control & Warmth & Control & Warmth & Control & Warmth & Control \\
\hline Physical Safety & .02 & .01 & $.29 * *$ & $-.25 * *$ & $.15^{*}$ & $-.15 *$ & $.27 * *$ & $-.30 * *$ & $.26 * *$ & $-.16^{*}$ & -.06 & .08 & $.20 * *$ & $-.20 * *$ \\
\hline $\begin{array}{l}\text { Keep out of } \\
\text { Trouble }\end{array}$ & -.01 & .11 & -.09 & .13 & -.14 & .07 & -.14 & $.14^{*}$ & $-.15 *$ & .03 & -.10 & .08 & $-.18 *$ & .13 \\
\hline Future Success & -.01 & $-.15^{*}$ & -.01 & -.02 & .00 & -.04 & .05 & -.04 & -.09 & -.05 & .08 & $-.17 *$ & .10 & -.10 \\
\hline $\begin{array}{l}\text { Emotional } \\
\text { Well-Being }\end{array}$ & .06 & -.04 & $.24 * *$ & $-.15 *$ & $.22 * *$ & $-.17 *$ & $.19 * *$ & -.13 & $.23 * *$ & -.11 & $.18 *$ & -.12 & .05 & -.09 \\
\hline $\begin{array}{l}\text { Maintain } \\
\text { Relationship }\end{array}$ & $.14^{*}$ & -.07 & $.34 * *$ & $-.28 * *$ & $.29 * *$ & $-.18 *$ & $.18 *$ & $-.20 * *$ & $.26^{* *}$ & -.12 & $.30 * *$ & $-.23 * *$ & $.17 *$ & -.05 \\
\hline Good to Others & $.21 * *$ & $-.20 * *$ & -.12 & .07 & $-.17 *$ & .10 & -.05 & .09 & .09 & -.02 & -.06 & .00 & .02 & -.02 \\
\hline $\begin{array}{l}\text { Adolescent's } \\
\text { Reputation }\end{array}$ & -.02 & .06 & $-.21 * *$ & $.18 *$ & $-.16^{*}$ & $.19 * *$ & -.13 & $.21 * *$ & $-.15 *$ & .05 & -.13 & $.17 *$ & $-.22 * *$ & $.16^{*}$ \\
\hline $\begin{array}{l}\text { Family's } \\
\text { Reputation }\end{array}$ & $-.19 * *$ & .08 & -.12 & .06 & $-.22 * *$ & .13 & $-.23 * *$ & .07 & $-.24 * *$ & .12 & $-.17 *$ & $.14^{*}$ & $-.15^{*}$ & .05 \\
\hline Being Nosey & $-.19 * *$ & $.19 * *$ & $-.30 * *$ & $.21 * *$ & $-.20 * *$ & $.20 * *$ & $-.20 * *$ & $.18^{*}$ & $-.25 * *$ & $.23 * *$ & $-.14 *$ & .05 & -.08 & .11 \\
\hline
\end{tabular}

Note. $* p=.05, * * p<.01$ 


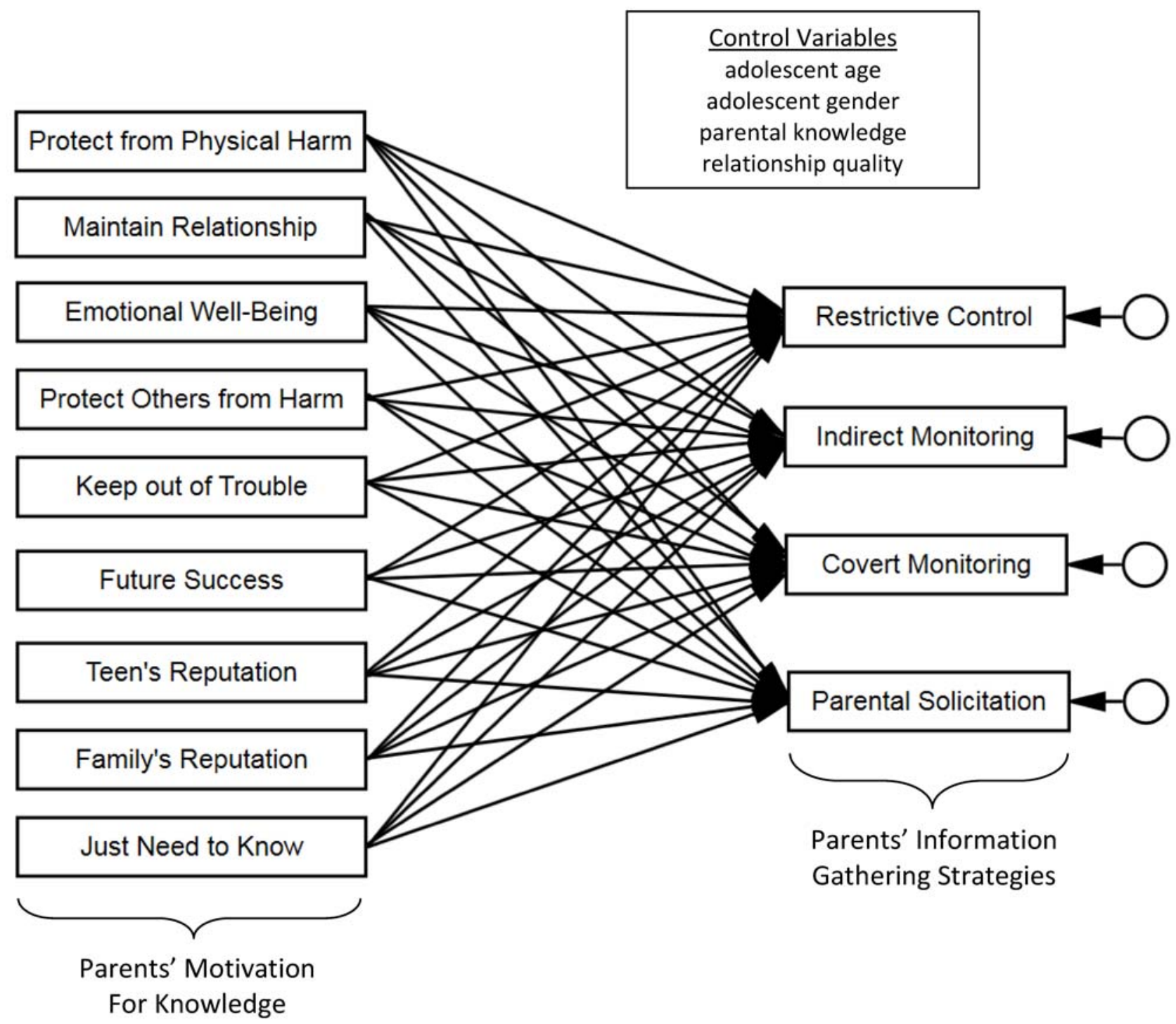

Figure 1. Proposed model predicting parental information gathering strategies from parental knowledge-seeking motivations. 


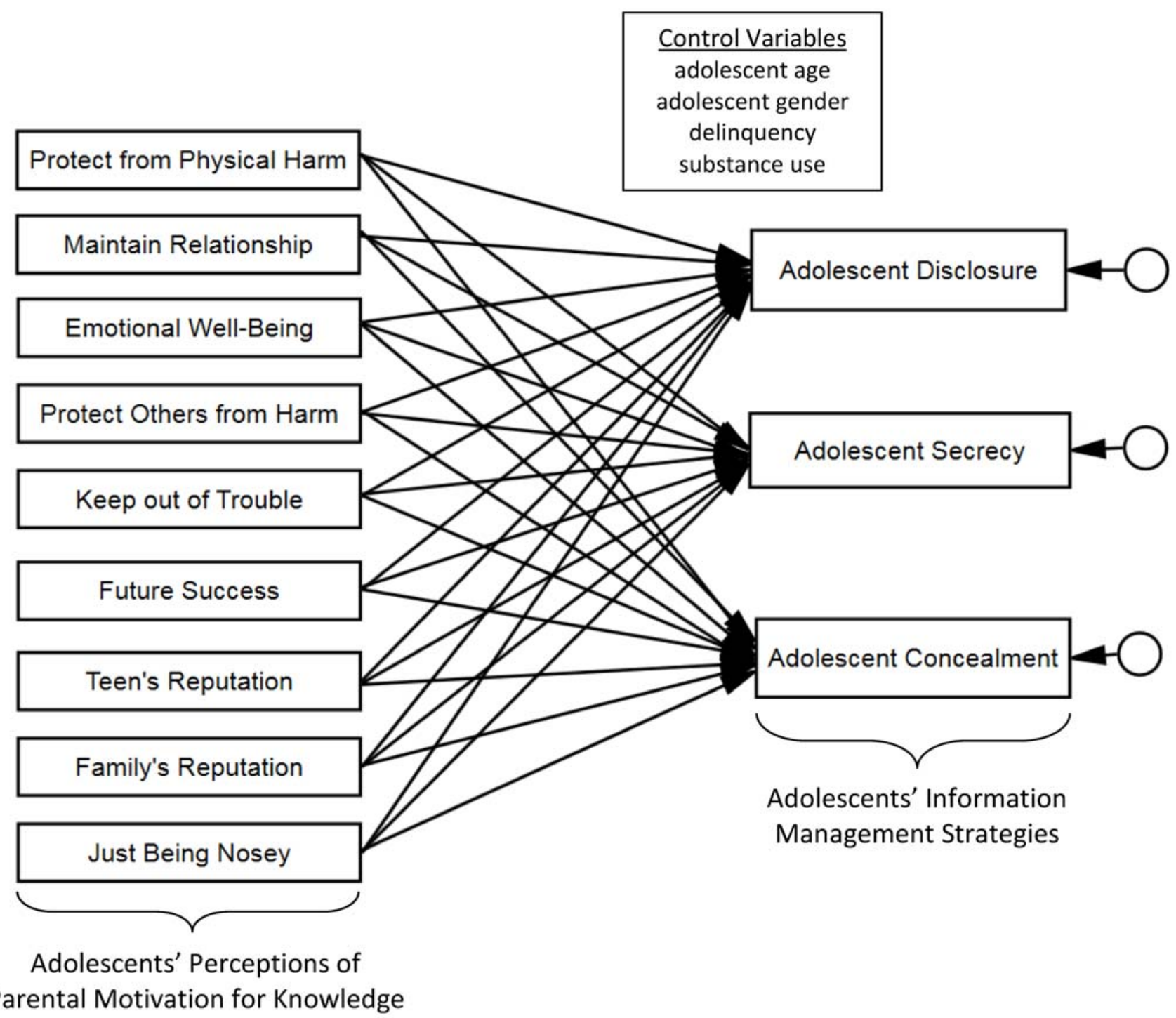

Figure 2. Proposed model predicting adolescent information management strategies from adolescent-reported parental knowledge-seeking motivations. 


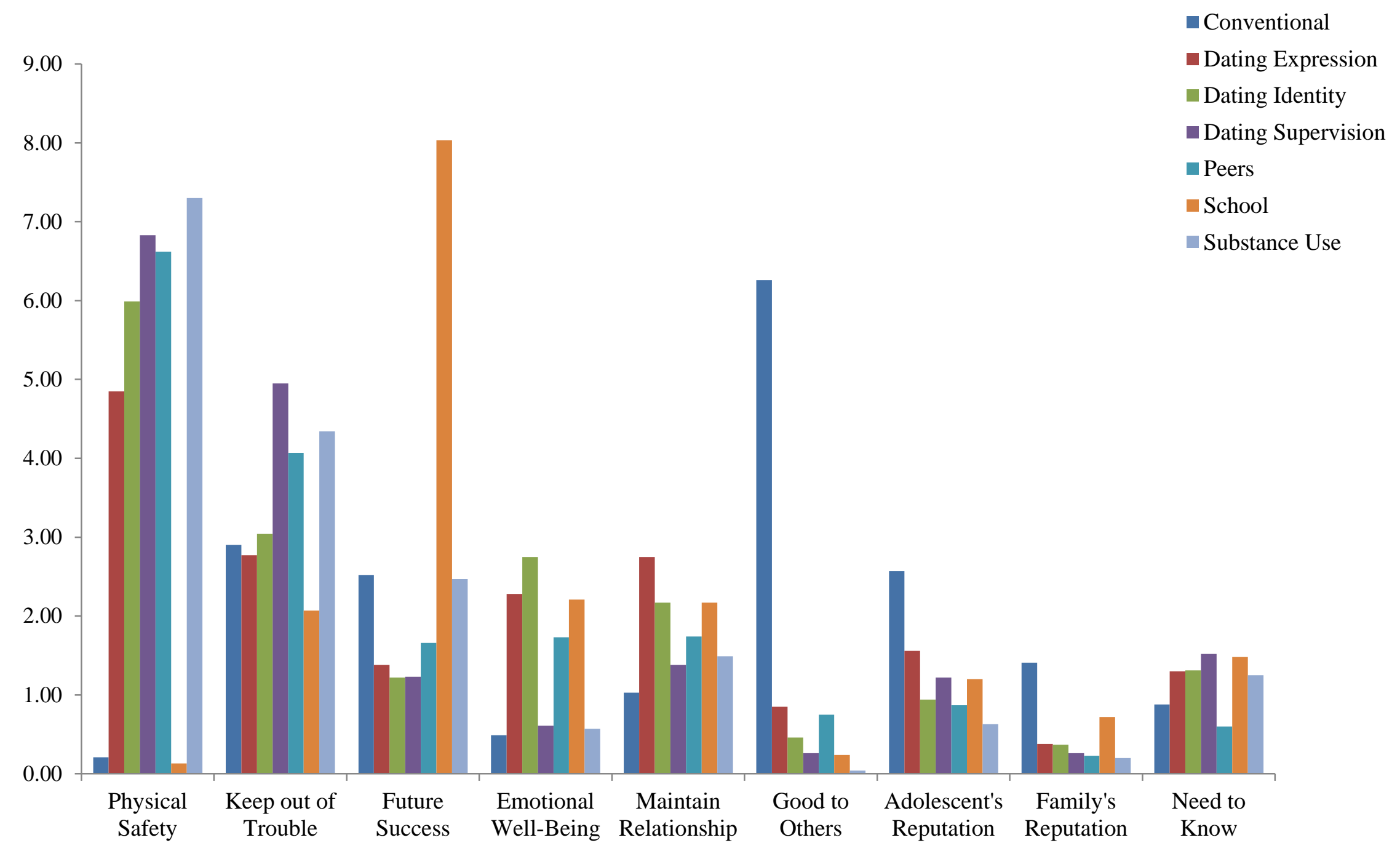

Figure 3. Parent-reported knowledge-seeking motivations by behavior category. 


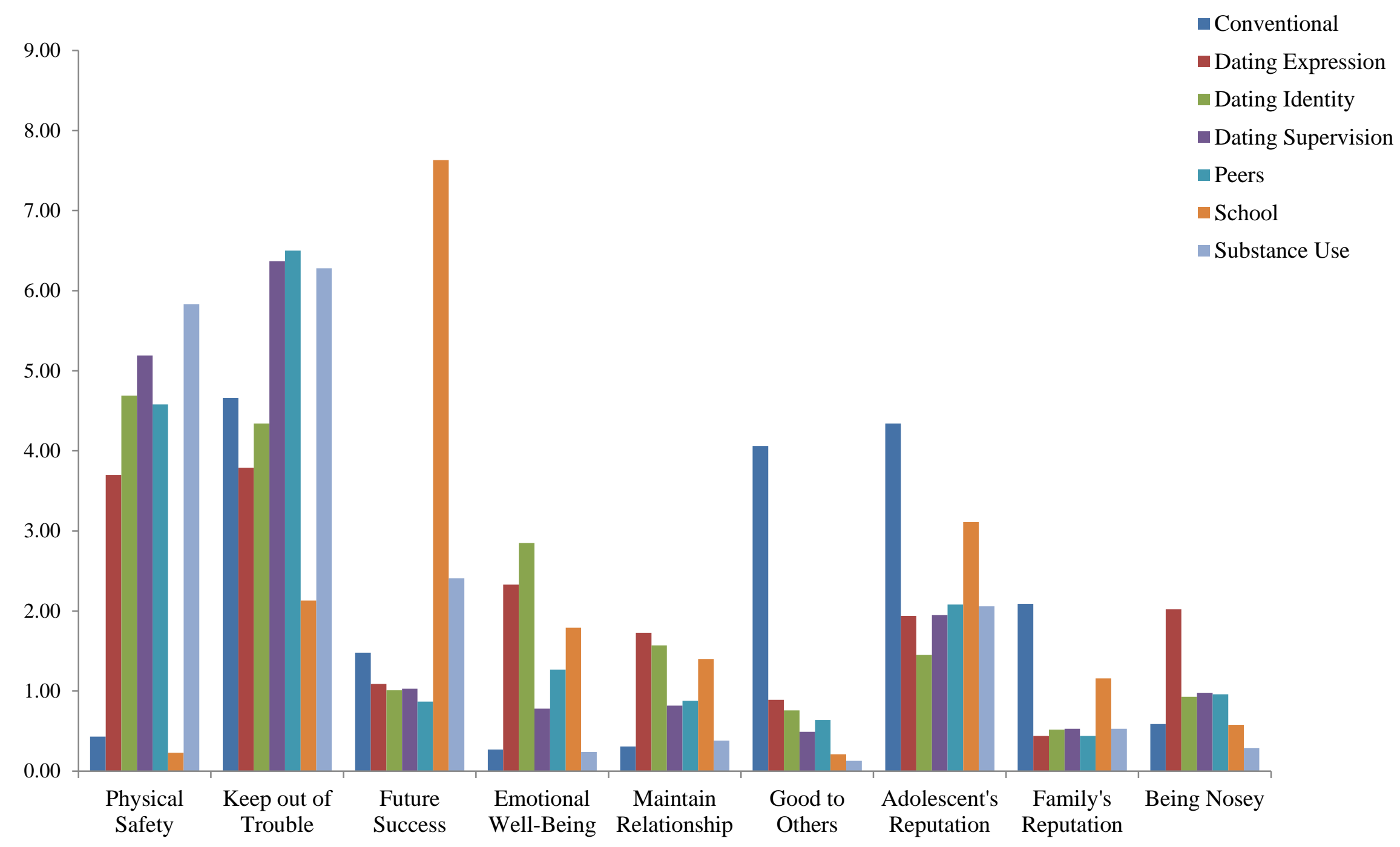

Figure 4. Adolescent-reported parental knowledge-seeking motivations by behavior category. 
Appendix A

\section{Parent-report of Parental Motivation for Knowledge}

\section{Directions Page}

Parents have different reasons for wanting to know about various things in their teenagers' lives. Regardless of whether you already know a lot about your teen's life, we are interested in the reasons you would want to know about different issues in your own teen's life.

In the next task, you will be presented with an issue relevant to teens' lives, followed by a list of reasons why parents may want to know about the issue.

You will then be asked to rank the top 3 reasons you would want to know about each issue.

\section{Sample Item}

\section{Regardless of whether you already know about the issue presented below:}

Please rank the top three reasons that you would want to know about the issue.

- Place a 1 next the reason that is most important

- Place a 2 next to the reason that is second most important

- Place a 3 next to the reason that is the third most important.

- Leave all other reasons blank.

1. I want to know the type of language my teen uses because

I want my teen to be happy.

I want my teen to be physically safe.

I want to keep my teen out of trouble.

I want my teen to be good to others.

I want to have a good relationship with my teen.

I want my teen to do well in the future.

I want my teen to represent our family well.

I want my teen to have a good reputation.

I just need to know. 


\section{Appendix B}

\section{Adolescent-report of Parental Motivations for Knowledge}

\section{Directions}

\section{Please answer the next set of questions based on your mother/father.}

Parents have different reasons for wanting to know about various things in their teenagers' lives.

Regardless of whether your parent already knows a lot about your life, we are interested in why your parent would want to know about different issues in your life.

For each issue, please rank the top three reasons your parent would want to know:

- Place a 1 next the reason that is most important

- Place a 2 next to the reason that is second most important

- Place a 3 next to the reason that is the third most important.

- Leave all other reasons blank.

\section{EXAMPLE:}

1. My parent wants to know what color pens I use because my parent

$$
\begin{aligned}
& \text { 1 wants to keep me out of trouble. } \\
& \text { wants me to have a good reputation. } \\
& \text { w wants me to be good to others. } \\
& \mathbf{2} \text { wants me to do well in the future. } \\
& \text { wants me to be physically safe. } \\
& \text { wants me to be happy. } \\
& \text { wants me to represent our family well. } \\
& \text { is just being nosey. }
\end{aligned}
$$




\section{Sample Item}

Regardless of whether your parent already knows, please rank the top three reasons that your parent would want to know about the issue.

My parent wants to know if I am finishing homework and assignments because my parent

wants to keep me out of trouble.

wants me to have a good reputation.

wants me to be good to others.

wants me to do well in the future.

wants me to be physically safe.

wants to have a good relationship with me.

wants me to be happy.

wants me to represent our family well. is just being nosey. 


\section{Appendix C}

\section{Parent-Report Measures}

\section{Demographics}

1. What gender are you? $\bigcirc$ Male $\bigcirc$ Female

2. What is your relationship to the adolescent in the study?
Birth Mother
$\bigcirc$ Birth Father
Grandparent
Step Mother
Step Father
$\bigcirc$ Other relative (e.g., aunt, uncle)
$\bigcirc$ Adoptive Mother
Adoptive Father
Other relative (please specify)
$\bigcirc$ Other guardian (please specify)

3. How old is your teen? (years) What is your teen's birthday?

4. What is your teen's gender?

5. How many children do you have?

What is your teen's birth order? $\left(1^{\text {st }}, 2^{\text {nd }}, 3^{\text {rd }}\right)$

6. What is your present marital status?
Never Married
$\bigcirc$ Separated
$\bigcirc$ Married or civil union
$\bigcirc$ Widowed
$\bigcirc$ Divorced
$\bigcirc$ Living with a romantic partner

7. How old are you? (years) What is your birthday?

8. What is your ethnicity?
$\bigcirc$ Caucasian/White
$\bigcirc$ Asian-American/Pacific Islander
$\bigcirc$ African-American/Black
$\bigcirc$ Native American
Hispanic/Latino
$\bigcirc$ Other (describe)

9. What is the highest level of education you have completed?
Completed $8^{\text {th }}$ grade
Completed college
Completed high school
Business or Technical School
Completed some college
$\bigcirc$ Graduate degree (doctor, lawyer, $\mathrm{PhD}$ )

10. Are you currently employed? $\bigcirc$ Yes, full-time $\bigcirc$ Yes, part-time $\bigcirc$ No

11. What is your occupation?

12. Which best describes your yearly, total household income?
$\$ 11,999$ or less
○ $\$ 75,000$ to 99,999
O $\$ 12,000$ to 24,999
○ $\$ 100,000$ to 149,999
○ $\$ 25,000$ to 49,999
O $\$ 150,000$ or above
$\bigcirc \$ 50,000$ to 74,999 


\begin{tabular}{|c|c|c|c|c|c|}
\hline How much do you know about... & $\begin{array}{l}\text { Don't } \\
\text { Know }\end{array}$ & & & & $\begin{array}{l}\text { Know } \\
\text { A Lot }\end{array}$ \\
\hline Who your child has as friends & 1 & 2 & 3 & 4 & 5 \\
\hline How your child is doing on schoolwork or tests & 1 & 2 & 3 & 4 & 5 \\
\hline When your child has an exam or paper due at school & 1 & 2 & 3 & 4 & 5 \\
\hline How your child does in different subjects at school & 1 & 2 & 3 & 4 & 5 \\
\hline Where your child goes when he/she is out with friends & 1 & 2 & 3 & 4 & 5 \\
\hline Who your child is dating & 1 & 2 & 3 & 4 & 5 \\
\hline Whether your child is drinking alcohol & 1 & 2 & 3 & 4 & 5 \\
\hline Whether your child is doing drugs & 1 & 2 & 3 & 4 & 5 \\
\hline Who your child is hanging out with in his/her free time & 1 & 2 & 3 & 4 & 5 \\
\hline Whether your child is having sex & 1 & 2 & 3 & 4 & 5 \\
\hline Who your child's boyfriend/girlfriend's parents are & 1 & 2 & 3 & 4 & 5 \\
\hline $\begin{array}{l}\text { Whether your child is home alone with his/her } \\
\text { boyfriend/girlfriend }\end{array}$ & 1 & 2 & 3 & 4 & 5 \\
\hline Whether your child talks back or is rude to teachers & 1 & 2 & 3 & 4 & 5 \\
\hline Where your child goes with his/her boyfriend/girlfriend & 1 & 2 & 3 & 4 & 5 \\
\hline $\begin{array}{l}\text { Whether your child is in unsupervised areas (e.g., bedroom) with } \\
\text { boyfriend/girlfriend }\end{array}$ & 1 & 2 & 3 & 4 & 5 \\
\hline Whether your child smokes cigarettes & 1 & 2 & 3 & 4 & 5 \\
\hline Whether your child is using bad manners away from home & 1 & 2 & 3 & 4 & 5 \\
\hline The type of language your child uses when away from home & 1 & 2 & 3 & 4 & 5 \\
\hline Whether your child kisses his/her boyfriend/girlfriend & 1 & 2 & 3 & 4 & 5 \\
\hline Whether your child holds hands with his/her boyfriend/girlfriend & 1 & 2 & 3 & 4 & 5 \\
\hline The kind of person your child's boyfriend/girlfriend is & 1 & 2 & 3 & 4 & 5 \\
\hline
\end{tabular}




\section{Parental Knowledge}

\section{Parental Restrictive Control}

\begin{tabular}{|c|c|c|c|c|c|}
\hline $\begin{array}{l}\text { Please rate the extent to which your family has rules for each } \\
\text { issue listed below: }\end{array}$ & $\begin{array}{l}\text { No } \\
\text { clear } \\
\text { rules }\end{array}$ & & & & $\begin{array}{l}\text { Firm } \\
\text { clear } \\
\text { rules }\end{array}$ \\
\hline Who your child has as friends & 1 & 2 & 3 & 4 & 5 \\
\hline How your child is doing on schoolwork or tests & 1 & 2 & 3 & 4 & 5 \\
\hline How your child studies for exams or papers due at school & 1 & 2 & 3 & 4 & 5 \\
\hline How your child does in different subjects at school & 1 & 2 & 3 & 4 & 5 \\
\hline Where your child goes when he/she is out with friends & 1 & 2 & 3 & 4 & 5 \\
\hline Who your child is dating & 1 & 2 & 3 & 4 & 5 \\
\hline Whether your child drinks alcohol & 1 & 2 & 3 & 4 & 5 \\
\hline Whether your child does drugs & 1 & 2 & 3 & 4 & 5 \\
\hline Who your child hangs out with in his/her free time & 1 & 2 & 3 & 4 & 5 \\
\hline Whether your child is having sex & 1 & 2 & 3 & 4 & 5 \\
\hline Who your child's boyfriend/girlfriend's parents are & 1 & 2 & 3 & 4 & 5 \\
\hline Whether your child is home alone with his/her boyfriend/girlfriend & 1 & 2 & 3 & 4 & 5 \\
\hline Whether your child talks back or is rude to teachers & 1 & 2 & 3 & 4 & 5 \\
\hline Where your child goes with his/her boyfriend/girlfriend & 1 & 2 & 3 & 4 & 5 \\
\hline $\begin{array}{l}\text { Whether your child is in unsupervised areas (e.g., bedroom) with } \\
\text { boyfriend/girlfriend }\end{array}$ & 1 & 2 & 3 & 4 & 5 \\
\hline Whether your child smokes cigarettes & 1 & 2 & 3 & 4 & 5 \\
\hline Whether your child is using bad manners away from home & 1 & 2 & 3 & 4 & 5 \\
\hline The type of language your child uses when away from home & 1 & 2 & 3 & 4 & 5 \\
\hline Whether your child kisses his/her boyfriend/girlfriend & 1 & 2 & 3 & 4 & 5 \\
\hline
\end{tabular}




\begin{tabular}{|llllll|}
\hline Whether your child holds hands with his/her boyfriend/girlfriend & 1 & 2 & 3 & 4 & 5 \\
\hline The kind of person your child's boyfriend/girlfriend is & 1 & 2 & 3 & 4 & 5
\end{tabular}

\section{Parental Solicitation}

\begin{tabular}{|c|c|c|c|c|c|}
\hline $\begin{array}{l}\text { How often to you talk to your child or ask about the } \\
\text { following issues? }\end{array}$ & $\begin{array}{l}\text { Almost } \\
\text { Never }\end{array}$ & Rarely & Sometimes & Often & $\begin{array}{l}\text { Almost } \\
\text { Always }\end{array}$ \\
\hline Who your child has as friends & 1 & 2 & 3 & 4 & 5 \\
\hline How your child is doing on schoolwork or tests & 1 & 2 & 3 & 4 & 5 \\
\hline When your child has an exam or paper due at school & 1 & 2 & 3 & 4 & 5 \\
\hline How your child does in different subjects at school & 1 & 2 & 3 & 4 & 5 \\
\hline Where your child goes when he/she is out with friends & 1 & 2 & 3 & 4 & 5 \\
\hline Who your child is dating & 1 & 2 & 3 & 4 & 5 \\
\hline Whether your child drinks alcohol & 1 & 2 & 3 & 4 & 5 \\
\hline Whether your child does drugs & 1 & 2 & 3 & 4 & 5 \\
\hline Who your child hangs out with in his/her free time & 1 & 2 & 3 & 4 & 5 \\
\hline Whether your child is having sex & 1 & 2 & 3 & 4 & 5 \\
\hline Who your child's boyfriend/girlfriend's parents are & 1 & 2 & 3 & 4 & 5 \\
\hline $\begin{array}{l}\text { Whether your child is home alone with his/her } \\
\text { boyfriend/girlfriend }\end{array}$ & 1 & 2 & 3 & 4 & 5 \\
\hline Whether your child talks back or is rude to teachers & 1 & 2 & 3 & 4 & 5 \\
\hline Where your child goes with his/her boyfriend/girlfriend & 1 & 2 & 3 & 4 & 5 \\
\hline $\begin{array}{l}\text { Whether your child is in unsupervised areas (e.g., bedroom) } \\
\text { with boyfriend/girlfriend }\end{array}$ & 1 & 2 & 3 & 4 & 5 \\
\hline Whether your child smokes cigarettes & 1 & 2 & 3 & 4 & 5 \\
\hline Whether your child is using bad manners away from home & 1 & 2 & 3 & 4 & 5 \\
\hline
\end{tabular}




\begin{tabular}{|c|c|c|c|c|c|}
\hline The type of language your child uses when away from home & 1 & 2 & 3 & 4 & 5 \\
\hline Whether your child kisses his/her boyfriend/girlfriend & 1 & 2 & 3 & 4 & 5 \\
\hline $\begin{array}{l}\text { Whether your child holds hands with his/her } \\
\text { boyfriend/girlfriend }\end{array}$ & 1 & 2 & 3 & 4 & 5 \\
\hline The kind of person your child's boyfriend/girlfriend is & 1 & 2 & 3 & 4 & 5 \\
\hline
\end{tabular}

\section{Indirect Strategies}

\begin{tabular}{|c|c|c|c|c|c|}
\hline $\begin{array}{l}\text { How often do you ask or talk to other people, such } \\
\text { as your child's teachers, friends, or friends' parents } \\
\text { about... }\end{array}$ & $\begin{array}{c}\text { Almost } \\
\text { Never }\end{array}$ & Rarely & Sometimes & Often & $\begin{array}{l}\text { Almost } \\
\text { Always }\end{array}$ \\
\hline Who your child has as friends & 1 & 2 & 3 & 4 & 5 \\
\hline How your child is doing on schoolwork or tests & 1 & 2 & 3 & 4 & 5 \\
\hline When your child has an exam or paper due at school & 1 & 2 & 3 & 4 & 5 \\
\hline How your child does in different subjects at school & 1 & 2 & 3 & 4 & 5 \\
\hline Where your child goes when he/she is out with friends & 1 & 2 & 3 & 4 & 5 \\
\hline Who your child is dating & 1 & 2 & 3 & 4 & 5 \\
\hline Whether your child drinks alcohol & 1 & 2 & 3 & 4 & 5 \\
\hline Whether your child does drugs & 1 & 2 & 3 & 4 & 5 \\
\hline Who your child hangs out with in his/her free time & 1 & 2 & 3 & 4 & 5 \\
\hline Whether your child is having sex & 1 & 2 & 3 & 4 & 5 \\
\hline Who your child's boyfriend/girlfriend's parents are & 1 & 2 & 3 & 4 & 5 \\
\hline $\begin{array}{l}\text { Whether your child is home alone with his/her } \\
\text { boyfriend/girlfriend }\end{array}$ & 1 & 2 & 3 & 4 & 5 \\
\hline Whether your child talks back or is rude to teachers & 1 & 2 & 3 & 4 & 5 \\
\hline Where your child goes with his/her boyfriend/girlfriend & 1 & 2 & 3 & 4 & 5 \\
\hline
\end{tabular}




\begin{tabular}{|c|c|c|c|c|c|}
\hline $\begin{array}{l}\text { Whether your child is in unsupervised areas (e.g., } \\
\text { bedroom) with boyfriend/girlfriend }\end{array}$ & 1 & 2 & 3 & 4 & 5 \\
\hline Whether your child smokes cigarettes & 1 & 2 & 3 & 4 & 5 \\
\hline $\begin{array}{l}\text { Whether your child is using bad manners away from } \\
\text { home }\end{array}$ & 1 & 2 & 3 & 4 & 5 \\
\hline $\begin{array}{l}\text { The type of language your child uses when away from } \\
\text { home }\end{array}$ & 1 & 2 & 3 & 4 & 5 \\
\hline Whether your child kisses his/her boyfriend/girlfriend & 1 & 2 & 3 & 4 & 5 \\
\hline $\begin{array}{l}\text { Whether your child holds hands with his/her } \\
\text { boyfriend/girlfriend }\end{array}$ & 1 & 2 & 3 & 4 & 5 \\
\hline The kind of person your child's boyfriend/girlfriend is & 1 & 2 & 3 & 4 & 5 \\
\hline
\end{tabular}

\section{Parental Covert Monitoring}

\begin{tabular}{|lcccccc|}
\hline How often do you... & $\begin{array}{c}\text { Almost } \\
\text { Never }\end{array}$ & Rarely & Sometimes & Often & $\begin{array}{c}\text { Almost } \\
\text { Always }\end{array}$ \\
\hline Listen in on your teen's phone conversations & 1 & 2 & 3 & 4 & 5 \\
\hline $\begin{array}{l}\text { Review your phone statements or call history to see } \\
\text { what calls your teen has made }\end{array}$ & 1 & 2 & 3 & 4 & 5 \\
\hline Look through your teen's drawers or closets & 1 & 2 & 3 & 4 & 5 \\
\hline Read your teen's personal notes or diary/journal & 1 & 2 & 3 & 4 & 5 \\
\hline $\begin{array}{l}\text { Check the number of miles your teen has driven in the } \\
\text { car }\end{array}$ & 1 & 2 & 3 & 4 & 5 \\
\hline $\begin{array}{l}\text { Use a tracking app on your mobile device to check } \\
\text { your teen's whereabouts }\end{array}$ & 1 & 2 & 3 & 4 & 5 \\
\hline Read your teen's comments on social networking sites & 1 & 2 & 3 & 4 & 5 \\
\hline Sign into your teen's social networking sites & 1 & 2 & 3 & 4 & 5 \\
\hline Track your teen using the GPS technology in the car & 1 & 2 & 3 & 4 & 5 \\
\hline $\begin{array}{l}\text { Read your teen's online communication (such as e- } \\
\text { mails or IM conversations) }\end{array}$ & 1 & 2 & 3 & 4 & 5 \\
\hline
\end{tabular}




\begin{tabular}{|c|c|c|c|c|c|}
\hline Go through your teen's personal computer & 1 & 2 & 3 & 4 & 5 \\
\hline $\begin{array}{l}\text { Check where your teen goes using GPS technology on } \\
\text { his/her cell-phone }\end{array}$ & 1 & 2 & 3 & 4 & 5 \\
\hline $\begin{array}{l}\text { Eavesdrop on conversations your teen has when } \\
\text { friends are at your house }\end{array}$ & 1 & 2 & 3 & 4 & 5 \\
\hline $\begin{array}{l}\text { Read messages on your teen's cell-phone or mobile } \\
\text { device }\end{array}$ & 1 & 2 & 3 & 4 & 5 \\
\hline Go through your teen's bags & 1 & 2 & 3 & 4 & 5 \\
\hline $\begin{array}{l}\text { Check how fast your teen drives using a GPS tracking } \\
\text { application }\end{array}$ & 1 & 2 & 3 & 4 & 5 \\
\hline $\begin{array}{l}\text { Check website history on the computer to see what } \\
\text { your teen does on the computer }\end{array}$ & 1 & 2 & 3 & 4 & 5 \\
\hline
\end{tabular}

\section{Parental Harmfulness Beliefs}

\begin{tabular}{|c|c|c|c|c|c|}
\hline How harmful are the following activities? & $\begin{array}{c}\text { Not } \\
\text { harmful } \\
\text { at all }\end{array}$ & & & & $\begin{array}{c}\text { Extremely } \\
\text { harmful }\end{array}$ \\
\hline Who your child has as friends & 1 & 2 & 3 & 4 & 5 \\
\hline How your child is doing on schoolwork or tests & 1 & 2 & 3 & 4 & 5 \\
\hline When your child has an exam or paper due at school & 1 & 2 & 3 & 4 & 5 \\
\hline How your child does in different subjects at school & 1 & 2 & 3 & 4 & 5 \\
\hline Where your child goes when he/she is out with friends & 1 & 2 & 3 & 4 & 5 \\
\hline Who your child is dating & 1 & 2 & 3 & 4 & 5 \\
\hline Whether your child drinks alcohol & 1 & 2 & 3 & 4 & 5 \\
\hline Whether your child does drugs & 1 & 2 & 3 & 4 & 5 \\
\hline Who your child hangs out with in his/her free time & 1 & 2 & 3 & 4 & 5 \\
\hline Whether your child is having sex & 1 & 2 & 3 & 4 & 5 \\
\hline Who your child's boyfriend/girlfriend's parents are & 1 & 2 & 3 & 4 & 5 \\
\hline
\end{tabular}




\begin{tabular}{|c|c|c|c|c|c|}
\hline $\begin{array}{l}\text { Whether your child is home alone with his/her } \\
\text { boyfriend/girlfriend }\end{array}$ & 1 & 2 & 3 & 4 & 5 \\
\hline Whether your child talks back or is rude to teachers & 1 & 2 & 3 & 4 & 5 \\
\hline Where your child goes with his/her boyfriend/girlfriend & 1 & 2 & 3 & 4 & 5 \\
\hline $\begin{array}{l}\text { Whether your child is in unsupervised areas (e.g., bedroom) } \\
\text { with boyfriend/girlfriend }\end{array}$ & 1 & 2 & 3 & 4 & 5 \\
\hline Whether your child smokes cigarettes & 1 & 2 & 3 & 4 & 5 \\
\hline Whether your child is using bad manners away from home & 1 & 2 & 3 & 4 & 5 \\
\hline $\begin{array}{l}\text { The type of language your child uses when away from } \\
\text { home }\end{array}$ & 1 & 2 & 3 & 4 & 5 \\
\hline Whether your child kisses his/her boyfriend/girlfriend & 1 & 2 & 3 & 4 & 5 \\
\hline $\begin{array}{l}\text { Whether your child holds hands with his/her } \\
\text { boyfriend/girlfriend }\end{array}$ & 1 & 2 & 3 & 4 & 5 \\
\hline The kind of person your child's boyfriend/girlfriend is & 1 & 2 & 3 & 4 & 5 \\
\hline
\end{tabular}




\section{Appendix D}

\section{Adolescent-Report Measures}

\section{Demographics}

1. What gender are you? $\bigcirc$ Male $\bigcirc$ Female

3. How old are you? (years)

What is your birthday?

4. What is your year in school? $9^{\text {th }} 10^{\text {th }} 11^{\text {th }} \quad 12^{\text {th }}$

5. School grades (average for the year):
Mostly A's
$\bigcirc$ Mostly C's
$\bigcirc$ Some A's some B's
$\bigcirc$ Some C's some D's
Mostly B's
Mostly D's or lower
Some B's some C's

8. What is your ethnicity? (check all that apply)

$\bigcirc$ Caucasian/White

African-American/Black

O Hispanic/Latino
Asian-American/Pacific Islander

$\bigcirc$ Native American

$\bigcirc$ Other (describe)

9. Who currently lives in your home? (check all that apply)

Mother (birth or adopted)

$\bigcirc$ Father (birth or adopted)

Siblings (please list their ages)

What is the highest level of schooling your MOTHER completed?

Completed $8^{\text {th }}$ grade

$\bigcirc$ Completed high school

$\bigcirc$ Completed some college

$\bigcirc$ Completed college

$\bigcirc$ Business or technical school

$\bigcirc$ Graduate degree (doctor, lawyer, Ph.D.)

What type of job does your MOTHER work?
Stepmother

Stepfather

$\bigcirc$ Other adults (describe)

What is the highest level of schooling your FATHER completed?

$\bigcirc$ Completed $8^{\text {th }}$ grade

$\bigcirc$ Completed high school

$\bigcirc$ Completed some college

$\bigcirc$ Completed college

$\bigcirc$ Business or technical school

$\bigcirc$ Graduate degree (doctor, lawyer, Ph.D.)

What type of job does your FATHER work? 


\section{Adolescent Disclosure}

\begin{tabular}{|c|c|c|c|c|c|c|}
\hline $\begin{array}{l}\text { How often do you tell your parents about the } \\
\text { following behaviors, without them asking? } \\
\text { If you do not engage in a behavior, choose "I } \\
\text { don't do this behavior" }\end{array}$ & $\begin{array}{c}\text { Almost } \\
\text { Never }\end{array}$ & Rarely & Sometimes & Often & $\begin{array}{l}\text { Almost } \\
\text { Always }\end{array}$ & $\begin{array}{l}\text { I don't } \\
\text { do this } \\
\text { behavior }\end{array}$ \\
\hline Whether you finish homework or assignments & 1 & 2 & 3 & 4 & 5 & 6 \\
\hline $\begin{array}{l}\text { Whether you are home alone with your } \\
\text { boyfriend/girlfriend }\end{array}$ & 1 & 2 & 3 & 4 & 5 & 6 \\
\hline Where you go when you are out with friends & 1 & 2 & 3 & 4 & 5 & 6 \\
\hline Who your boyfriend/girlfriend's parents are & 1 & 2 & 3 & 4 & 5 & 6 \\
\hline Whether you talk back or are rude to teachers & 1 & 2 & 3 & 4 & 5 & 6 \\
\hline $\begin{array}{l}\text { Whether you are in unsupervised areas (e.g., } \\
\text { bedroom) with your boyfriend/girlfriend }\end{array}$ & 1 & 2 & 3 & 4 & 5 & 6 \\
\hline How you do in different school subjects & 1 & 2 & 3 & 4 & 5 & 6 \\
\hline Whether you have sex & 1 & 2 & 3 & 4 & 5 & 6 \\
\hline Whether you use bad manners away from home & 1 & 2 & 3 & 4 & 5 & 6 \\
\hline Whether you do drugs & 1 & 2 & 3 & 4 & 5 & 6 \\
\hline $\begin{array}{l}\text { Whether you hold hands with your } \\
\text { boyfriend/girlfriend }\end{array}$ & 1 & 2 & 3 & 4 & 5 & 6 \\
\hline Who your friends are & 1 & 2 & 3 & 4 & 5 & 6 \\
\hline Whether you kiss your boyfriend/girlfriend & 1 & 2 & 3 & 4 & 5 & 6 \\
\hline Whether you smoke cigarettes & 1 & 2 & 3 & 4 & 5 & 6 \\
\hline The kind of person your boyfriend/girlfriend is & 1 & 2 & 3 & 4 & 5 & 6 \\
\hline $\begin{array}{l}\text { The type of language you use when away from } \\
\text { home }\end{array}$ & 1 & 2 & 3 & 4 & 5 & 6 \\
\hline Where you go with your boyfriend/girlfriend & 1 & 2 & 3 & 4 & 5 & 6 \\
\hline $\begin{array}{l}\text { Whether you hang out with friends your parents } \\
\text { don't like }\end{array}$ & 1 & 2 & 3 & 4 & 5 & 6 \\
\hline
\end{tabular}




\begin{tabular}{|l|lllll|l|}
\hline How you are doing on schoolwork or tests & 1 & 2 & 3 & 4 & 5 \\
\hline Whether you drink alcohol & 1 & 2 & 3 & 4 & 5 & 6 \\
\hline Who your boyfriend/girlfriend is & 1 & 2 & 3 & 4 & 5 & 6 \\
\hline
\end{tabular}

\section{Secrecy \& Partial Disclosure Strategies}

\begin{tabular}{|c|c|c|c|c|c|c|}
\hline $\begin{array}{l}\text { Please "check" what you typically do } \\
\text { when you don't tell your parents } \\
\text { everything about each behavior. } \\
\text { If you do not engage in a behavior, choose } \\
\text { "I don't do this behavior" }\end{array}$ & $\begin{array}{c}\text { I Tell } \\
\text { Only if } \\
\text { my } \\
\text { Parents } \\
\text { Ask }\end{array}$ & $\begin{array}{c}\text { I Tell } \\
\text { Some } \\
\text { but } \\
\text { Not All }\end{array}$ & $\begin{array}{c}\text { I Avoid } \\
\text { the } \\
\text { Topic/ } \\
\text { Change } \\
\text { Subject }\end{array}$ & $\begin{array}{l}\text { I Lie } \\
\text { to } \\
\text { Them }\end{array}$ & $\begin{array}{l}\text { I Keep } \\
\text { it } \\
\text { Secret }\end{array}$ & $\begin{array}{l}\text { I don't } \\
\text { do this } \\
\text { behavior }\end{array}$ \\
\hline $\begin{array}{l}\text { Whether you finish homework or } \\
\text { assignments }\end{array}$ & & & & & & \\
\hline $\begin{array}{l}\text { Whether you are home alone with your } \\
\text { boyfriend/girlfriend }\end{array}$ & & & & & & \\
\hline Where you go when you are out with friends & & & & & & \\
\hline Who your boyfriend/girlfriend's parents are & & & & & & \\
\hline $\begin{array}{l}\text { Whether you talk back or are rude to } \\
\text { teachers }\end{array}$ & & & & & & \\
\hline $\begin{array}{l}\text { Whether you are in unsupervised areas (e.g., } \\
\text { bedroom) with your boyfriend/girlfriend }\end{array}$ & & & & & & \\
\hline How you do in different school subjects & & & & & & \\
\hline Whether you have sex & & & & & & \\
\hline $\begin{array}{l}\text { Whether you use bad manners away from } \\
\text { home }\end{array}$ & & & & & & \\
\hline Whether you do drugs & & & & & & \\
\hline $\begin{array}{l}\text { Whether you hold hands with your } \\
\text { boyfriend/girlfriend }\end{array}$ & & & & & & \\
\hline Who your friends are & & & & & & \\
\hline Whether you kiss your boyfriend/girlfriend & & & & & & \\
\hline Whether you smoke cigarettes & & & & & & \\
\hline
\end{tabular}




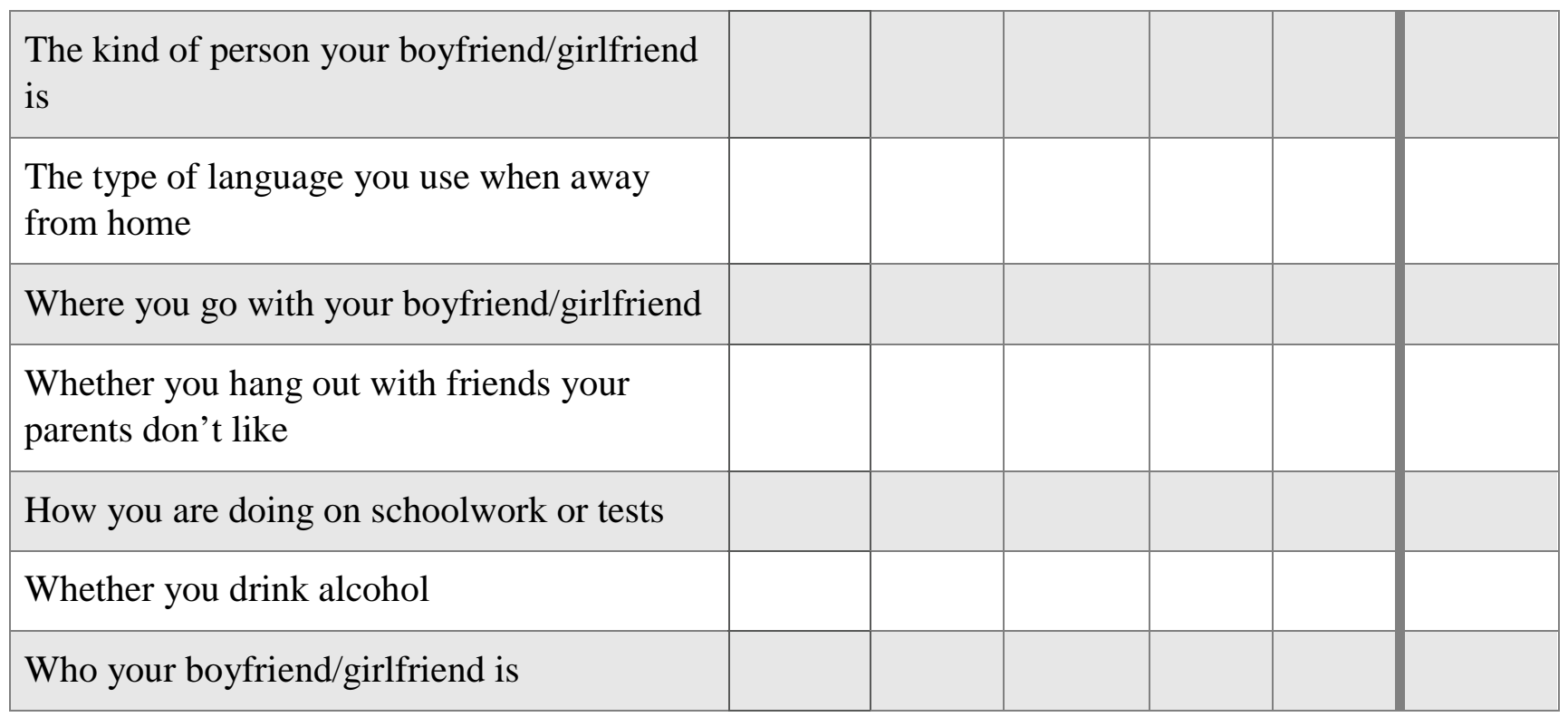

\section{Adolescent Concealment}

\begin{tabular}{|c|c|c|c|c|c|}
\hline Please rate how often you do the following... & $\begin{array}{l}\text { Almost } \\
\text { Never }\end{array}$ & Rarely & Sometimes & Often & $\begin{array}{l}\text { Almost } \\
\text { Always }\end{array}$ \\
\hline I hide personal belongings from my parents & 1 & 2 & 3 & 4 & 5 \\
\hline $\begin{array}{l}\text { I change passwords for online accounts so that my } \\
\text { parents will not snoop on me }\end{array}$ & 1 & 2 & 3 & 4 & 5 \\
\hline $\begin{array}{l}\text { I delete online communication (such as e-mails or IM } \\
\text { conversations) so that my parents won't see it }\end{array}$ & 1 & 2 & 3 & 4 & 5 \\
\hline I hide my cell phone from my parents & 1 & 2 & 3 & 4 & 5 \\
\hline $\begin{array}{l}\text { I exercise caution about what I post on social } \\
\text { networking sites (e.g., Facebook, Twitter), because my } \\
\text { parents might see. }\end{array}$ & 1 & 2 & 3 & 4 & 5 \\
\hline I avoid making phone calls when my parents are around & 1 & 2 & 3 & 4 & 5 \\
\hline $\begin{array}{l}\text { I avoid meeting face-to-face with my friends when my } \\
\text { parents are around }\end{array}$ & 1 & 2 & 3 & 4 & 5 \\
\hline $\begin{array}{l}\text { I delete text messages so that my parents will not see } \\
\text { them }\end{array}$ & 1 & 2 & 3 & 4 & 5 \\
\hline I leave papers at school so my parents will not see them. & 1 & 2 & 3 & 4 & 5 \\
\hline $\begin{array}{l}\text { I leave my cell phone at a friend's house if we go } \\
\text { somewhere else, so my parents can't track me. }\end{array}$ & 1 & 2 & 3 & 4 & 5 \\
\hline
\end{tabular}


I turn the GPS off on my mobile device(s) so my parents can't track me.

1

I avoid meeting face-to-face with my

boyfriend/girlfriend when my parents are around.
1

23

4

5

1

23

$3 \quad 4 \quad 5$

\section{Adolescent Delinquency}

\begin{tabular}{|lrccc|}
\hline In the PAST 30 DAYS, how often have you... & o & $\begin{array}{c}1-2 \\
\text { times }\end{array}$ & $\begin{array}{c}3-4 \\
\text { times }\end{array}$ & $\begin{array}{c}\text { more } \\
\text { times }\end{array}$ \\
\hline Gotten into a fight? & 0 & $1-2$ & $3-4$ & $5+$ \\
\hline Been in trouble with the law? & 0 & $1-2$ & $3-4$ & $5+$ \\
\hline Skipped school or played hooky? & 0 & $1-2$ & $3-4$ & $5+$ \\
\hline Stayed out all night without your parents' permission? & 0 & $1-2$ & $3-4$ & $5+$ \\
\hline Taken something that belonged to a classmate without them knowing it? & 0 & $1-2$ & $3-4$ & $5+$ \\
\hline Shoplifted something from a store? & 0 & $1-2$ & $3-4$ & $5+$ \\
\hline Destroyed school or other property? & 0 & $1-2$ & $3-4$ & $5+$ \\
\hline
\end{tabular}

\section{Adolescent Substance Use}

\begin{tabular}{|lccccc|}
\hline In the PAST 30 DAYS, how often have you used... & $\begin{array}{c}0 \\
\text { times }\end{array}$ & $\begin{array}{c}1-2 \\
\text { times }\end{array}$ & $\begin{array}{c}3-9 \\
\text { times }\end{array}$ & $\begin{array}{c}10-19 \\
\text { times }\end{array}$ & $\begin{array}{c}20 \text { or } \\
\text { more }\end{array}$ \\
\hline Tobacco products & 0 & $1-2$ & $3-9$ & $10-19$ & $20+$ \\
\hline Marijuana & 0 & $1-2$ & $3-9$ & $10-19$ & $20+$ \\
\hline Drank alcohol? & 0 & $1-2$ & $3-9$ & $10-19$ & $20+$ \\
\hline
\end{tabular}




\section{Appendix E}

\section{Pilot Study}

The purpose of this pilot study was to examine the measurement properties of a novel parental motivation for knowledge measure, which was developed for the current dissertation project. The primary goal of the pilot study was to assess whether a Likert-type response scale or an ordinal response scale would provide the best format for measuring parents' motivations. The second goal of the current pilot study was to evaluate variations in verbiage chosen for potential motivations, which would ensure the valence of motivation choices were not overly positive or negative. This measure was developed because there are no known measures for investigating parents' motivations for desiring knowledge about adolescents' behaviors. The goal of the current study's motivation items is to capture variability in parents' motivations across distinct behavior categories. Four versions of the measure were piloted to investigate the primary and secondary goals of this study.

\section{Method}

\section{Participants and Procedure}

Three hundred and seventeen parents of adolescents between the ages of 12 and 18 were recruited through Amazon's Mechanical Turk (MTurk) and completed one of four versions of an online survey $\left(N_{\mathrm{A}}=78, N_{\mathrm{B}}=80, N_{\mathrm{C}}=77, N_{\mathrm{D}}=81\right)$. Upon completion of the questionnaire, participants received a 50-cent Amazon credit. Twenty-nine participants were removed from the sample due to failing validity checks built into the questionnaire. Twenty-three participants were removed for failing an adolescent birthdate validity check and six participants were removed for failing at least one other validity check. The version of the survey was not associated with the likelihood of a participant failing a validity check. In addition, participants who passed and failed 
the validity checks did not differ on demographic variables. Participants who completed the Likert-type scale format of the motivation measure and failed the validity check did not differ on motivation responses compared to participants who did not fail. However, participants who completed the ordinal scale format and failed the validity check did differ on multiple motivation items compared to participants who did not fail validity checks. See Table E1 for differences in motivation responses by validity check results. The final analytic sample consisted of 287 parents $\left(N_{\mathrm{A}}=71, N_{\mathrm{B}}=70, N_{\mathrm{C}}=72, N_{\mathrm{D}}=74\right)$ ages 27 to $60\left(M_{\text {age }}=40.61, S D=7.21,70.4 \%\right.$ female). The analytic sample responded to the survey questions based on their adolescent children aged 12 to $18\left(M_{\mathrm{age}}=14.74, S D=1.98,52.6 \%\right.$ female $)$.

\section{Measures}

Adolescent behavior categories. Eighteen behaviors were chosen from previous social domain research (Daddis \& Randolph, 2010; Daddis \& Smetana, 2005; Smetana, 2000; Smetana, Metzger et al., 2006) to represent six distinct behavior categories (3-items per category). Categories included conventional issues (i.e., if my child is using bad manners), substance use (i.e., if my child is smoking cigarettes), schoolwork (i.e., if my child is finishing homework or assignments), peers (i.e., who my child's friends are), dating (i.e., who my child's boyfriend/girlfriend is), and dating risks (i.e., if my child is having sex).

Likert-type response format. Parents were provided each adolescent behavior along with eight reasons (e.g., I want my child to do well in the future) that parents may want to know about the behaviors in their own adolescents' lives. Participants rated the extent to which each reason was important to why they would want to know about the behavior on a 5-point Likerttype scale, ranging from $1=$ least important to $5=$ most important . Behavior specific motivation scores were computed by averaging motivation responses across items within a behavior 
category, with higher scores indicating higher levels of a motivation's importance within a respective behavior category.

Ordinal scale response format. Parents were provided each behavior along with the same eight reasons as the rating scale, but were asked to rank the top three reasons they would want to know about the behavior in their own adolescents' lives. Parents were asked to rank the top three reasons for each behavior and to leave all other reasons blank. Ranked responses were reverse coded and summed to create behavior-specific motivation scores whereby higher scores indicated greater importance of motivations within each category of behavior.

Variations in motivation wording. Two versions of the motivation measure were created for each response format in order to evaluate the potential wording developed for three of the motivations; emotional well-being, building a relationship, and family reputation. For the emotional well-being motivation, one version was worded as I want my child to feel good emotionally and the second version was worded as I want my child to be happy. Building a relationship was worded as I want to have a good relationship with my child in one version and I want to be a part of my child's life in the second version. Finally, family reputation was worded as I want my child to represent our family well in the first version and I don't want my child to make our family look bad in the second version. See Table E2 for detail regarding each version.

\section{Results}

Descriptive statistics were examined at the scale level to determine which response format (rating scale vs. ordinal scale) captured more variability in parents' responses. Results regarding the Likert-type scale revealed that parents' average motivation ratings were between 3 (mid-point) and 5 (most important) across all behavior categories (Table E3). The ordinal scale exhibited more variability, which was likely due to forcing parents' to choose three motivations 
rather than rating all motivations (Table E4). Independent sample t-tests were performed to investigate differences in parents' responses by motivation verbiage. Results indicated no significant mean differences by version, which suggests that wording did not influence parents' responses.

Item level descriptive statistics were evaluated to assess consistency in motivation responses within behavior categories. Results revealed unexpected item variation within the dating and dating risk behavior categories across the motivation responses. The dating behavior category was comprised of the following items: who my child's boyfriend/girlfriend is, about my child's boyfriend/girlfriend's family, and where my child is going with his/her boyfriend. The dating risk behavior category included the following items: if my child is in his/her bedroom with boyfriend/girlfriend, if my child is home alone with his/her boyfriend/girlfriend, and if my child is having sex. The results indicated that parents ranked different motivations for where the teen goes with his/her boyfriend compared to the other two dating items, and different motivations for whether the teen is having sex compared to the other two dating risk items. Research suggests that parents conceptualize dating behaviors according to three subcategories, including identity of the significant other, expression of the relationship, and behaviors that require supervision (Daddis \& Randolph, 2010). Based on our results and previous research, three behaviors will be added to the dissertation measure to represent the three dating subcategories (see Table 1 for behaviors by behavior category). 
Table E1

Motivation Response Differences by Validity Check

\begin{tabular}{lll}
\hline Passed & Failed & Significance test \\
\hline
\end{tabular}

Conventional

$\begin{array}{llllll}\text { Emotional Well-being } & 2.16 & (2.49) & 4.67 & (2.15) & t(156)=-3.37, p=.001 \\ \text { Harm Others } & 1.04 & (2.04) & 4.00 & (3.62) & t(156)=-4.50, p=.000 \\ \text { Teen's Reputation } & 1.40 & (2.17) & 3.33 & (2.64) & t(156)=-2.91, p=.004\end{array}$

Substance Use
Teen's Reputation
$3.75 \quad(2.12)$
$1.57 \quad(2.45)$
$t(156)=-3.39, p=.001$

School
Family's Reputation
$0.85 \quad(1.78)$
$2.25 \quad(2.05)$
$t(156)=-2.59, p=.010$
Teen's Reputation
$2.13(2.46)$
$4.00 \quad(2.45)$
$t(156)=-2.53, p=.012$

Peers

$\begin{array}{llllll}\text { Physical Harm } & 0.38 & (1.33) & 2.92 & (3.29) & t(156)=-5.44, p=.000 \\ \text { Family's Reputation } & 0.60 & (1.55) & 3.00 & (2.73) & t(156)=-4.83, p=.000 \\ \text { Teen's Reputation } & 1.66 & (1.99) & 3.67 & (2.74) & t(156)=-3.25, p=.001\end{array}$

Dating
Emotional Well-being
1.19 (1.75)
$3.75(2.96)$
$t(156)=-4.58, p=.000$

Dating Risks

\begin{tabular}{llllll} 
Emotional Well-being & 1.51 & $(1.97)$ & 4.08 & $(3.60)$ & $t(156)=-4.03, p=.000$ \\
Harm Others & 1.38 & $(2.11)$ & 3.75 & $(3.44)$ & $t(156)=-3.54, p=.001$ \\
\hline
\end{tabular}


Table E2

Parental Motivations by Pilot Version

Version A (Rating Scale) \& Version C (Ordinal Scale)

* I want my child to feel good emotionally.

* I want my child to represent our family well.

* I want to have a good relationship with my child.

I don't want my child to hurt someone else.

I want to keep my child out of trouble.

I want my child to do well in the future.

I don't want my child to get physically hurt.

I want my child to have a good reputation.

Version B (Rating Scale) \& Version D (Ordinal Scale)

* I want my child to be happy.

* I don't want my child to make our family look bad.

* I want to be a part of my child's life.

I don't want my child to hurt someone else.

I want to keep my child out of trouble.

I want my child to do well in the future.

I don't want my child to get physically hurt.

I want my child to have a good reputation.

Note. $*$ indicates different wording. 


\section{Table E3}

Means and Standard Deviations for Likert-type Response Format

\begin{tabular}{lcccccc}
\hline & \multicolumn{5}{c}{ Behavior Category } \\
\cline { 2 - 6 } Motivations & Conventional & Substance Use & School & Peers & Dating & Dating Risk \\
\hline Emotional well-being & $4.28(.82)$ & $4.37(.79)$ & $4.10(.97)$ & $4.62(.93)$ & $4.26(.92)$ & $4.03(1.02)$ \\
Physical harm & $4.61(.63)$ & $4.37(.91)$ & $4.38(.91)$ & $2.98(1.40)$ & $4.33(.71)$ & $4.00(1.00)$ \\
Keep out of trouble & $4.67(.69)$ & $4.56(.71)$ & $4.62(.83)$ & $4.18(.99)$ & $4.66(.70)$ & $4.40(.87)$ \\
Future success & $4.52(.74)$ & $4.44(.77)$ & $4.50(.78)$ & $4.82(.58)$ & $4.74(.57)$ & $4.48(.80)$ \\
Relationship building & $4.43(.77)$ & $4.47(.72)$ & $4.27(.92)$ & $4.23(.99)$ & $4.33(.91)$ & $4.14(1.09)$ \\
Harm to others & $3.96(1.13)$ & $3.80(1.24)$ & $3.98(1.15)$ & $2.92(1.40)$ & $4.31(.84)$ & $3.89(1.16)$ \\
Family reputation & $3.34(1.24)$ & $3.26(1.26)$ & $3.33(1.28)$ & $3.12(1.29)$ & $3.56(1.28)$ & $3.47(1.21)$ \\
Teen's reputation & $4.07(1.04)$ & $4.05(1.07)$ & $4.15(1.04)$ & $3.91(1.12)$ & $4.24(.99)$ & $4.12(.98)$ \\
\hline
\end{tabular}




\section{Table E4}

Means and Standard Deviations for Ordinal Scale Response Format

\begin{tabular}{lcccccc}
\hline & \multicolumn{5}{c}{ Behavior Category } \\
\cline { 2 - 7 } Motivations & Conventional & Substance Use & School & Peers & Dating & Dating Risk \\
\hline Emotional well-being & $2.16(2.49)$ & $2.64(2.36)$ & $1.92(2.33)$ & $2.73(2.20)$ & $1.19(1.75)$ & $1.51(1.97)$ \\
Physical harm & $4.12(2.88)$ & $3.56(2.91)$ & $3.18(2.89)$ & $.38(1.33)$ & $4.15(2.29)$ & $2.54(1.69)$ \\
Keep out of trouble & $5.29(2.50)$ & $4.75(2.52)$ & $4.84(2.94)$ & $2.82(2.37)$ & $4.47(2.49)$ & $3.66(2.40)$ \\
Future success & $2.64(2.53)$ & $2.12(2.35)$ & $3.18(2.72)$ & $7.59(2.29)$ & $3.55(2.44)$ & $3.45(2.67)$ \\
Relationship building & $2.65(2.74)$ & $3.47(2.89)$ & $2.23(2.81)$ & $2.98(2.56)$ & $1.54(2.47)$ & $1.89(2.63)$ \\
Harm to others & $1.04(2.04)$ & $.74(1.79)$ & $1.19(2.17)$ & $.40(1.55)$ & $1.47(2.02)$ & $1.38(2.11)$ \\
Family reputation & $.72(1.67)$ & $.90(1.83)$ & $.85(1.78)$ & $.60(1.55)$ & $.84(1.68)$ & $1.74(2.22)$ \\
Teen's reputation & $1.40(1.67)$ & $1.57(2.12)$ & $2.13(2.46)$ & $1.66(1.99)$ & $1.81(1.86)$ & $3.09(2.37)$ \\
\hline
\end{tabular}

